Zweiter Beratungsgegenstand:

\title{
Die Organisationsgewalt
}

1. Bericht von Professor Dr. Arnold Köt tgen, Göttingen

Ein von seinem heimatlichen Landtag zu Rate gezogener Experte des Verfassungsrechts erteilte vor einigen Jahren der Organisationsgewalt das Ursprungsattest: Arsenal der preuBischen Monarchie von $\mathbf{1 8 5 0}^{1}$ ). Unwillikürlich fragt sich daher der Referent über ein solches Thema, ab der Vorstand ihn etwa zur Vorhut eines Rückmarsches in jenen "vorrechtsstaatlichen Urwald" erkoren habe, aus dem erst vor Jahresfrist Herbert Krüger eine allendings zuweilen etwas widerstrebende Versammlung herauszuführen versuchte ${ }^{2}$ ).

Ich würde das mir gestellte Thema verharmlosen, wollte ich hier über organisatorische Kompetenzen jeglicher Art referieren. Zwar ist in der Literatur hier und dort auch von einer Organisationsgewalt der Legislative die Rede ${ }^{3}$ ), jedoch seinen prägnanten Sinn erhält dieser staatsrechtliche Terminus erst dann, wenn er zwar nicht auf die Regierung, wohl aber auf die Exekutive in ihrer Gesamtheit beschränkt wind. Ja, man wird noch einen Schritt weiter gehen müssen. Von Organisationsgewalt im engsten und eigentlichen Sinne sollte nur dort gesprochen werden, wo sich ihr Inhaber nicht auf ein voraufgegangenes Placet des Gesetzgebers berufen kann. Außerhalb meiner Utherlegungen bleiben daher gleich dem durch die Verfassung selbst gesetzten Organisationsrecht auch alle organisatorischen Regelungen durch Gesetz ader auf Grund eines solchen.

Auf dem in dieser Art abgegrenzten Thema lastet von jeher eine verfassungsgeschichtliche Hypothek, die sich in aller Regel bei Diskussionen über die Organisationsgewalt alsbald aktualisiert. Während die einen in ihr ein unvergängliches

1) Werner We ber (in „Die Verfassungsfrage in Niedersachsen", Landtagsdrucksache vom 24. 11. 1950, S.6).

2) Verh. d. VDStRL Heft 15, S. 108. In verwandter Richtung bewegen sich die Ausführungen Spanners über „Organisationsgewalt und Organisationsrecht" (DOVV 1957 S. 640 ff.) mit ihrem Hinweis auf Uberreste des absoluten Staates, die die Theorie unter eine Art unjuristischen Naturschutzes gestellt habe.

s) O b e r m y er: Verwaltungsakt und innerdienstlicher Rechtsakt, 1956, S. 117 . 
Verfassungserbgut erblicken möchten'), gilt sie den anderen nur als der illegitime Versuch einer Prolongation des monarchischen Beamtenstaates bis in die so gänzlich anders verfaßte Gegenwart ${ }^{5}$ ). Damit drohen Sentiments und Ressentiments nicht nur auf der politischen Bühne einer nüchternen staatsrechtlichen Analyse Abbmuch zu tun.

Wer über die Organisationsgewalt als ein aktuelles Problem referiert, muß sich vorbehaltlos auf den Boden der juristischen, aber auch soziologischen Gegebenheiten von heute stellen. Juristisch ist evident das Fehlen eines harmonisierenden thberleitungsrechts, das nach 1919 in Fragen der Organisationsgewalt spezielle Bedeutung besa $\left.B^{6}\right)$. Tiefe Skepsis gegenüber rein traditioneller Verfassungsauslegung gehört heute mit zu dem Erbe, dessen ressentimentfreie Bewältigung uns aufgegeben ist.

Allerdings auch der politische Sachverhalt ist offenbar ein anderer geworden. Kontroversen über die Organisationsgewalt vermögen die öffentliche Meinung nicht mehr im Stil liberaler Verfassungskämpfe ${ }^{7}$ ) von einst zu erregen. Nur mit dem geschichtlich einmaligen Komplex Bundeshauptstadt Bonn verband sich die Möglichkeit eines fundamentalen Konflikts über die Organisationsgewalt des Kanzlers, aber kaum ohne tieferen Grund wurde er nicht aktualisiert').

Auf Grund mannigfacher Erfahrungen aus den letzten Jahren wird man ohne Uthertreibung behaupten können, daß heute betriebswirtschaftliche Argumente bei der Entscheidung

4) Das gilt insbesondere von der auf $\mathrm{Th}$ o $\mathrm{m}$ a zurückgehenden Charakterisierung der Organisationsgewalt als Hausgut der Verwaltung, die sich Werner We ber in der Diskussion zu eigen gemacht hat. Hierher gehört aber auch die Bemerkung von F o r s t $h$ of $f$, die Organisationsgewalt sei selbstverständlicher und anerkannter Ausdruck der obersten Leitungsgewalt der Exekutive (Lehrbuch des Verwaltungsrechts, Bd. 1, 6. Aufl., S. 366). K r ü g e r, der in Mainz die Organisationsgewalt nur im Sinne kritischer Abwehr zu den naturgegebenen Fähigkeiten gerechnet hatte (Verh. der VDStRL Heft 15, S. 119), hat offenbar diese Meinung in seiner Diskussionsbemerkung korrigiert.

5) So neuestens $\mathrm{H}$ a m a n n : Das Grundgesetz, 1956, S. 56. Der gleiche Verf. in NJW 1956, S. 1 ff.

b) Daraus erklärte sich, daß damals die h. M. mit gutem Grunde einen salva substantia erfolgten Ubergang der kaiserlichen Organisationsgewalt auf den Reichspräsidenten annehmen konnte, was die GemGO der Reichsministerien - bes. Teil \$65 - nur bestätigte.

7) Die reich dokumentierte Darstellung der Organisationsgewalt bei v. R ö n ne (Preuß. Staatsrecht, 4. Aufl. Bd. 1, S. 422 ff.) spiegelt diese Konflikte wider.

8) Die Frankfurter Nationalversammlung hatte in vergleichbarer Lage die Bestimmung des Regierungssitzes dem Reichsgesetzgeber vorbehalten (RV \& 71). 
organisatorischer Fragen eine noch vor kurzem unvorstellbar große Bedeutung besitzen. Gleich der Regierung bemüht sich dabei auch das Parlament um ein betriebswirtschaftliches Optimum, hinter dem politische, aber auch rechtsstaatliche Anliegen durchaus nicht selten zurücktreten müssen. Dieser Wandel der Perspektive wind insbesondere auch durch die wechselvolle Geschichte der Verwaltungsreform bestätigt, deren enger Nachbarschaft zu unserem Thema Lutz Richter sogar in dem Untertitel seiner Schrift über die Organisationsgewalt Ausdruck gab: Verwaltungsreform und Rechtsstaat.

Von immer neuen Ansätzen aus hat sich das 20. Jahrhundert um eine Verwaltungsreform bemüht. Dabei geriet in Vergessenheit, daß diese in den Jahrzehnten von Stein bis Gneist ein eminentes Politikum gewesen war, das als solches zu den wesentlichen Anliegen des wendenden Verfassungsstaates gehörte $\left.{ }^{\text {a }}\right)$. Geblieben war nur die Vokabel Verwaltungsreform, hinter der sich jedoch nur allzu oft lediglich eine Büroreform verborgen hielt. Trotz aller Bemühungen des Erneuerungsbundes blieb auch die alsbald nach dem ersten Weltkrieg erhobene Forderung nach einer Reichsreform ohne die notwendige Resonanz.

So war auch jene Verwaltungsreform, mit der sich Lutz Richter im Jahre 1926 kritisch befaßte, nur eine bescheidene Abschlagszahlung ohne politische Tiefenwirkung. Seine Kritik will uns heute als ein Beitrag zum Thema "Bürger und Bourgeois im deutschen Staatsrecht" ${ }^{\text {") }}$ erscheinen, da sie ausschließlich rechtsstaatliche Maßstäbe gelten ließ. Zwar sind die verfassungsrechtlichen Thesen dieser Schrift über die Organisationsgewalt alsbald auf mancherlei Widerspruch gestoßen, aber der um die Jahrhundertwende abgerissene Faden politischer Verwaltungsreform wunde nicht wieder aufgenommen. Die von dem Politiker, wenn nicht ausgeschlagene, so doch vernachlässigte Erbschaft haben dabei nicht die von Lutz Richter angesprochenen Juristen, sondern Betriebswirte angetreten.

Das gilt offenbar bis auf den heutigen Tag. Ja, erst die Gegenwart hat unter dem von der Kommunalen Gemeinschaftsstelle für Verwaltungsvereinfachung geprägten Stichworte "sachliche Verwaltungsreform" diesen langfristigen Bedeutungswandel eindeutig verifiziert. Frei von jedem Pathos der Politik, aber auch des Rechts soll die Verwaltung am Maßstab betriebswirtschaftlicher Erkenntnisse nicht so sehr reformiert,

Ba) Dazu neuestens $\mathrm{K}$ itz e l: Die Herrfurthsche Landgemeindeordnung, 1957.

9) S m e n d (Staatsrechtliche Abhandlungen, S. 309 ff.). 
als vielmehr rationalisiert werden ${ }^{10}$ ). Ulber die tieferen Gründe einer derart veränderten Fragestellung wird ein nüchterner Betrachter zeitgenössischer Verwaltungswirklichkeit nicht streiten wollen.

Dieser Wandel der Perspektive konnte nicht ahne Einfluß auf die Wahl der Mittel bleiben. Wer erinnert sich heute noch daran, daß einst Heinrich v. Treitschke den Gesetzgeber als Reformator der Verwaltung aufgerufen und von ihm gerade auf organisatorischem Gebiet eine „höchstgesteigerte Tätigkeit" verlangt hatte $\left.{ }^{11}\right)$ ? Als fast ein Jahrhundert später der 2. Bundestag sein Interesse der Verwaltungsreform zuwandte, geschah dies zu dem gleichen Zeitpunikt, in dem man die Möglichkeiten eines Gesetzgebungsstops intra et extra muros diskutierte ${ }^{12}$ ).

In der Tat hat der moderne Gesetzgeber die Grenzen seiner technischen Leistungsfähigkeit so nachhaltig spüren müssen, $\mathrm{da} B$ die Forderung seiner Entlastung vorerst kaum von der Tagesordnung verschwinden dürfte. Dem kommt eine betriebswirtschaftlich motivierte Verwaltungsreform auch insofern entgegen, als diese ohnehin mit einem Mindestaufwand auch politischer Kräfte die Verwirklichung ihrer Ziele versuchen und daher nicht ungern an die Selbsthilfe der Exekutive appellieren wird ${ }^{13}$ ). Mit all dem ist aber offenbar gegenüber der Frühzeit des Verfassungsstaates eine neue Lage gegeben. Die einst um ihr Hausrecht besorgte Verwaltung befindet sich anscheinend nicht mehr in jener politischen Defensive, die für die Verfassungsgeschichte des 19. Jahrhunderts so charakteristisch war.

Allerdings kann und soll nicht behauptet wenden, daß nur im Bereich der Verwaltung eine verfassungsunmittelbare

10) Daraus erklärt sich, daß auch die einst so bedeutsame Unterscheidung zwischen politischer und technischer Verwaltung (Smend, aaO., S. $236 \mathrm{f}$.) keine zureichende Beachtung mehr findet, wie ich bereits in einer Besprechung (N o r d s i e c k: Rationalisierung der Betriebsorganisation, 2. Aufl. 1955) bemängelt habe (DOV 1956, S. 191). Im übrigen sei hier verwiesen auf die instruktive Studie von $\mathrm{M}$ a r k u 11 über „Rationalisierung der ö. Verwaltung“ (Verw. Archiv Bd. 48, S. 5 ff.).

11) Das constitutionelle Königtum in Deutschland, in „Historische und Politische Aufsätze", 5. Aufl. Bd. 3, S. 516.

12) Es ist dabei nur bezeichnend, daß $R$ e us demgegenüber auf den Rationalisierungseffekt des Gesetzes verweist (Verw. Archiv Bd. 48, S. 68) und diesem so offenbar auch gegenüber dem betriebswirtschaftlichen Trend der Zeit seine Schlüsselstellung sichern möchte.

13) Ein solcher Appell verbindet sich etwa mit dem $\mathrm{He} 11 \mathrm{mut}$ B e c kers Kritik an der "verwalteten Schule" (Kulturpolitik und Schule, 1956, S. 55 ff.). 
Organisationsgewalt in Anspruch genommen würde. Schon die konstitutionelle Monarchie hatte die Organisationsgewalt keineswegs ausschließlich dem Inhaber der monarchischen Prärogative vorbehalten, mag auch die staatsrechtliche Nomenclatur diesen Sachverhalt noch so sehr vendunkelt haben. Vielmehr gehörte es damals wie heute zu den Attributen aller Verfassungsorgane, daß sie in den Grenzen ihrer geschäftsordnungsmäßigen Autonomie eine solche Organisationsgewalt für sich in Anspruch nehmen können. Ob auch das vom Bundesgesetzgeber als Verfassungsorgan deklarierte Bundesverfassungsgericht im Besitz dieser Vollmachten ist und sich darin von allen anderen Gerichten unterscheidet, muß hier dahingestellt bleiben ${ }^{13 a}$ ).

Theorie und Praxis hat allerdings dieses Recht der obersten Staatsorgane zur Selbstorganisation in der Regel nur dort beschäftigt, wo diese Organisationsgewalt auf den benachbarten Bereich des Behördenwesens ausstrahlt. Daraus erklärt sich das unterschiedliche Interesse an Kabinetts- und Parlamentsverfassung, ohne daß der Wechsel der Staatsform hier etwa einen Wandel nach sich gezogen hätte. Kaum zufällig wird deshalb auch heute die Selbstorganisation der Parlamente nicht etwa unter dem Stichwort der Organisationsgewalt abgehandelt.

Die mit diesem Terminus angesprochenen Probleme beschränken sich vielmehr nach wie vor auf die Organisation der Verwaltung, der Streitkräfte und der Gerichte, denen auch im Falle des Zugeständnisses einer „vollständigen Selbstverwaltung" im Sinne der Verhandlungen des 40. Deutschen Juristentages keinesfalls eine ähnliche Position eingeräumt werden könnte wie den Verfassungsorganen. Im übrigen hat sich das Bundesverfassungsgericht bereits $\mathrm{zu}$ den Grenzen ministerieller Organisationsgewalt im Bereich des Gerichtswesens geäußert. Jedwede Änderung von Gerichtsbezirken unterliegt nach diesem Urteil dem Gesetzesvorbehalt ${ }^{14}$ ). Zur Organisation der Landesverteidigung hat das Grundgesetz selbst nur unter haushaltsrechtlichen Gesichtspunkten Stellung genommen (Art. 87:a) ${ }^{15}$ ). Allerdings hatte schon das dieser Ver-

13a) Vgl. L e i b h ol z: Der Status des Bundesverfassungsgerichts (Jahrbuch des öffentl. Rechts, Bd. 6).

14) Entscheidungen des BVfG Bd. 2, S. 320.

15) Wenn $\mathrm{H}$ a ma n n den Art. 87 a als eine Grundsatzentscheidung gegen die Organisationsgewalt bezeichnet, deren Bedeutung vorerst noch nicht übersehbar sei (Grundgesetz, S. 319), so muß dem widersprochen werden. Schon die RV von 1871 hatte die Friedenspräsenzstärke dem Gesetzgeber vorbehalten (Art. 60). Eher könnte umgekehrt gefragt werden, ob nicht mit dieser Vorschrift, was ins- 
fassungsinovelle voraufgegangene Freiwilligengesetz einen organisationsrechtlichen Gesetzesvorbehalt für die militärische Spitzengliederung und das Ministerium angemeldet (BGBl. 1955 I S. $449, \S 7$ ).

Nicht nur aus zeitlichen Gründen möchte ich meine Betrachtungen über die Organisationsgewalt auf die Verwaltung beschränken $\left.{ }^{16}\right)$. Zur sachlichen Rechtfertigung dieses Verzichts darf daran erinnert wenden, daß die Organisationsgewalt keine abstrakte Größe ist, die sich von der Eigenart ihres Gegenstandes völlig abtrennen ließe. Sicherlich ist es nicht das Gleiche, ob ein Behöndenchef oder eine militärische Kommandostelle organisatorische Maßnahmen trifft. Diese sachlogischen Unterschiede müssen auch heute respektiert werden, wo von einer parakonstitutionellen Kommandogewalt gewiß keine Rede sein kann.

Zum Schluß dieser einleitenden Bemerkungen ein Wort über das tiefere Recht der Staatsrechtslehrer, hier und heute über die von ihnen so lange vernachlässigte Organisationsgewalt zu diskutieren. Bemühen wir uns damit nicht um eine fruchtlose Repristination bereits in die Verfassungsgeschichte eingegangener Streitfragen? Ja, bieten wir nicht der am verwaltungsorganisatorischem Optimum interessierten Staatspraxis lediglich Steine statt jenes Brotes, das die Betriebswirtschaftslehre für sie bereit hält?

Die Frage stellen, heißt sie verneinen. Entgegen dem äußeren Anschein hat jeder Anspruch auf verfassungsunmittelbare Onganisationsgewalt auch heute das Gewicht eines aktuellen Politikum. Der "Herr im Hause" bietet zwar nicht die gleichen Aspekte wie in den Tagen der konstitutionellen Monarchie, aber er ist ein politisches Ärgernis geblieben. Die in Mainz so deutlich gewondene Unsicherheit in Fragen des Statusrechts lastet als eine schwere Hypothek auch auf der nur scheinbar entpolitisierten Organisationsgewalt.

Das gemeinsame Anliegen aller organisatorischen Vorkehrungen ist eine spezifische Kambination personeller und mate-

besondere ein Vergleich mit dem Art. 87 nahelegen könnte, für den Bereich der Truppe die Organisationsgewalt ausdrücklich anerkannt werden sollte.

16) Keine Frage eigentlicher Organisationsgewalt ist entgegen einer verbreiteten Meinung die Verleihung der Körperschaftsrechte an Religionsgesellschaften (anders $K$. M ülle $\mathrm{r}$ in Z. ev. KR Bd. 2, S. 167). Mag diese nun dem Gesetzgeber vorbehalten sein oder nicht, das staatskirchenrechtliche Interventionsverbot widerstreitet der Vorstellung, daß eine staatliche Instanz Religionsgesellschaften zu organisieren vermöchte. Die Gegenstände der Organisationsgewalt betreffen ausschließlich staatliche Interna (anders F or s t h of $f$, Lehrbuch, S. 365). 
rieller Potenzen, unterschiedlich ist nur die organisatorische Intensität Während man sich im gesellschaftlichen Bereich auch heute nur allzu gern mit lediglich occasionellen Kontakten begnügt, war die Verwaltungsorganisation stets - darin ein Vorbild des gesellschaftlichen Großbetriebes - von charakteristischer Dichte. Jede derart verdichtete Organisation ist aber in dem Sinne anspruchsvoll, daß sie eine mehr oder minder intensive Eingliederung des Organisierten verlangt ${ }^{17}$ ). Dies gilt dabei keineswegs nur für die Bediensteten, sondern möglicherweise auch für das einen Verwaltungsdienst begehrende Publikum, so sehr dessen statusrechtliche Entstrickung im Zeichen des "Verwaltungskunden" propagiert werden mag ${ }^{18}$ ).

Diese Wechselwirkungen zwischen status und institutio drohen bei einer lediglich betriebswirtschaftlichen Betrachtung organisatorischer Fragen leicht in Vergessenheit zu geraten. Sicherlich hat der viel diskutierte Weg vom Status zum Kontrakt starke organisatorische Potenzen freigesetz ${ }^{10}$ ). Deshalb gibt es auch ohne Zweifel mancherlei nicht an statusrechtliche Prämissen gebundene Organisationen. Allerdings gilt dieses für die öffentliche Verwaltung höchstens im Bereich ihrer Peripherie, auch wenn gerade die moderne Verwaltung sicherlich nicht so voraussetzungsbeladen ist wie die Armee $\left.{ }^{20}\right)$. Deshalb gilt auch für die Verwaltungsorganisation, da $B$ die nicht lediglich das Produkt gesetzgeberischer oder sonstiger Dezisionen, sondern ein Stück "verwalteter Erbschaft" ist"1).

1i) Hierzu die arbeitsrechtliche Eingliederungstheorie, vgl. $\mathrm{Ni}$ k i s c h: Arbeitsrecht, 2. Aufl. Bd. 1, S. 140. Für die Aktualität des Problems im außerstaatlichen Bereich ist die verstärkte Bedeutung negativer Koalitionsfreiheit kennzeichnend. Vgl. dazu S c h e u n e r, in "Der Staat und die Verbände“ 1957, S, 17.

18) Hierauf zielte offenbar W. W e bers Diskussionsbemerkung über die schlichten Anstaltsbenutzungsverhältnisse ab (Verh. d. VDStRL Heft 15, S. 188), wenngleich man in Mainz von einer Bestandsaufnahme und anschließenden kritischen Untersuchung der heute im Ubermaß angebotenen ,besonderen Gewaltverhältnisse" Abstand genommen hat.

19) Wenn allerdings Erler moderne Organisationsprobleme unter dem Stichwort ,vom internationalen Kontrakt zum internationalen Status" behandelt (Grundprobleme des Internationalen Wirtschaftsrecht, 1956 S. 129 ff.), so wäre zu fragen, ob sich etwa bereits ganz allgemein eine eigentümlich rückläuflge Entwicklung anbahnt.

20) Hierzu ergänzend mein Vortrag über „Die Meinungsfreiheit des Soldaten“ (B e r g s t r ä s s e r u. a. „Von den Grundrechten des Soldaten", 1957).

21) Gehle n : Soziologische Voraussetzungen im gegenwärtigen Staat (Beilage zur Staatszeitung für Rheinland-Pfalz vom 15. 1.1956, vierte Seite). 
Damit ist aber die Alktualität unseres. Themas hinreichend erwiesen. Heute ist dieses Erbe weitgehend verzehrt. Deshalb ist, um Arnold Gehlen zu zitieren ${ }^{22}$ ), auch die Verwaltung von der dauernden Revolte des modernen Menschen gegen das Institutionelle bedroht und sollten die Diskussionen über den Bürger in Uniform mit all ihrem Für und Wider unseren Blick für verwandte Probleme der Verwaltung nicht trüben. Gerade unser eigener Tübinger Rückblick auf ein statusrechtliches wie institutionelles Trümmerfeld ${ }^{23}$ ) wollte ja auch nicht so verstanden wenden, als seien status und institutio bereits wieder intakte Größen ${ }^{24}$ ). Daß dem offenbar nicht so ist, hat uns das Mainzer Referat Herbert Krügers erneut bewiesen.

\section{Der institutionelle Gesetzesvorbehalt}

Im modernen Verfassungsstaat hatte das Gesetz von jeher eine Doppelfunktion, was durch die Unterschiedlichikeit der Gesetzesvorbehalte nur bestätigt wind ${ }^{25}$ ). Neben dem rechtsstaatlichen Gesetzesvorbehalt, wie er bereits in der ständischen Freiheit und Eigentumsklausel vorbereitet war, stand und steht eine andere Gruppe von Vorbehalten, die eine bestimmte politische Entscheidung für die gesetzgebende Versammlung reklamieren. In diesem Zusammenhang gehören auch jene Gesetzesvorbehalte, die ausgewählte Einrichtungen an gesetzliche Vorentscheide binden ${ }^{25 a}$ ).

Die ursprüngliche Funktion des institutionellen Gesetzesvorbehalts war eindeutig, er sollte die Organisationsgewalt der Knone beschneiden. Er verstand sich als Wegbereiter einer "Verbürgerlichung“ überkommener Staatlichkeit über das urkundliche Verfassungsrecht hinaus. Nur so wird verständlich, warum die Verfassung des Großherzogtums Hessen (1820) sogar bestimmte, das künftige Gemeindegesetz solle in seinen Grundbestimmungen einen Bestandteil der Staatsverfassung bilden (Art. 45).

Das Verfassungsrecht des 19. Jahrhunderts kannte eine Vielzahl onganisationsrechtlicher Gesetzesvonbehalte. Allendings

22) Urmensch und Spätkultur, 1956, S. 234. Vgl. auch P a u l G e r h a rd t : Amt und Person, 1955, S. 5 ff.

23) Heft 13 der Verh. d. VDStRL.

24) Hierzu auch Dombois : Recht und Institution, 1956.

25) Darin liegt eine Bestätigung jenes Wechselspiels zwischen dem „rechtsstaatlichen" und dem "politischen“ Gesetzesbegriff, das in der Verfassungslehre C. Schmitts eine beherrschende Rolle spielte (S. 138 ff.).

25a) Diese Technik ist auch dem kirchlichen Verfassungsrecht nicht unbekannt. Vgl. die Verfassung der Evangelisch-Lutherischen Kirche in Bayern vom 10.9.1920, Art. 29, Ziffer 4. 
nahm der preußische Großstaat hier eine Sonderstellung ein ${ }^{26}$ ), an der sich der politische Kampf um die Auslegung des Art. 110 der preuß. Verfassung von 1850 entzündet hat ${ }^{27}$ ). Alle durch vorkonstitutionelle Gesetze angeordneten Behönden sollten hiernach bis zur Ausführung künftiger organischer Gesetze in Tätigkeit bleiben.

Keineswegs nur über das Budgetrecht des Parlaments hat sich der Vormarsch des Bürgertums in das Innere des monarchischen Beamtenstaates vollzogen. Eine wesentlich breitere Plattform boten ihm jene institutionellen Gesetzesvorbehalte, deren eigentliche Aufgabe es war, eine der Verfassungsorganisation adäquate Organisation der Verwaltung $\mathrm{zu}$ erzwingen. Auch Preußen, wo mangels eines eindeutigen Vorbehalts vorerst über den Vorrang vorkonstitutioneller Organisationsgesetze gestritten wurde, vermochte sich dieser Entwicklung auf die Dauer nicht zu entziehen. Abgesehen von den verschiedenen preußischen Kommunalordnungen wurde hier insbesondere das Gesetz über die Organisation der allgemeinen Landesverwaltung vom 26. 7. 1880 ein Wahrzeichen des sich selbst entfaltenden Verfassungsstaates.

1. Begreiflicher wunde ein derart institutioneller Gesetzesvorbehalt nicht für beliebige, sondern nur für politisch relevante Einrichtungen angemeldet. Unter diesen standen zu aller Zeit die Gemeinden im Vordergrund, die zwar keinerlei Verfassungsautonomie erhielten ${ }^{28}$ ), aber ihr Organisationsstatut nur aus der Hand des Gesetzgebers entgegennehmen sollten $^{29}$ ). Allerdings wurden einer ähnlichen Schmälerung der Organisationsgewalt im Bereich landesherrlicher Verwaltung stärkste politische Widerstände entgegengesetzt. Trotzdem waren die Verfassungen der Königreiche Württemberg $\left.(1819)^{30}\right)$ und Sachsen $\left.(1831)^{31}\right)$ schon früh bereit, zumindest

20) Charakteristisch für diese die Revision des Art. 105 (Gemeinden) im Jahre 1853 (GS, S. 228).

27) $\mathrm{Zu}$ der literarischen Kontroverse vgl. insbesondere A n$s \mathrm{c}$ ü $\mathrm{tz}$ (Die gegenwärtigen Theorien über den Begriff der gesetzgebenden Gewalt, 2. Aufl. 1901) und A r ndt (Das selbständige Verordnungsrecht, 1902).

28) Eine Sonderstellung nimmt hier auch heute die Verfassung von Bremen ein (Art. 144). Im übrigen vgl. Pre u s s : Städtisches Amtsrecht in Preußen, 1902, S. 150.

29) Darin kommt nur zum Ausdruck, daß die Freiheit des Bürgers und die seines Rathauses als ein Ganzes galten. Hierzu ergänzend meine Studie "Die Gemeinde und der Bundesgesetzgeber" 1957, S. 30.

30) Im Anschluß an die verfassungsrechtliche Fixierung der Verwaltungsdepartments ( $\$ 56$ ) erging das Verfassungsgesetz von 1876 , das eine eingehende Organisationsregelung brachte (Abgedruckt bei $\mathbf{S}$ t o e r k: Handbuch der Deutschen Verfassungen 1884).

31) $\S 41$. 
die Ministerialverfassung dem Gesetzgeber vorzubehalten. Ja, die neue Landschaftsondnung von Braunschweig (1832) hatte sogar die Organisation der herzoglichen Kreisdirektionen dem Gesetzgeber übertragen ${ }^{32}$ ).

Diese eklektischen Hinweise auf die verfassungsgeschichtliche Genesis unseres Problems sollen nur deutlich machen, wie sehr sich seitdem die Dinge gewandelt haben. Zwar ist der institutionelle Gesetzesvorbehalt auch dem geltenden Verfassungsrecht keineswegs fremd, jedoch diesem fehlt offenbar die politische Plastik vergangener Tage. Geblieben ist nur ein durchgehender Gesetzesvorbehalt in allen Fragen der Gemeindeverfassung, während die Ministerialorganisation nur in Baden-Württemberg gesetzlich geordnet werden soll (Art. $\left.{ }^{45}\right)^{33}$ ). Was die sonstige Staatsverwaltung anlangt, so lassen sich hier zwei verschiedene Tendenzen unterscheiden.

Die Verfassungen von Bayern (Art. 77), Niedersachsen (Art. 43) und Nordrhein-Westfalen (Art. 77) verlangen nur für die allgemeine, will sagen politische Verwaltung eine Organisation durch den Gesetzgeber. Auf diese durchaus sinnvolle Selektion haben die Verfassungen von Baden-Württemberg (Art. 70), Schleswig-Holstein (Art. 38) und Hamburg (Art. 57) verzichtet. Stattdessen wind hier ein Gesetzesvorbehalt für die Verwaltungsorganisation schlechthin angemeldet, über dessen Tragweite die für Baden-Württemberg ${ }^{34}$ ) und Hamburg ${ }^{35}$ ) bereits erlassenen Organisationsgesetze unterrichten.

2. Wesentlich anderen Motiven entspringt der Gesetzesvorbehalt des Art. 87 GG. Hier wind eine - allendings lange unterbrochene $-{ }^{36}$ ) Verfassungstradition wiederaufgenommen, die auf die Deutschen Bundesakte ${ }^{37}$ ) zurückgeht und deren

32) Ein thberblick über das damalige Organisationsrecht findet sich bei H. A. Z a ch a ri a e: Deutsches Staats- u. Bundsrecht, 2. Aufl. Teil 2, S. 7 ff. (1854).

33) Bislang ist dieses Gesetz allerdings noch nicht erlassen (DVBl. 1957, S. 748). Eines solchen bedarf es ansonsten auch nicht in Bayern, wo die Verfassung unter Verzicht auf eine gesetzliche Regelung die Organisationsgewalt dem Landtage überträgt (Art. 49). Vgl. aber auch Art. 104 der hessischen Verfassung.

34) Bemerkenswert ist, daß sich das Landesverwaltungsgesetz von 1955 (Ges.Bl., S. 225) nur für den behördlichen Sektor der Verwaltungsorganisation interessiert, wie übrigens auch die Verfassung selbst das einleitend verwandte Stichwort „Landesverwaltung" interpretiert (Art. 70).

s5) Gesetz über Verwaltungsbehörden $1947 / 1952$ (GVB1. 25/163). Näheres bei I psen: Hamburgs Verfassung und Verwaltung, 1956, S. 364.

36) Die Reichsverfassungen von 1848 (\$ 63), 1871 (Art. 7) und 1919 (Art. 14) haben den Ausbau zentralstaatlicher Verwaltung mit anderen Mitteln zu regulieren versucht. 
qualifizierte Bundesbeschlüsse über „organische Einrichtungen, das heißt bleibende Anstalten, als Mittel zur Erfüllung der ausgesprochenen Bundeszwecke ${ }^{88}$ )."

Da das Grundgesetz keinesfalls die einstmalige Regelung des Art. 14 WV übernehmen wollte, sollte der institutionelle Gesetzesvorbehalt seines Art. 87 den erwarteten Ausbau bundeseigener Verwaltung unter verfassungsrechtlicher Kontrolle halten. Nur die Einrichtungen ohnehin obligatorischer Bundesverwaltung (Art. 87 Abs. $1 \mathrm{~S}$. 1) können auch weiterhin im Wege der Organisationsgewalt, also unter Verzicht auf ein Organisationsgesetz errichtet werden ${ }^{39}$ ). Das gleiche gilt dort, wo die Aufgaben einer Bundeseinrichtung außerhalb des Gesetzesvollzuges liegen ${ }^{40}$ ).

Damit entfiel das einst für die Position des Reichspräsidenten so wichtige Junctim zwischen Organisationsgewalt und Beamtenernennungsrecht ${ }^{41}$ ). Der Bundespräsident hat keinerlei Behörden oder sonstige Verwaltungseinrichtungen $\mathrm{zu}$ errichten. Das gilt dabei keineswegs nur insoweit, als bereits der institutionelle Gesetzesvonbehalt des Art. 87 GG gegen eine Organisationsgewalt des Staatsobenhauptes entschieden hat. Nichts anderes gilt auch dort, wo auch heute noch eine verfassungsunmittelbare Organisationsgewalt, wie insbesondere im Fall der in Art. 87 GG bewußt nicht erwähnten obersten

37) Bundesakte Art. 7, Schlußakte Art. 13 f. Näheres bei K l ü b e r : Offentliches Recht des Teutschen Bundes, 4. Aufl., S. 67 (1840).

38) Eine Variante zu Art. 116 des Verfassungsentwurfs von Herrenchiemsee sah sogar einen institutionellen numerus clausus vor.

so) Das schließt nicht aus, daß sowohl zwei der dort genannten Verkehrsverwaltungen (Bundesbahngesetz von 1951 und Postverwaltungsgesetz von 1953), als auch die Finanzverwaltung (Finanzverwaltungsgesetz von 1950) und schließlich der Konsulardienst (Gesetz betr. die Organisation der Bundeskonsulate vom 8.11.1867) durch den Gesetzgeber organisiert worden sind. Im übrigen ist in diesem Zusammenhang die recht bedeutungsvolle Uberleitungsvorschrift in Art. 130 GG zu nennen (Jahrbuch des ö. Rechts NF Bd. 3, S. 76).

40) Köttgen: Der Einfluß des Bundes auf die deutsche Verwaltung und die Organisation der bundeseigenen Verwaltung (Jahrbuch des ö. Rechts nF Bd. 3, S. 109 f.).

41) Anschütz (Die Verfassung des Deutschen Reiches vom 11. 8. 1919, 14. Aufl., S. 316 f.). Schon in der Ubergangszeit hatte der Reichspräsident in dem Erlaß vom 21.3.1919 (RGBl. S. 327) die Errichtung und Bezeichnung der obersten Reichsbehörden geregelt. Die GO der Reichsregierung hatte ihn in dieser Prärogative bestätigt $(\$ 8)$ und die Gem.GO der Reichsministerien hatte die Organisationsgewalt des Reichspräsidenten für alle Reichsbehörden anerkannt (Besonderer Teil § 67). 
Bundesbehörden, beansprucht werden kann ${ }^{42}$ ). Nach der Geschäftsordnung der Bundesregierung ist es deshalb Sache des Bundeskanzlers, die Geschäftsbereiche der einzelnen Bundesminister in ihren Grundzügen zu fixieren ( $(9)$. Ansonsten hat die Staatspraxis die restierende Organisationsgewalt teils der Bundesregierung ${ }^{43}$ ), teils aber auch den Ressortchefs ${ }^{44}$ ) zugebilligt. Die organisatorischen Volmachten des Bundespräsidenten beschränken sich daher auf das ohnehin eine Sonderstellung einnehmende Bundespräsidialamt ${ }^{45}$ ).

Die verfassungsrechtliche Grundlage dieser unter Kanzler, Kabinett und Ressortministern aufgeschlüsselten Organisationsgewalt bildet dabei mitnichten der Art. 86 GG. Die hier der Bundesregierung zuerkannte Einrichtungsvollmacht ist vielmehr nur ein Akzidenz des voraufgegangenen Organisationsgesetzes $\left.{ }^{46}\right)$. Die an keinerlei derartige Vorleistungen des Gesetzgebers gebundene Organisationsgewalt im eigentlichen Sinne hat das Grundgesetz ebensowenig ausdrücklich bestätigt wie die Weimarer Verfassung. Darin unterscheidet es sich von der RV von 1871, deren Art. 7 dem Bundesrat die Organisationsgewalt zusprach, ohne allendings damit die Entstehung einer konkurrierenden Organisationsgewalt des Kaisers verhindert zu haben ${ }^{47}$ ).

3. Zwischen dem (politisch motivierten) institutionellen Gesetzesvorbehalt und dem (rechtsstaatlich motivierten) funktionellen Gesetzesvorbehalt besteht auch rechtstechnisch ein erheblicher Unterschied. Während im einzelnen oft nur schwer zu beantworten ist, welche Sachentscheidungen dem Gesetzesvorbehalt unterliegen sollen, ist der Kreis der dem Ge-

12) Die Verfassungsauslegung im Text hängt mit der nicht unumstrittenen Rolle des Bundespräsidenten bei der Kabinettsbildung zusammen. Hierzu v. Mang o ld t (Das Bonner Grundgesetz, S. 465), M e der (,Bonner Kommentar“" zu Art. 62), M ü n c h (Die Bundesregierung, 1954, S. $198 \mathrm{ff}$.), E s c h e n b u r g (Staat und Gesellschaft in Deutschland, 1956, S. 740) sowie $\mathrm{H} \mathrm{u} \mathrm{ber}$ (Wirtschaftsverwaltungsrecht, 2. Aufl. Bd. 1, S. 62).

13) GemMinBl. 1953, S. 117.

44) GemMinBl. 1953, S. 507.

45) Na wi a sk y : Grundgedanken des Grundgesetzes für die Bundesrepublik Deutschland, 1950, S. 123. Im übrigen vgl. $\S 26$ BBG, der in seinem Absatz 2 die Organisationsgewalt der Bundesregierung bestätigt.

46) Das erste Gesetz über die Maßnahmen zum Schutze der Zivilbevölkerung (BGBl. 1957 I, S. 1696) hat dem Bundesinnenminister eine an die Form allgemeiner Verwaltungsvorschriften gebundene Organisationsgewalt zugestanden ( $\$ 9$ Abs. 2).

17) Hierzu L a b a n d (Staatsrecht des Deutschen Reiches, 4. Aufl., Bd. 1, S. 344 ff.), der sich ausdrücklich gegen die Annahme wendet, die kaiserliche Personalhoheit impliziere notwendig die Organisationsgewalt. 
setzgeber vorbehaltenen Staatseinrichtungen in aller Regel völlig eindeutig.

Die eigentliche Problematik des institutionellen Gesetzesvorbehalts liegt daher im Bereich des Negativen. Hier ist die Frage, ob der Verzicht auf einen solchen Vorbehalt etwa im Sinne einer verfassungsrechtlich verbindlichen Ausschaltung des Organisationsgesetzes verstanden sein will. Sicherlich läßt dieses sich nicht ohne weiteres behaupten. Es wünde vielmehr stets einer besonderen Begründung bedürfen, wenn in dieser Art eine verfassungsrechtliche Schranke gesetzgeberischer Aiktivität behauptet wird. Deshalb ist die der Exekutive verbliebene Organisationsgewalt zumindest nicht generell, etwa aus Gründen der Gewaltenteilung verfassungskräftig garantiert worden. Nur eine rein negative Blockierung dieser Organisationsgewalt würde stets, wie später zu zeigen sein wird, die Vollmachten des Gesetzgebers überschreiten.

Allerdings ist die Frage, ob das Gesagte auch für die Ministerialorganisation gilt, soweit diese nicht etwa nach dem Landesverfassungsrecht nur durch den Gesetzgeber organisiert werden kann (so die Verfassung Baden-Württembergs Art. 45 A.bs. 3) oder dort ihre gesetzliche Regelung doch ausdrücklich zugelassen wurde (so die Verfassung Hessens Art. 104). Kaum ohne Grund hat allerdings in der überwiegenden Mehrzahl der deutschen Länder das Landesverfassungsrecht - nach dem Vorbilde des Grundgesetzes - eine gesetzliche Regelung der Ministerialorganisation weder als notwendig bezeichnet, noch zumindest ausdnücklich zugelassen ${ }^{48}$ ).

Daraus könnte der Schluß gezogen werden, daß durch dieses „beredte Schweigen“ für die Ministerialebene eine verfassungskräftige Organisationsgewalt anerkannt werden sollte. Zur Begründung dessen könnte man sich insbesondere auf die enge Verbindung zwischen Ministerialbehönden und Kabinett ${ }^{19}$ ) in dem Sinne berufen, daB hier die für die Verfassungsorgane charakteristische und essentielle Organisationsgewalt auch auf die dem Kabinett eng benachbarten Spitzenbehörden übergreifen müsse ${ }^{50}$ ).

Allerdings hat sich der Bundesgesetzgeber bei Verabschiedung des Freiwilligengesetzes von 1955 gegen diese Auslegung

48) Deshalb behauptet $\mathrm{H}$ a m a n n zu Unrecht, die Organisationsgewalt sei heute als Ganzes auf den Gesetzgeber übergegangen (Das Grundgesetz, S. 254).

49) Köttgen: Bundesregierung und Oberste Bundesbehörden (DOV 1954 S. 4 ff.).

50) Nur zur Veranschaulichung des Gesagten wäre darauf hinzuweisen, daß ein Gebilde gleich dem Bundespräsidialamt sicher nicht gesetzlich organisiert werden könnte. 
des Grundgesetzes entschieden ${ }^{51}$ ). Die endgültige Organisation des Verteidigungsministeriums soll hiernach einer gesetzlichen Regelung vorbehalten bleiben (\$ 7). Ein solcher Zugriff auf eine in Art. 87 GG ausgesparte oberste Bundesbehörde ist nicht ohne jedes historische Vorbild. Nicht nur die kaiserlichen Reichsämter ${ }^{32}$ ), sondern auch die königlich preußischen Ministerien ${ }^{53}$ ), wurden, wenn auch nur vereinzelt, ähnlich durch den Gesetzgeber organisiert. Anders die Weimarer Praxis, die auf diesem Gebiet in keinem Fall des Reichspräsidenten seine Organisationsgewalt streitig gemacht hat ${ }^{54}$ ).

Diese Zurückhaltung der Reichsgesetzgebung war nicht ohne tieferen Grund. Soweit die Verfassung nicht ausdrücklich wie in Baden-Württemberg etwas anderes bestimmt, kann der Gesetzgeber mangels eines verfassungsergänzenden Regelungsauftrages in die Autonomie der Regierung jedenfalls nicht so weit eingreifen, daB er die Zahl der Kabinettsmitglieder, aber auch die Abgrenzung der ministeriellen Geschäftsbereiche von sich aus verbindlich bestimmt ${ }^{55}$ ). Beides gehört vielmehr $\mathrm{zu}$ den der Autonomie eines Verfassungsorgans zwingend vorbehaltenen Gegenständen, nur daß hier nach der bayerischen Verfassung die Autonomie des Parlaments auf Kosten der Autonomie der Regienung ausgedehnt wurde (Art. 49 Abs. 3).

4. Eine verfassungsrechtliche Begründung dafür, daB der Exekutive überhaupt eine derart verfassungsunmittelibare Organisationsgewalt zusteht, wurde bislang nicht gegeben. Diese Kernfrage unseres Themas ist insbesondere nicht bereits damit beantwortet, da $B$ die institutionellen Gesetzesvorbehalte einen solchen Spielraum ausgespart haben. Da jedoch diese Begründung erst in einem späteren Zusammenhang gegeben wer-

51) Bislang ist das hier in Aussicht gestellte Gesetz noch nicht verabschiedet. Hingegen erging in Osterreich ein Bundesgesetz über die Errichtung eines Bundesministeriums für Landesverteidigung und über die Neuordnung des Wirkungsbereichs einiger Bundesministerien (BGBI. 1956 Nr. 134), da nach der österreichischen Verfassung (Art. 77) die Zahl der Bundesministerien, ihr Wirkungsbereich und ihre Einrichtung durch Bundesgesetz bestimmt werden müssen.

52) Gesetz über Errichtung des Reichseisenbahnamts von 1873 (RGBl. S. 164).

53) Gesetz betr. Abänderung der gesetzl. Bestimmungen über die Zuständigkeiten des Ministers der ö. Arbeiten und des Ministers für Handel u. Gewerbe (GesS 1890, S. 37).

54) Ich entnehme dies der Ubersicht bei $T r$ iepel (Quellensammlung des Reichsstaatsrechts, 5. Aufl., S. 33).

55) Von solchen Organisationsgesetzen müssen Zuständigkeitsnormen unterschieden werden, die ein Ministerialressort zum Setzen von Verwaltungsakten ermächtigen. Darüber siehe unten S. 178. 
den kann, darf ich mich hier auf die Bemerkung beschränken, da B der Gesetzgeber - unbeschadet gewisser Vorbehalte im Sonderfall der Ministerialorganisation - diesen Spielraum der Organisationsgewalt zwar beschneiden, daß er ihn aber nicht zur Gänze kassieren kann. Dem widerstreitet bereits jener unzerstörbare Rest an Organisationsgewalt, der in der späteren Analyse gesetzesfreier Verwaltung seine Bestätigung finden wird.

Die jüngste Entwicklung nötigt allerdings zur Beantwortung der weiteren Frage, ab der Gesetzgeber etwa den Inhaber einer Organisationsgewalt gegebenenfalls auswechseln kann. Die Aktualität dieser Frage beruht, wie noch zu zeigen sein wird, auf den veränderten politischen Aspekten, unter denen die Gegenwart die einst so umstrittene Organisationsgewalt betrachtet. Hatte man in der Vergangenheit den damals aus der monarchischen Prärogative abgeleiteten Anspruch auf Organisationsgewalt als solchen in Frage gestellt, so ist heute offenbar ungleich wichtiger, wer diese Vollmacht jeweils für sich in Anspruch nimmt.

Unter den mancherlei Konkurrenten der Exekutive sind insbesondere Personalräte und Elternbeiräte zu nennen, die beide eine Beteiligung auch an der Organisationsgewalt begehren. Von bloßen Mitwirkungs- und Mitbestimmungsrechte bis zu einer förmlichen Auswechslung des Inhabers der Organisationsgewalt ist politisch der Weg möglicherweise nicht weit. Eben deshalb ist wichtig, daß insbesondere die einem Verfassungsorgan zustehende Organisationsgewalt diesem nicht ohne weiteres durch den Gesetzgeber genommen werden kann. Nicht nur das Institut der Organisationsgewalt, sondern nicht minder ihr Inhaber sind gesetzgeberischen Manipulationen nur begrenzt zugänglich.

In erkennbarer Parallele zur Wirtschaft, wo das Mitbestimmungsrecht nicht in Widerspruch mit der Verfassungsgarantie des Eigentums geraten darf, hat auch jede Zubilligung von Mitbestimmungsrechten im Bereich öffentlicher Verwaltung einmal die verfassungsrechtlich abschließend geordnete Organisation der politischen Willensbildung und zum anderen etwaige institutionelle Garantien zu respektieren. Das gilt dabei keineswegs nur für die eigentlichen Personalangelegenheiten, sondern nicht minder für die mit diesen vielfach in einer Gemenglage befindlichen Organisationsgewalt ${ }^{56}$ ).

Das geltende Personalvertretungsrecht hat ein begrenztes organisatorisches Kondominium zwischen Behördenleiter und

B6) Hierzu die Entscheidung des Bremischen Staatsgerichtshofes vom 3.5.1957 - St 1/56 - und das zu ihr ergangene Sondervotum. 
Personalrat geschaffen. Dabei ist nicht lediglich an die bundesgesetzliche Generalklausel zu denken, die in allen Fragen der inneren Dienststellenordnung ein Mitwirkungsrecht des Personalrates anerkannt hat (\$ 66). Wichtiger als diese Mitwirkung ist das Mitbestimmungsrecht, das zwar nicht bei der organisatorisch so entscheidenden Versetzung von Beamten, wohl aber von Angestellten und Arbeitern anerkannt ist (\$70f.).

Diese, ähnlich auch Elternbeiräten zugestandenen Mitwirkungsrechte in Fragen der Organisation markieren offenbar einen politischen Wendepunkt gegenüber der älteren politischen Praxis, die sich vornehmlich eine Zurückdrängung der Organisationsgewalt hatte angelegen sein lassen. Nunmehr verbindet sich diese Organisationsgewalt mit der zugkräftigen Parole einer Betriebsautonomie, deren Ansprüche sich schon lange nicht mehr allein gegen den Privatunternehmer richten. Es mag sein, daß das im Personalvertretungsrecht verankerte Privileg der "Selbstverwaltung der Verwaltenden" ein Widerspruch in sich selbst ist ${ }^{57}$ ), jedenfalls beweist diese Entwicklung, daB zumindest nicht jede Domestikation des Vorgesetzten ${ }^{\text {(8) }}$ zu Lasten der Organisationsgewalt gehen muß.

\section{Organisationsgewalt \\ und Zuständigkeitsordnung}

Unter dem Blickwinkel bürgerlicher Freiheit interessieren primär die Aktionen „öffentlicher Gewalt" und nicht die Institutionen eines Gemeinwesens. Trotzdem ist nicht ohne weiteres erwiesen, daß der rechtsstaatliche Gesetzesvorbehalt auf einer trennscharfen Unterscheidung von Aktion und Institution beruht und sich deshalb auf materiellrechtliche Fragen beschräniktso).

Allerdings hat sich die herrschende Lehre zugunsten ihrer Hypothese einer verfassungsunmittelbaren Organisationsgewalt vor allem auf dieses Argument berufen. Ihr Vorkämpfer, Anschütz, hat ob des "absolutistischen Hintergrundes" seiner Lehre ${ }^{00}$ ), die den Rechtssatzbegriff künstlich verengere ${ }^{01}$ ), manche Kritik erfahren. Allendings haben seine Kritiker zumeist nicht beachtet, da $B$ dem deutschen Verfassungsrecht jene sozialwissenschaftliche Binsenwahrheit von jeher suspekt war, derzufolge Organisation- und Sachfragen keine wechselseitige

s7) E s c h e n b u r g , in „Der Staat und die Verbände“; 1957, S. 30.

s8) $\mathrm{K}$ r ü g e r (Verh. d. VDStRL Heft 15, S. 128).

39) Hierzu Forsth of $f$ (Lehrbuch S. 359).

60) Helle r (Verh. d. VDStRL Heft 4, S. 111).

61) $R$ i c h t e r (Organisationsgewalt, S. 12). 
Isolierung vertragen. Unser Bundesstaatsrecht fordert genau das Gegenteil ${ }^{62}$ ).

Aber auch abgesehen von diesen Besonderheiten bundesstaatlicher Ordnung verbietet sich jede summarische Antwort auf die Frage, welche institutionellen Nebenwirkungen etwa mit dem Gesetzesvorbehalt des Rechtsstaates verbunden sind. Die stark unterschiedliche juristische Qualifikation der verschiedenen Verwaltungsaufträge kann gerade dort nicht bedeutungslos sein, wo eine Verwaltungseinrichtung nicht mehr um ihrer selbst willen, sondern nur mit Rücksicht auf ihre Publikumsausstrahlung einem Gesetzesvorbehalt unterworfen sein soll. Deshalb kann ein summarischer Gesetzesvorbehalt zu Lasten der Organisationsgewalt jedenfalls nicht mit rechtsstaatlichen Argumenten begründet werden ${ }^{63}$ ).

1. Die Mannigfaltigkeit der Verwaltungsaufträge zeigt sich schon daran, daß Verwaltung und Gesetzesvollzug mitnichten Synonyma sind. Die praktische Bedeutung gesetzesfreier Verwaltung ist bekannt. Den Gemeinden wurde diese Chance durch Art. 28 GG verfassungskräftig garantiert, von den Ländern kann nichts anderes gelten. Das gleiche gilt aber auch für den Bund ${ }^{64}$ ). Auch die Bundesverwaltung beschränkt sich daher nicht auf die verfassungsrechtlich ausdrücklich sanktionierten Sparten des Gesetzesvollzugs, auch der Bund besitzt eine - allendings ungeschriebene und sicher nur begrenzte - Zuständigkeit zur Entfaltung gesetzesfreier Verwaltungsinitiative. Auch für diese ist im Sinne des Art. 30 GG eine Zulassung gegeben, deren verfassungsrechtliche Begrenzung dahingestellt bleiben muß.

Dieser "allgemeine Verwaltungsauftrag"(85) von Gemeinden, Ländern und Bund ist schon begrifflich an institutionelle Prämissen gebunden, die ihm aber nur eine ebenfalls vom

62) Das ist vor allem von F orsth of $\mathrm{f}$ in „Die öffentliche Körperschaft im Bundesstaat" (1931) näher ausgeführt (S. 39).

63) Die Landessatzung von Schleswig-Holstein enthält die merkwürdige Bestimmung, daß die Verwaltung durch die gesetzmäßig bestellten Organe, die Rechtsprechung durch unabhängige Gerichte ausgeübt werde (Art. 2). Aber damit sollte wohl kaum in Analogie zu dem gesetzlichen Richter der gesetzliche Verwaltungsbeamte gefordert werden.

B4) A. A. M a unz (Staatsrecht, 6. Aufl., S. 183), der nur eine geschriebene Widerlegung der Vermutung des Art. 30 GG kennt. Da dem Text des Grundgesetzes gesetzesfreie Bundesverwaltung fremd ist, würde danach die Staatspraxis (über diese vgl. Kö t t g e $\mathbf{n}$ in Jahrbuch des ö. Rechts Bd. 3, S. $78 \mathrm{ff}$.) auf wichtigsten Sachgebieten verfassungswidrig sein.

o5) Hatschek (Lehrbuch des deutschen u. preußischen Verwaltungsrechts, 3. Aufl., S. 77), E. K a u f m a n n (Verh. der VDStRL Heft 9, S. 8). 
Gesetzgeber unabhängige Organisationsgewalt zu bieten vermag. Hat die Verfassung die Möglichkeit originärer Verwaltungsinitiative eingeräumt, so kann dieses Zugeständnis nicht in der Weise um jede Winkung gebracht werden, daß die organisatorischen Vorbedingungen dieser gesetzesfreien Verwaltungsinitiative erst vom Gesetzgeber geschaffen werden müssen $\left.^{68}\right)$. Deshalb glaube ich auch Herrn Friesenhahn widersprechen zu müssen, der dem Parlament in seinen gestern vorgelegten Leitsätzen unter II 4 vorbehaltlos das Recht eingeräumt hat, durch einfaches Gesetz Aufgaben der Organisationsgewalt an sich zu ziehen oder einen Gesetzesvorbehalt in diesem Bereich zu schaffen. Kein lediglich negatives Sperrgesetz zu Lasten der Organisationsgewalt darf die verfassungskräftige Chance gesetzesfreier Verwaltung vereiteln, die keineswegs nur den Gemeinden garantiert worden ist.

Allerdings bleibt es dem Gesetzgeber unbenommen, die Exekutive auch dort, wo sie sich im Besitz einer verfassungskräftigen Organisationsgewalt befindet, an bestimmte Organisationstypen $z u$ binden. Das öffentliche Recht kann die Organisationsgewalt sogar sehr viel stärker beschneiden als das private Gesellschaftsrecht, dem hier durch Art. 9 GG eine gewisse Schranke gezogen sein dürfte.

Diese Einflußnahme des Gesetzgebers auf den Organisationstyp ist keineswegs immer von gleicher Stärke. Die dem Privatrecht geläufige Form des Modellgesetzes bildet im öffentlichen Recht durchaus nicht die Regel. Mit der Bereitstellung solcher Modelle hat sich der Gesetzgeber insbesondere im Fall der kommunalen Eigenbetriebe und Sparkassen begnügt ${ }^{67}$ ). Wesentlich anders zu beurteilen sind die Gemeindeverfassungsgesetze, da sie sich keineswegs mit der Aufstellung eines verbindlichen Modells begnügen, sondern darüber hinaus dessen Praktizierung - insbesondere in der entscheidenden Frage der Errichtung einer neuen Gemeinde - ebenfalls dem Gesetzgeber vorbehalten. Auch der Bundesgesetzgeber hat die ihm vorbehaltene „Errichtung“ neuer Verwaltungseinrichtungen nicht etwa in Gestalt von Modellgesetzen abgegolten, deren Anwen-

B6) Deshalb geht $O$ berma yers Behauptung einer unbegrenzten Organisationsgewalt der Legislative sicher zu weit (Verwaltungsakt und innerdienstlicher Rechtsakt, S. 118).

B7) Eigenbetriebsverordnung (RGBl. 1938 I, S. 1650), ähnlich für die Sparkassen schon das preußische Sparkassenreglement von 1838 (GS., S. 39). Vor allem sind in diesem Zusammenhang die Zweckverbände zu nennen. Das als Landesrecht fortgeltende Zweckverbandsgesetz von 1939 überläßt den Gemeinden den Zusammenschluß $\mathrm{zu}$ solchen Verbänden und stellt lediglich den Organisationstypus als solchen bereit. 
dung in concreto einer gesetzlich regulierten Organisationsgewalt überlassen bliebe.

Unter diesen Umständen bedeutet es kaum noch eine wesentliche Steigerung legislativer Einflußnahme, daß der Bundes- wie auch der Landesgesetzgeber eine große Zahl von Verwaltungseinrichtungen durch konkret gezielte Organisationsakte ins Leben rufen. Diese Praxis beschränkt sich dabei durchaus nicht auf singuläre Gebilde. Sie findet insbesondere dort gern Anwendung, wo sich die Verwaltung auf Neuland begibt und etwa vorhandene Organisationsmodelle versagen.

Dabei ist allendings die Frage, inwieweit die Verwaltungspraxis überhaupt auf solche Modellgesetze angewiesen ist und ob eine unbestreitbare Starrheit des öffentlichrechtlichen Organisationsrechts ausweglos einem Elastizitätsbedürfnis widerstreitet, das Verwaltung und Wirtschaft gemeinsam ist ${ }^{\text {68 }}$ ). Von einem solchen Angewiesensein auf den Gesetzgeber kann dabei nur im Bereich mittellbarer Bundes-, Landes- oder auch Gemeindeverwaltung die Rede sein. Nur dort, wo die in Aussicht genommene Aufgabe einer juristischen Person des öffentlichen Rechts übertragen werden soll, verlangt der Rechtsstaat, daß deren Errichtung - wie übrigens auch Kassation - nur durch oder auf Grund eines Gesetzes erfolgen darf $\left.{ }^{80}\right)$. Modellgesetze, auf Grund deren aber die Verwaltung von sich aus eine neue Sparte mittelbarer Verwaltung zu organisieren vermöchte, sind allerdings dem geltenden Recht so gut wie fremd ${ }^{70}$ ).

68) $\mathbf{R}$ i e b e l : Die Elastizität des Betriebes, 1954.

69) $\mathrm{Zu}$ der umstrittenen Frage vgl. die Literaturangaben bei Kr ü g e r (Verh. d. VDStRL Heft 15, S. 119). F or s th of f verlangt im Fall der Körperschaft stets ein Gesetz (Lehrbuch S. 411), bei Anstalten nur, falls das neue Sozialgebilde hoheitliche Befugnisse ausüben soll, was allerdings "wohl immer zutreffen dürfte“ (aaO., S. 420). Hierzu ein Urteil des RG über die Errichtung von Außenhandelsstellen von 1930 (Ausgewählte staatsrechtliche Entscheidungen des Reichsgerichts in Zivilsachen, S. 205 ff.). Zur Frage der Errichtung neuer Hochschulen vgl. We nde (Grundlagen des preuß. Hochschulrechts, 1930, S. 15), K öt tge n (Deutsches Universitätsrecht, 1933, S. 8) u. Th i e m e (Deutsches Hochschulrecht, 1956, S. 110 f.).

70) Umso bedeutsamer ist, daß der Entwurf einer Verwaltungsrechtsordnung für Württemberg (1931) eine Modellösung für rechtsfähige Körperschaften und Anstalten vorsah und der Exekutive die Verleihung dieses öffentlichrechtlichen Status überließ (Art. 118 u. Art. 153). Schon die preußische Verfassung von 1850 sah eine ähnliche Regelung vor, aber ihr Art. 31 blieb unausgeführt (C. F. K O C h : Allg. Landrecht, 8. Aufl. Bd. 3, S. 543). Der Bundesgesetzgeber könnte sich kaum auf Art. 87 GG berufen, wenn auch er sich mit solchen Modellen begnügen wollte. Die jetzt von I m b ode n näher untersuchte Frage, inwieweit verwaltungsrechtliche Verträge eine zureichende Grundlage für Akte der Organisations- 
Hier liegt der Grund - oder doch ein Grund - für das seit langem beabachtete Ausweichen der Verwaltung in das private Gesellschaftsrecht ${ }^{71}$ ), mit dem sich auch unsere Vereinigung bereits mehrfach beschäftigt hat ${ }^{72}$ ). Daß auch die Gesetzgebung diese Entwicklung in vielen Einzelfällen gefördert hat, soll nicht verschwiegen werden ${ }^{73}$ ). Allendings hat das neuere Recht mit seinen Bestimmungen über die wirtschaftliche Betätigung der Gemeinden bereits Mittel und Wege gewiesen, wie der Gesetzgeber diesen Rückzug der Organisationsgewalt auf das Privatrecht unter seine Kontrolle bringen kann. Unter der Voraussetzung, daß nicht etwa ein radikaler Organisationsstop angeordnet wird, wäre ein ähnliches Vorgehen auch gegenüber den Inhabern der Organisationsgewalt in Bund und Ländern denkbar ${ }^{74}$ ).

2. Nunmehr wenden wir uns der Rolle der Organisationsgewalt im Bereich des Gesetzesvollżuges zu. Hier besteht nur für die Bundesverwaltung eine annähernd eindeutige Rechtslage. Ohne Rücksicht auf den jeweiligen Gesetzesinhalt unterliegen alle Verwaltungseinrichtungen des Bundes, die zum Vollzug eines Bundesgesetzes benötigt werden, einem lückenlosen Gesetzesvorbehalt (Art. $87 \mathrm{GG}$ ).

Für die Landesverwaitung besagt dieses verfassungsrechtliche Diktum auch dort nichts, wo sie einen vom Bundesgesetzgeber gestellten Verwaltungsauftrag durchführt. $\mathrm{Da}$ aber keine Landesverfassung eine dem Art. 87 GG vergleichbare Vorschrift kennt, können die im Interesse des Gesetzesvollzuges benötigten Institutionen der Landesverwaltung nur dann einem generellen Vorentscheid des Gesetzgebers unterworfen sein, wenn ein solcher etwa aus rechtsstaatlichen Gründen gefordert sein sollte ${ }^{75}$ ). Dabei ist selbstverständlich, daß diese Frage für alle Länder einheitlich beantwortet wer-

gewalt abgeben können, muß hier auf sich beruhen bleiben. (Der verwaltungsrechtliche Vertrag, $1958 \mathrm{~S}$. $76 \mathrm{ff}$.).

71) Forst h of $f$ : Lehrbuch, S. 420.

72) So schon 1925 in einer Diskussionsbemerkung von Erich $\mathrm{K}$ a u f $\mathrm{m}$ a $\mathrm{n}$ (Verh. d. VDStRL Heft 2, S. 114).

73) Zum Grundsätzlichen vgl. $\mathrm{H}$ a n S H u b e r : Recht, Staat und Gesellschaft, 1954, S. 35 f.

74) Damit soll allerdings nicht behauptet werden, der Bundesgesetzgeber besäße eine durchgreifende Zuständigkeit zur Regelung der wirtschaftlichen Betätigung der öffentlichen Hand im Sinne eines im zweiten Bundestag eingebrachten Initiativentwurfs (Dr: Nr. 2712).

75) Ein offenbares Dilemma besteht dort, wo der Bundesgesetzgeber wie im Fall der Kriegsopferversorgung ausnahmsweise auch die Organisation der Landesverwaltung regelt (BGBl. 1951 I, S. 169), jedoch die Ausführung seines föderativ motivierten Mindestprogramms der Organisationsgewalt in den Ländern überläßt. 
den muß, da sich offenbar landesrechtliche Variationen des rechtsstaatlichen Minimums schon im Hinblick auf Art. 28 GG verbieten.

Die Beantwortung der Frage, inwieweit der primär funiktionell orientierte Gesetzesvorbehalt des Rechtsstaates auch die organisatorischen Modalitäten des Gesetzesvollzuges einbegreift, ist heute schwieriger denn je. Dies schon deswegen, weil insbesondere seit Imbodens Kritik an der herrschenden Lehre die Spannweite des rechtsstaatlichen Gesetzesvorbehalts schon materiellrechtlich umstritten ist ${ }^{70}$ ). Allerdings ist die Beantwortung der Frage, ob die traditionelle Unterscheidung zwischen Eingriffs- und Leistungsverwaltung etwa einer sozialstaatlichen Korrektur bedarf und ob auch die Leistungsverwaltung einem Gesetzesvorbehalt unterliegt, so folgenschwer, daß sie hier nicht mit wenigen Sätzen versucht werden soll. Solange man aber auf dem Boden der herrschenden Lehre verbleibt, müssen auch die organisatorischen Formen des Gesetzesvollzuges für die gewährende Leistungsverwaltung gesondert betrachtet wenden. Daran ändert auch nichts, daß Art. 87 GG für seinen Teil Eingriffs- und Leistungsverwaltung über den gleichen Leisten geschlagen hat.

Die für die Leistungsverwaltung charakteristische Mannigfaltigkeit organisatorischer Methoden hat Ipsen am Beispiel der Subventionsverwaltung geschildert, nicht ohne hierbei der "Aushöhlung des Gesetzesvorbehalts" durch einen zumeist nur auf Haushaltspositionen gestützten Staatsinterventionismus zu gedenken ${ }^{77}$ ). Hier ist nicht der Ort für eine Untersuchung etwaiger Lücken des Rechtsstaates. Soweit der Gesetzgeber im Bereich gewährender Leistungsverwaltung und daher, wie bis auf weiteres angenommen werden muß, außerhallb des ihm durch die Verfassung vorbehaltenen Bereichs einen Verwaltungsauftrag erteilt, muß ihm überlassen bleiben, ob er auch die begleitenden Vollzugsfragen selber entscheiden will oder nicht. Das ist schon deswegen wichtig, weil solche Gesetze heute in aller Regel vom Bunde erlassen werden. Hat sich aber der Bundesgesetzgeber hier zumeist - und sei es auch nur aus bundesstaatlichen Gründen - verschwiegen, so muß in den Ländern der Organisationsgewalt unverwehrt sein, diese Entscheidungen aus eigenem Recht $z u$ treffen. Nicht anders

76) I m b o den (Das Gesetz als Garantie rechtsstaatlicher Verwaltung, 1954, S. $41 \mathrm{f}$.). Ahnliche toberlegungen bei $\mathrm{B} \mathrm{a} \mathrm{c} \mathrm{h} \mathrm{of} \mathrm{(Verh.}$ d. VDStRL Heft 12, S. 63 und JZ 1956, S. 36), Menger (DOVV 1955, S. 592), I p s e n (Offentliche Subventionierung Privater, 1956, S. 15). In die gleiche Richtung weist auch der Diskussionsbeitrag von werner weber.

77) aaO., S. $52 \mathrm{f}$. 
dürfte wohl auch jenes Urteil des Bundesverwaltungsgerichts zu verstehen sein, das die niedersächsischen Landesernährungsämter für die Abwicklung einer vom Bundesgesetzgeber gewährten Frühdruschprämie zuständig erklärte ${ }^{78}$ ).

3. Ihre eigentliche Zuspitzung erfährt die Problematik gesetzesunabhängiger Organisationsgewalt erst auf dem Boden jener Eingriffsverwaltung, für die nur ein vom Gesetzgeber gestellter Verwaltungsauftrag in Betracht kommt. Allerdings sollte auch für diese nach Anschütz gelten, daB durch die Organisation der Behönden in den „Rechtszustand der Untertanen " nicht eingegriffen wird ${ }^{79}$ ).

Als rechtsstaatliches, wie auch demokratisches Ärgernis hat diese Lehre in Vergangenheit und Gegenwart mancherlei henbe Kritik erfahren. Allerdings haben sich dabei die Argumente erheblich gewandelt. Nur so wird verständlich, daß Herbert Krüger ahne jede Berufung auf Lutz Richter der nach 1926 weitgehend verstummten Kritik an der herrschenden Lehre neuen Auftrieb gab ${ }^{80}$ ). In der Tat läßt sich nicht behaupten, daß Krüger nur den Faden von 1926 wieder aufgenommen hätte. Alle bisherige Kritik rührte noch nicht in der Weise an den Nerv verfassungsunmittelbarer Organisationsgewalt, wie dies Krüger mit seiner These der Unmöglichkeit jeder wirklichen Trennung von Innen und Außen getan hat ${ }^{81}$ ).

Schon in Mainz hat Werner Weber auf die Sprengwirkung dieser Konzeption hingewiesen ${ }^{82}$ ). Jener rechtsstaatliche Rationalismus, den man einst Lutz Richter zum Vorwurf gemacht hat ${ }^{83}$ ), gestattet deshalb keinen Vergleich mit dem Radikalismus der heute gestellten Frage. Allerdings wird damit nur bestätigt, welche Fortschritte der Abbau einstiger Selbstverständlichkeiten seit 1926 gemacht hat. In der Perspektive von Herbert Krüger verschwindet das altumstrittene Problem der Organisationsgewalt hinter einer umfassenden Problematik des Staatbegriffs.

Trotzdem darf ich mich vorerst auf eine Auseinandersetzung mit Richter beschränken, der die von Anschütz begründete Lehre der Organisationsgewalt in ihr genaues Gegenteil ver-

78) Entscheidungen Bd. 3, S. 103.

70) So im Anschluß an frühere Außerungen noch einmal zusammenfassend bei M e y e r-A n s c ü tz: Staatsrecht, 7. Aufl., S. 670 (1919).

e0) Das gilt sowohl von der Studie über Rechtsverordnung und Verwaltungsverordnung (Festgabe für $\mathbf{S}$ m e $\mathrm{n}$ d), als von dem Referat über das besondere Gewaltverhältnis (Verh. d. VDStRL Heft 15).

81) Festgabe für $S$ m end S. 217.

82) Verh. d. VDStRL Heft 15, S. $191 \mathrm{f}$.

89) Hell e r (Verh. d. VDStRL Heft 4, S. 124). 
kehrt hatte. Seine polemische These, daß jede organisatorische Änderung notwendig auch die Rechtsstellung des Bürgers tangiere und daher dem Gesetz vorbehalten sein müsse ${ }^{84}$ ), war allerdings nicht ohne Vorläufer. Schon Ludwig v. Rönne hatte verkündet, $\mathrm{da} \beta$ nur durch Gesetz Obrigkeit konstituiert werden könne ${ }^{85}$ ). Laband ${ }^{86}$ ) und Triepel ${ }^{87}$ ) sowie insbesondere $\mathrm{Hänel}^{88}$ ) haben ähnliche Auffassungen vertreten ${ }^{89}$ ).

Die praktische Tragweite dieser älteren Lehren war allerdings nicht sonderlich groß, solange der Bundesrat über eine unstreitige verfassungsunmittelbare Organisationsvollmacht verfügte (V 1871 Art. 7) und ähnliches auch für das gliedstaatliche Verfassungsrecht behauptet wurde. Jedoch schon in der Weimarer Verfassung klaffte hier eine positivrechtliche Lücke. Dem geltenden Verfassungsrecht ist eine ausdrückliche Bestätigung unabhängiger Organisationsgewalt nicht bekannt, es fehlt ihr somit eine rechtsstaatliche Legitimation. Auch die Niedersächsische Verfassung gestattet schon deswegen keine andere Auslegung ihres Art. 29, weil der rechtsstaatliche $\mathrm{Ge}-$ setzesvorbehalt keine landesrechtlichen Variationen verträgt ${ }^{\text {90}}$ ).

Trotzdem wind man sich die aus diesem positivrechtlichen Befund zu ziehenden Konsequenzen sehr genau überlegen müssen. Das gilt insbesondere im Hinblick auf das in den letzten Jahren durch die Rechtsprechung stark herausgearbeitete Konkretisierungsgebot ${ }^{\text {11 }}$ ). Wird der rechtsstaatliche Gesetzesvorbehalt vorbehaltlos auf das Organisationswesen ausgedehnt, dann kann sich der Gesetzgeber auch hier von diesem Gebot

84) Organisationsgewalt, S. 11.

85) PreuB. Staatsrecht, 4. Aufl., Bd. 1, S. 427.

86) Staatsrecht des Deutschen Reiches, 4. Aufl, Bd. 1, S. 345 f.

87) Reichsaufsicht, 1917, S. 585 f.

88) Gesetz im formellen und materiellen Sinne, S. $222 \mathrm{ffi}$.

80) Dagegen hat A n s $\mathrm{h}$ ü $\mathrm{z}$ Zustimmung gefunden bei: $\mathbf{H}$ a $\mathrm{t}$ schek (Deutsches und Preußisches Staatsrecht, Bd.1, S. 571), Th o m a (Handbuch des Deutschen Staatsrechts, Bd. 2, S. 223), F ors th off (Offentliche Körperschaft, S. 39), B ilf inger (Reichssparkommissar, 1928, S. 15), neben denen aus der älteren Literatur auch $M$. v. Sey del zu nennen wäre (Bayr. Staatsrecht, 3. Aufl., S. 71). Auch bei H elle r (Verh. d. VDStRL Heft 4, S. 124) werden keine grundsätzlichen Einwendungen gegen eine selbständige Organisationsgewalt erhoben. Abweichend allerdings Fle in e r (Institutionen des Deutschen Verwaltungsrechts, 2. Aufl., S. 61), aber auch G. Jellinek (System der subjektiven öffentlichen Rechte, S. 229). Aus jüngster Zeit vgl. das Urteil des OVG Hamburg (VerwRspr. Bd. 10 S. 37).

20) J a c o b i hatte sich auf ein Gewohnheitsrecht zugunsten der Organisationsgewalt berufen (Handbuch des deutschen Staatsrechts, Bd. 2, S. 251). Ahnlich heute $S$ p a n n $\mathrm{r}$ (aaO., S. 642).

91) Bay. Verfassungsgerichtshof (Verw.Rspr., Bd. 7 S. 782), Bundesverwaltungsgericht (Entsch., Bd. 3, S. 116). 
nicht selbstherrlich dispensieren. Die Lage ist eben eine grundsätzlich andere, als wenn eine Verwaltungseinrichtung nur um ihrer selbst willen einem institutionell motivierten Gesetzesvorbehalt unterworfen wird.

Die Praxis der Bundesgesetzgebung hat allerdings den Art. 87 GG im Sinne eines lediglich institutionellen Gesetzesvorbehalts interpretiert. Als Musterbeispiel sei das Gesetz über den Bundesgrenzschutz erwähnt (BGBl. 1951 I S. 201), dessen Blankovollmacht zugunsten der Organisationsgewalt bei Anlegung rechtsstaatlicher Maßstäbe sicherlich nicht bestehen könnte. Ähnliche Beobachtungen können erst recht dort gemacht werden, wo der Bundesgesetzgeber - entgegen der Regel - die Landesverwaltung organisiert und sich dabei begreiflicherweise größte Zurückhaltung auferlegt. Dessen ungeachtet wurde auch hier auf Ausführungsgesetze der Länder keineswegs nur vereinzelt zugunsten der Organisationsgewalt verzichtet.

Diese ähnlich auch im Landesbereich zu beobachtende Praxis findet ihre Erklärung in Elastizitätsbedürfnissen der Verwaltung, die nun einmal gerade auf organisatorischem Gebiet jeder allzu konkreten Gesetzgebung widerstreiten. Offenbar hat sich daher der Gesetzgeber, in Würdigung dieser Sachlage, die Entscheidung darüber vorbehalten, wo im einzelnen Fall die Grenze zwischen vorbehaltener „Errichtung“ und komple-

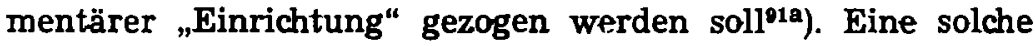
Staatspraxis ist jedoch, wie immer man den rechtsstaatlichen Pegel ansetzen mag, mit der Vorstellung unvereinbar, da $B$ der rechtsstaatliche Gesetzesvorbehalt auch auf institutionelle Bereiche übergreift.

Auf der Verlustliste des Rechtsstaates steht dabei nicht nur das Zeichnungsrecht ${ }^{22}$ ), sondern sogar die besonders wichtige Zuständigkeitsordnung. $\mathrm{Da}$ der Grundsatz des gesetzlichen Richters ${ }^{98}$ ) keine Ausdehnung auf die Verwaltung gestattet, hat man mit Recht an der Möglichkeit administrativer Manipulationen örtlicher Zuständigkeit keinen Anstoß genommen ${ }^{9 \cdot 1}$ ).

91a) Vgl. z. B. $\$ 4$ des Finanzverwaltungsgesetzes (BGB1. 1950 S. 449).

92) Nur das Gemeinderecht hat sich für diese Frage überhaupt interessiert, wie auch durch ein Urteil des des BGH bestätigt wird (VerwRspr., Bd. 5, S. 281 ff.). Im übrigen vgl. Trie pel: Delegation und Mandat im ö Recht, 1942, S. $27 \mathrm{f}$.

83) Hierzu neuestens B ockelmann: Strafprozessuale Zuständigkeitsordnung und gesetzlicher Richter (Goldtammers Archiv 1957, S. 357 ff.).

o4) Solche sind dann sogar unvermeidlich, wenn sich der Gesetzgeber mit der Bildung eines Organisationstypus begnügt, wie es nicht nur bei Mittel- und Unterbehörden die Regel sein muß. Im 
Aber auch die sachliche Zuständigkeit ist offenbar nicht in dem Maße gesetzlich fixiert, wie man bei Anlegung rechtsstaatlicher Maßstäbe erwarten müßte. Das zeigt sich vor allem bei Ministerialverwaltungsakten.

$\mathrm{Da} \beta$ die Organisationsgewalt vorhandene gesetzliche $\mathrm{Zu}-$ ständigkeitsbindungen respektieren muß, sollte nicht ernsthaft bestritten werden. Allerdings entspricht das Offenhalten einer Manipulationschance möglicherweise wohlüberlegten Absichten des Verfassungsrechts, denen sich auch der Gesetzgeber nicht ohne Not verschließen wird ${ }^{04 a}$ ). Die sich hier aufdrängende Frage nach der Zulässigkeit eines gesetzgeberischen Verzichts auf spezifizierte Ressortbindungen bliebe dabei auch dann zu beantworten, falls Ministerialverwaltungsakte oberster Bundesbehörden ohne eigenen Untenbau dem Grundgesetz wirklich unbekannt sein sollten ${ }^{95}$ ).

Ich möchte hier nur auf die Existenz dieser und verwandter Fragen verweisen. Die Kritiker einer derart "nachlässigen“ Staatspraxis können sie jedenfalls nur mit hinreichend präzisen Angaben darüber beantworten, bis zu welcher Demarkationslinie ein rechtsstaatlich gefonderter Gesetzgeber in die Interna der Staatsorganisation vorstoßen muß. Diese Angabe ist jedoch die bisherige Kritik schuldig geblieben ${ }^{96}$ ). Ja, es besteht auch kaum eine Aussicht auf künftige Schließung dieser wesentlichen Lücke ihrer Argumentation.

Anschütz und Lutz Richter waren bis zu dem Auftreten Herbert Krügers die Flügelmänner einer staatsrechtlichen Kontroverse, an der u. a. auch das unterschiedliche Verhältnis der staatsrechtlichen Theorie zur Staatspraxis sichtbar wird. Schon um die Jahrhundertwende hatte sich Anschütz auf den Boden jener Staatspraxis gestellt, die die preußische Regierung dem Herrenhaus im Jahre 1869 erläutert hatte ${ }^{87}$ ). Auch später hat er sich gegenüber Lutz Richter darauf berufen, es sei nicht Aufgabe der staatsrechtlichen Theorie, einer andauernd betätigten Verordnungsgewalt, deren rechtlich begründetes

übrigen ist hier jener Korrekturen einer gesetzlich fixierten $\mathrm{Zu}$ ständigkeitsordnung zu gedenken, die sich aus dem übergreifenden Institut der Amtshilfe erklären.

94a) Hierzu ein Urteil des OVG Münster (DÖV 1958 S. 156), das eine gesetzliche Zuständigkeitsnorm im Sinne des jeweils zuständigen Ressortministers auslegt.

05) Vgl. F üBle in : Der überregionale Verwaltungsakt (DVBl. 51, S. $33 \mathrm{ff}$.) und die dort angegebene Literatur.

06) Ahnlich F or s th off (Lehrbuch, S. 362).

97) Gegenwärtige Theorien über den Begriff der gesetzgebenden Gewalt, 2. Aufl., 1911, S. 153 ff. 
Dasein weder vom Parlament noch von der Rechtsprechung bezweifelt werde, dieses Dasein abzusprechen ${ }^{98}$ ).

Allerdings wird die gegenüber der Staatspraxis skeptisch gewordene Gegenwart durch solche Argumente nicht ahne weiteres zu überzeugen sein. Wenn schon dort, wo das Grundgesetz ausdrücklich auf „hergebrachte Grundsätze“ verwiesen hat, seine Auslegung in vieler Beziehung kontrovers ist, so darf diese Rezeption des hergebrachten Beamtenrechts erst recht nicht kritiklos auf das benachbarte Organisationswesen ausgedehnt werden ${ }^{99}$ ). Wenn trotz dieser Skepsis an den Ergebnissen der Lehre von Anschütz im wesentlichen festgehalten wird, so sei mit Nachdruck betont, da $B$ der Rechtsstaat sicherlich in gewissen Grenzen auch ein legal fixiertes Organisationssystem erfordert. Strittig ist nur, wo die Grenze dieses rechtsstaatlichen Minimums verläuft. Wer hier aber dem Gesetzgeber das Recht ihrer selbstherrlichen Bestimmung bestreitet, muß beweisen können, daß die Verfassung hier nicht

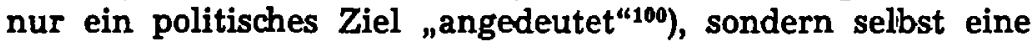
unmittelbar verbindliche Regelung getroffen hat. Solange dieser Nachweis aber nicht geführt werden kann, wird man den rechtsstaatlichen Gesetzesvorbehalt auf das materielle Recht beschränken müssen.

\section{Incorporation als Grundlage der Organisation}

Die Kernfrage unseres Themas haben alle bisherigen Betrachtungen über das Gesetz, seinen unstreitigen Vorrang und seinen umstrittenen Vorbehalt bewußt umgangen. Daher muß jetzt endlich eine verfassungsrechtliche Begründung des Anspruchs der Exekutive auf eine nicht vom Gesetzgeber delegierte Organisationsgewalt versucht werden. Nach dem Mainzer Kurssturz staatsrechtlicher Selbstverständlichkeiten ist hier offenbar doppelte Vorsicht geboten, da weder dem Wortlaut des Grundgesetzes noch auch der Landesverfassungen eine solche Begründung entnommen werden kann.

1. Bei genauerem Zusehen entpuppt sich die Organisationsgewalt als Kombination zweier verschiedener Vollmachten, die aber beide das Verfassungsrecht der Exekutive unstreitig gewährt hat.

Das zumeist nur als Schranke der Organisationsgewalt betrachtete Haushaltsrecht bildet zugleich ihre verfassungsrecht-

98) Kommentar zur Weimarer Verfassung, 14. Aufl., S. 316.

90) Vgl. allerdings $\mathrm{K}$ öt $\mathrm{tg}$ e $\mathrm{n}$, DOV 1954, S. 9.

100) S mend (Staatsrechtliche Abhandlungen, S. 191). 
liche Grundlage ${ }^{101}$ ). Sicherlich kann ohne verfügbare Haushaltsmittel nicht organisiert wenden, aber nicht dieses allein: ordnungsgemäß bereitgestellte Mittel bewirtschaftet die Exekutive auf Grund einer unmittelbar in der Verfassung begründeten Kompetenz. Dieses Recht trägt aber in Verbindung mit der Verfügungsbefugnis über das öffentliche Verwaltungsvermögen die materielle Komponente der Organisationsgewalt.

Für eine Legitimation der Organisationsgewalt genügt das allein allerdings noch nicht. Mit diesen sächlichen Verwaltungsmitteln sollen personelle Faktoren kombiniert werden. Eine weitere, ja die eigentliche Stütze der Organisationsgewalt bilden in Wirtschaft und Verwaltung Direktionsrechte des Dienstherrn gegenüber dem einzelnen Mitarbeiter, dem auf dieser Rechtsgrundlage sein Platz innerhalb der "Arbeitsaggregate“ auch der Verwaltung angewiesen wird. Darin ist die moderne Verwaltung als ein in sich mannigfach gegliederter Kosmos von „Betrieben“ dem privaten Großbetriebe durchaus verwandt. Auf diese Verwandtschaft, dem Ausland offenbar stärker gegenwärtig als uns, hat Simon in seiner Untersuchung über „Entscheidungsvorgänge in Behörden und privaten Unternehmen" angespielt. Es ist dabei nur bezeichnend, da $B$ die Grundlage dieser Maßnahmen nach seiner Untersuchung eine Wirtschaft und Verwaltung gemeinsame „Entscheidungsgewalt" bildet ${ }^{102}$ ).

Utber diese Entscheidungsgewalt oder im Sinne des deutschen Sprachgebrauchs über diese Direktionsrechte verfügt der Inhaber der Organisationsgewalt aber auch im Bereich der öffentlichen Verwaltung nicht etwa auf Grund spezieller Delegation. Das ist völlig eindeutig, soweit Arbeitnehmer in einen Verwaltungskörper "eingestellt“. werden, muß aber ähnlich auch für Beamte gelten. Auch hier beschränkt sich die Rolle der Gesetzgebung auf Bereitstellung eines Rechtsinstitutes, dessen sich die Verwaltungspraxis in concreto bedient.

Nicht, wie die ältere Literatur oft annahm ${ }^{103}$ ), das Beamtenernennungsrecht etwa des Staatsoberhauptes, wohl aber die aus der beamtenrechtlichen Dienstherrenfähigkeit der Anstellungskörperschaft abgeleiteten Vollmachten der obersten

101) Dem steht nicht entgegen, daß sich die Ausbreitung der Organisationsgesetzgebung auch aus dem Wunsch einer Vermeidung von Haushaltsrisiken erklärt. So $\mathrm{Heck}$ el (Handbuch des Deutschen Staatsrechts, Bd. 2, S. 399).

102) S imon: Das Verwaltungshandeln, eine Untersuchung der Entscheidungsvorgänge in Behörden und privaten Unternehmen, 1955, S. $80 \mathrm{ff}$.

103) Schon $\mathrm{L}$ a b a n d hatte dagegen polemisiert (Staatsrecht, Bd. 1, S. 344). 
Dienstbehörde tragen den Anspruch auf Organisationsgewalt. Die aus dieser Dienstherrnfähigkeit abgeleitete Befugnis zur Einstellung von und zur Verfügung über Beamte gründet sich nicht auf eine spezielle, ausdrücklich durch die Verfassung gegebene Ermächtigung, sondern ist mit dem Begriff einer Exekutive mitgesetzt. Insofern besteht also zwischen den verschiedenen Erscheinungsformen der Organisationsgewalt in Wirtschaft und Verwaltung kein Unterschied ${ }^{104}$ ), hier wie dort hat sich der Gesetzgeber mit der Bereitstellung dienstrechtlicher Institute begnügt. Die „Eingliederung “105) selbst unterliegt solange keinem Gesetzesvorbehalt, als die Verwaltung auf $\mathrm{Zwangsdienstpflichten}$ verzichtet.

Allerdings ist Dienstherrenfähigkeit nur im Falle der Gebietskörperschaften eine essentielle Qualität. Den sonstigen rechtsfähigen Verwaltungseinheiten muß diese Qualifikation - gleich ihrem Organisationsstatut überhaupt - durch Rechtsnorm zuerkannt werden, wie erst neuestens das BRRG wieder festgestellt hat $\left.(\S 121)^{100}\right)$. Unterbleibt aber diese Verleihung der Dienstherrenfähigkeit, so besagt auch dies nichts Entscheidendes gegen die Organisationsgewalt, da einer solchen auch dann arbeitsrechtliche Direktionsrechte die notwendige Basis bieten.

2. Demnach gründet sich die Organisationsgewalt auf Direktionsrechte der beiden dienstrechtlichen Varianten. Daraus folgt allerdings eine merkliche Abhängigkeit der Organisationsgewalt vom jeweiligen Stande des positiven Beamten- und Arbeitsrechts. Den hier bestehenden Wechselwirkungen muß gerade heute gesteigerte Beachtung zuteil werden ${ }^{108 a}$ ).

a) Im Verlauf der letzten Jahrzehnte ist deutlich geworden, daß unter sozialrechtlichen Perspektiven zwischen der Organisationsgewalt in Wirtschaft und Verwaltung zumindest keine grundsätzlichen Unterschiede bestehen. Der in die Defensive gedrängte "Herr im Hause" sah sich hier wie dort in seiner Organisationsgewalt beschnitten, soweit diese nicht etwa für die "Selbstverwaltung" des Betriebes in Anspruch genommen wurde. Daß auch die Verwaltung von dieser Entwicklung nicht unberührt blieb, erklärte sich vor allem aus einem unverkennbaren Strukturwandel des Beamtenrechts, das auch den öffent-

104) Uber die Organisation des Betriebes vgl. Nikis ch: Arbeitsrecht, 2. Aufl., Bd. 1, S. $127 \mathrm{f}$.

105) $\mathrm{N}$ i k i s ch aaO., S. $140 \mathrm{ff}$.

106) Das Beamtenrecht hat diese organisationsrechtliche Frage mit gutem Grund nur aufgezeigt.

106a) Uber ähnliche Wechselwirkungen W a genh ö f er: Der Förderalismus und die Notenbankverfassung (Festschrift für Ehard, 1957, S. 115). 
lichen Dienst seines einstmals patriarchalischen Zuschnitts mehr und mehr entkleidet hat. Trotz der verfassungsrechtlichen Verweisung auf die hergebrachten Grundsätze des Berufsbeamtentums hat sich das moderne Beamtenrecht gerade auf solchen Gebieten dem arbeitsrechtlichen Vorbilde genähert, die für die Chancen einer Organisationsgewalt wesentlich sind.

Daher ist es gewiß nicht zufällig, daß Lutz Richter, für den schon damals das Beamtenrecht nur eine Teilerscheinung des Arbeitsrechts war ${ }^{107}$ ), seine Kritik an der Praxis der Organisationsgewalt einleitend auf beamtenrechtliche Argumente gestützt hat ${ }^{108}$ ). Eine nur durch die Organisationsgewalt bewirkte Veränderung des Behördenkörpers erschien ihm für nachhaltige Eingriffe in den Status der betroffenen Beamten keine zureichende Legitimation. Obwohl das Reichsgericht im Jahre 1929 den von Lutz Richter zum Ausgang seiner Betrachtung genommenen Fall anders entschieden hat ${ }^{109}$ ), bedürfen auch heute die beamtenrechtlichen Rückwirkungen einer nur im Wege der Organisationsgewalt vollzogenen „Behördenauflösung, einer wesentlichen Änderung des Aufbaus oder der Verschmelzung mehrerer Behörden "110) sorgsamer Prüfung. Allerdings hat das positive Beamtenrecht zumindest nicht ausdrücklich gegen die Organisationsgewalt entschieden, was dem Rahmengesetz des Bundes ohnehin aus verfassungsrechtlichen Gründen verwehrt gewesen wäre.

Aber auch sonst besteht mancherlei Anlaß, etwaigen beamtenrechtlichen Schranken der Organisationsgewalt verstärkte Beachtung zuteil werden zu lassen. Das gilt insbesondere für die umstrittenen Rechtsinstitute der Abordnung und Versetzung, die jedenfalls nicht als Blankovollmacht der Organisationsgewalt intenpretiert werden können, auf Grund deren diese Arbeitspensum und Arbeitsplatz des Beamten bestimmt. Ähnliches gilt aber auch für die thbertragung von Nebenämtern, für Urlaubsregelungen und mancherlei andere Dispositionen der Organisationsgewalt ${ }^{111}$ ). Das Stichwort Fünftagewoche macht diese Abhängigkeit der Organisationsgewalt von dem Dienstrecht vollends deutlich. Dabei spielen

107) Verhandlungen der VDStRL, Heft 7, S. 108.

108) aaO., S. 3.

109) Ausgewählte beamtenrechtliche Entscheidungen des Reichsgerichts in Zivilsachen, S. $120 \mathrm{f}$.

110) So heute die Formulierung in $\S 19$ des BRRG (BGBl. 57 I, S. 670).

111) Ein Urteil des OVG Münster hat die Frage behandelt, inwieweit die Organisationsgewalt die Lehrbefugnis von Dozenten an pädagogischen Akademien respektieren müsse (VerwRspr. Bd. 9, S. 433). 
die Unterschiede zwischen Beamten und Arbeitnehmern offenbar keine entscheidende Rolle mehr, seitdem sich das ausdifferenzierte Beamtenrecht immer stärker seinem arbeitsrechtlichen Schrittmacher anpaßt. Nur solange, als die nichtvermögensrechtliche Position des Beamten im wesentlichen nur auf einer undifferenzierten Fürsorgepflicht des Staates beruhte, war auch die Organisationsgewalt in ihren personellen Dispositionen weitgehend ungehindert.

Heute überschneidet sich das Beamtenrecht mit der Organisationsgewalt ähnlich wie das Arbeitsrecht. Eben deshalb ist Ule's Unterscheidung zwischen einem Betriebsverhältnis, das nach wie vor durch die Organisationsgewalt gestaltet wird, und einem gerichtlich kontrollierten Grundverhältnis auch für unser heutiges Thema bedeutsam ${ }^{112}$ ). Ich muB mich hier mit einer Verweisung auf sein Mainzer Referat begnügen.

b) Allerdings hat diese Entwicklung des Dienstrechts keineswegs nur den Spielraum der Organisationsgewalt verengert, sondern vielmehr zugleich in eigenartiger Weise das Rechtsinstitut als solches bestätigt. Wurde die bisher rein hierarchische Struktur der Organisationsgewalt ${ }^{113}$ ) von den verschiedensten Ansätzen aus dienstrechtlich modifiziert, so wurde der also verwandelte Herr im Hause damit in der Sache bestätigt.

Nicht nur das Personalvertretungsrecht hat auf gewissen Gebieten ein organisatorisches Kondominium zwischen Dienststellenleiter und Personalrat begründet, auch Mitwirkungsrechte von Elternbeiräten dürfen in diesem Zusammenhang nicht unerwähnt bleiben ${ }^{114}$ ).

3. Demnach ist heute, abgesehen von etwaigen Drittwirkungen gegenüber dem allgemeinen Publikum der mit dem Begriff Organisationsgewalt umschriebene Sachverhalt in Wirtschaft und Verwaltung annähernd der gleiche. Deshalb kann es für verwaltungsrechtliche Diskussionen über die Organisationsgewalt nicht gleichgültig sein, da $B$ das moderne Sozialrecht mit ihr offenbar seinen Frieden gemacht hat. Mitbestimmungsrecht bedeutet Teilhabe an der Organisationsgewalt.

Mit diesem rechtspolitischem Petitum wurden die jeder Organisationsgewalt unentbehrlichen Direktionsrechte seitens der Demokratie nostrifiziert und in derart abgewandelter

112) Zuletzt dargelegt in dem Referat über das besondere Gewaltverhältnis (Verh. d. VDStRL Heft 15, S. 152).

11s) $S$ i m on aaO., S. $92 \mathrm{ff}$.

114) Hierzu Stein: Elterliche Mitbeteiligung im deutschen Schulwesen, JZ 1957, S. $11 \mathrm{ff}$. 
Form gerade auch durch das Sozialrecht bestätigt. Grade hier besteht keinerlei Unterschied zwischen Wirtschaft und Verwaltung, auch gegenüber den Beamten beruht die Organisationsgewalt auf Befehl und Gehorsam. Dabei sollte schließlich nicht vergessen werden, wie sehr zum historischen Rechtsstaat eine dialektische Antinomie zwischen bürgerlicher Freiheit und jenem Irregulare gehört, das eine makabre Terminologie als besonderes Gewaltverhältnis zu beschreiben pflegt. $\mathrm{Da} \beta$ dieses angebliche Ärgernis in Wahrheit ein rechtsstaatliches Essentiale ist, lehrt ein Blick auf das vorkonstitutionelle Statusrecht des Ständestaates und die totalitären Regime der Gegenwart.

Schon deshalb ist es eine abwegige Behauptung, mit der Organisationsgewalt werde nur die lange abgelaufene Epoche des monarchischen Beamtenstaates verlängert. Dies ist schon deswegen falsch, weil sich heute hinter der Organisationsgewalt niemals politische Ansprüche autokephaler Bürokratie verbergen können. Weder das parlamentarische Regierungssystem, noch das Organisationsprinzip der Selbstverwaltung dulden impermeable Arbeitsreservate eines Verwaltungsstabes, die als solche unter Berufung auf die Organisationsgewalt frei von aller politischen Verantwortung gestaltet werden könnten.

IV. Organisationsgewalt und innerstaatliche Gliederung

Die Literatur pflegt sich im allgemeinen nur für die Organisationsgewalt der Regierung zu interessieren. Darüber droht in Vergessenheit zu geraten, daß ganz allgemein mit jeder Verantwortung für eine hinreichend geschlossene Verwaltungseinheit auch ein Stück Organisationsgewalt verbunden ist.

Verwaltungseinheiten in diesem Sinne brauchen dabei keineswegs notwendig rechtsfähige Verwaltungseinheiten zu sein. Verlangt wird nur ein selbständiger Lebensbereich, der gegenüber seiner Umwelt in vielfacher Form abgesetzt sein kann ${ }^{115}$ ), wobei sich allerdings das selbständige Rechtssubjekt durch besondere Trennschärfe auszeichnet. Dessen ungeachtet gibt es aber auch andere Formen der Selbständigkeit, wie das Grundgesetz mit seiner Formel von der „selbständigen Bundesoberbehörde" ausdrücklich anerkannt hat.

Eine Verfassung, die sich zu den Prinzipien des Bundesstaates und der Dezentralisation bekennt, hat diese innerstaatliche Gliederung spezifisch akzentuiert. Andererseits be-

116) $\mathrm{Nik}$ is ch aaO., S. 124. 
weisen schon der selbständige ministerielle Geschäftsbereich (Art. 65 GG) und die selbständige Bundesoberbehörde (Art. 87 Abs. 3 GG), daß die innerstaatliche Gliederung keineswegs nur eine Folge des Bundesstaates und der Selbstverwaltung ist. Daher ist auch die Frage nach der Verklammerung eines so in der Breite und Tiefe vielfältig gegliederten Verwaltungskosmos von besonderer Bedeutung. Im Bereich des Behördenwesens vollzieht sich diese Verklammerung im wesentlichen über die zentrale Organisationsgewalt. Diese vermag allerdings nicht aus eigenem Recht auch auf die Organisation rechtsfähiger Verwaltungseinheiten Einfluß zu nehmen ${ }^{115 a}$ ). Die mit Rechtsfähigkeit ausgestattete Verwaltungseinheit wird damit zu einem „fremden Haus“, das von Staats wegen nur durch Gesetz oder auf Grund eines solchen organisiert werden kann. Jede Dezentralisation ${ }^{110}$ ) begründet eine Vermutung zugunsten organisatorischer Autonomie, sie unterbricht - wenngleich mit unterschiedlicher Stänke - den geschlossenen Stromikreis einer auf Befehl und Gehorsam gegründeten Hierarchie.

Dieses im Begriff der Dezentralisation gegebene Interventionsverbot richtet sich gegen die Organisationsgewalt der jeweils übergreifenden Einheit. Gegenüber rechtsfähigen Anstalten und Körperschaften hat also weder die Bundes- noch eine Landesregierung eine gesetzesunabhängige Organisationsgewalt. $\mathrm{DaB}$ insbesondere das positive Anstaltsrecht der Aufsichtsbehörde vielfach solche Vollmachten ausdrücklich eingeräumt hat, besagt mitnichten das Gegenteil. Besonders geregelt ist schließlich das Verhältnis von Bundes- und Landesverwaltung. Die Landesverwaltung ist vorbehaltlich der Ausnahmeregelungen in Art. 84 Abs. 1 und Art. 85 Abs. 1 GG auch dem Zugriffe des organisierenden Bundesgesetzgebers entzogen. Aber weder die mittelbare Bundesverwaltung noch die mittelbare Landesverwaltung sind durch ähnliche Zugeständnisse an eine Verfassungsautonomie dem für sie jeweils zuständigen Gesetzgeber entzogen worden.

1. Die verfassungsrechtlichen Voraussetzungen, unter denen der Bundesgesetzgeber, entgegen der Regel auf die Verwaltungsorganisation der Länder unter dem Stichwort Einrichtung der Behörden Einfluß nehmen kann, sind hier nicht zu untersuchen. Für unser spezielles Thema ist lediglich wichtig, ob die Bundesregierung unter dem Titel „allgemeine Verwal-

116a) Aber auch die Deutsche Bundesbahn ist gemäß \&14 des Bundesbahngesetzes im Besitz einer gesetzeskräftigen Organisationsgewalt, wenngleich bestimmte Organisationsmaßnahmen ministerieller Genehmigung bedürfen.

110) Zum Terminologischen Peters: Zentralisation und Dezentralisation, 1928, S. 17 . 
tungsvorschriften" vielleicht doch eine in den Raum der Landesverwaltung hineinwirkende Organisationsgewalt für sich in Anspruch nehmen kann. Dabei ist unzweifelhaft, daB ein mit Zustimmung des Bundesrats beschlossenes Gesetz bestimmte organisatorische Maßnahmen auf den Weg der allgemeinen Verwaltungsvorschrift verweisen kann. Aber solche gesetzliche Regelungen sind zumindest nicht die Regel, ja § 9 des ersten Gesetzes über Maßnahmen zum Schutz der Zivilbevölkerung (BGBl. 1957 I S. 1696) ist offenbar ein singulum. Wo der Gesetzgeber aber schweigt, ist insbesondere die akzessorische Natur dieser allgemeinen Verwaltungsvorschriften zu beachten, die daher thematisch nicht über das Gesetz selibst hinausgehen können.

Daraus würde folgen, daß zu einem Bundesgesetz, das keinerlei Regelung über die Einrichtung der Behörden und das Verwaltungsverfahren getroffen hat, lediglich solche Verwaltungsvorschriften ergehen können, die sich ebenfalls auf reine Sachfragen beschränken. Dem widerspricht allerdings die vielfach belegbare Erfahrung, daß eine Gemenglage von Sach- und Organisationsfragen nun einmal zu den charakteristischen Eigentümlichkeiten der Verwaltungsverordnung gehört. Es wäre daher zumindest denksbar, daß das Grundgesetz sub titulo "allgemeine Verwaltungsvorschrift" Bundesregierung und Bundesrat gegenüber den Ländern eine Organisationsgewalt zur gesamten Hand einräumen wollte ${ }^{117}$ ).

2. Die Beantwortung dieser Frage darf nicht mit dem anderen Problem kombiniert werden, inwieweit die Organisationsgewalt des Bundes oder der Länder jeweils in die Räume mittelbarer Bundes- bzw. Landesverwaltung hineinwirken kann. Wenn überhaupt, so kann nur die jeweilige Staatsaufsichtsbehörde als Inhaber einer derart übergreifenden Organisationsgewalt in Betracht kommen, aber auch sie bedarf dazu einer besonderen gesetzlichen Ermächtigung.

Die Gemeindeverwaltung nimmt dabei schon insofern eine Sonderstellung ein, weil hier der Austeilung solcher Ermächtigungen an die staatliche Exekutive verfassungsrechtliche Grenzen gezogen sein könnten. Daß die Organisationshoheit der Gemeinden, deren Organisierung durch den Gesetzgeber nicht ausschließt, bedeutet noch nicht, daß mit dem gleichen Recht auf Grund eines Gesetzes auch die Aufsichtsbehörde die Gemeinde zu organisieren vermöchte.

Allerdings waren in der Vergangenheit solche Organisationsvollmachten der Aufsichtsbehörde insbesondere in den

117) Köttgen : Gemeinde und Bundesgesetzgeber, S. $84 \mathrm{ff}$. 
Bereichen von Polizei ${ }^{18}$ ) und Schule ${ }^{119}$ ) durchaus nicht selten. Spielen sie hier heute keine Rolle mehr, so erklärt sich dies aus der Verstaatlichung der Polizeiexekutive, aber nicht viel anders auch des Schulwesens. Trotzdem kennt auch das geltende Gemeinderecht auf anderen Sachgebieten nach wie vor ähnliche Zugeständnisse an die staatliche Organisationsgewalt, wie insbesondere das Eingemeindungsrecht keineswegs alle Grenzänderungen dem Gesetz vorbehalten hat.

Dem Bundesverfassungsgericht liegt z. Z. eine gegen das niedersächsische Durchführungsgesetz zum Kriegsgefangenenentschädigungsgesetz gerichtete Verfassungsbeschwerde vor $\left.{ }^{120}\right)$. Hier wird beanstandet, da $B$ die Gemeinden ihre eigenen Ausgleichsämter nur mit Zustimmung des Landesflüchtlingsministers in den ihnen obliegenden Vollzug dieses Bundesgesetzes einschalten können. $\mathrm{DaB}$ eine solche Regelung idealtypischer Selibstverwaltung widerstreitet, ist evident. Ob sie deshalb bereits das Grundgesetz verletzt, ist eine Frage der Effektivität seines Art. 28, die hier dahingestellt bleiben muß121).

Da meine Zeit abgelaufen ist, darf ich hier abbrechen. Viele Aspekte des Themas wurden vernachlässigt. $\mathrm{Zu}$ ihnen gehört das Haushaltsrecht, obwohl gerade hier die neue Alternative zwischen funktionellem und institutionellem Haushalt ${ }^{122}$ ) reizvolle Perspektiven für unser Thema eröffnet. Nicht minder bedarf es der Nachsicht, daß entgegen der Regel auch die Probleme des materiellen Gesetzesbegriffs radikal ausgeklammert wurden.

Während ich hier den Faden der Mainzer Diskussion mit Vorbedacht nicht wieder aufgenommen habe, war er nicht möglich, das der Organisationsgewalt so eng verbundene besondere Gewaltverhältnis in ähnlicher Weise auszuklammern. Die damit verbundene Zumutung des Rückmarsches in den Urwald wiegt um so schwerer, weil offenbar zwischen Hamburg und Göttingen gewisse Kompaßdifferenzen bestehen. Zur Vermeidung von Mißverständnissen darf ich daher mit

118) Z. B. preuß. Polizeiverwaltungsgesetz von 1850 (§ 4).

119) Hierzu etwa die Kontroverse zwischen P e t e r $s$ (Der Städtetag 1952, S. 99 ff.) und B e r k e n k o p f (DVBl. 1952, S. 424).

120) DOV 1955 (S. 246), Die Selbstverwaltung 1955 (S. 358).

121) Die andere Frage, welchem kommunalen Organ die Organisationsgewalt zusteht, muß an Hand der Gemeindeverfassungsgesetze beantwortet werden (vgl. etwa LKO für Baden-Württemberg $\S 37$ Abs. 1).

122) O ef tering u. v. S chmiedeberg in ,Staats- und Verwaltungswissenschaftliche Beiträge" (Speyer 1957). 
zwei Feststellungen schließen, die mir gleichermaßen wichtig sind:

Vollgewichtige Institutionen müssen durch den Gesetzgeber verfaßt werden. Nur das in der Idee auf Dauerregelung zugeschnittene Gesetz ist die adäquate Organisationsform echter Institution, die sich von organisatorischen Improvisationen grundsätzlich unterscheidet. Umgekehrt sollte für gewichtlose organisatorische Maßnahmen nicht ohne Not ein Gesetzgeber bemüht werden, dessen Notlage Jahrreiss so eindrucksvoll geschildert hat ${ }^{123}$ ). Schon aus Gründen sinnvoller Okonomie der Kräfte sollte man deshalb dem „Herren im Hause“ seine Chance belassen, die auch das geltende Verfassungsrecht nur beschnitten, aber nicht etwa kassiert hat.

123) Größe und Not der Gesetzgebung (Mensch u. Staat, 1957, S. 52). 


\title{
Leitsätze des Berichterstatters über: Dic Organisationsgewalt
}

\author{
$I$
}

1. Das Thema bezieht sich auf alle diejenigen organisatorischen Maßnahmen nicht, die durch Gesetz oder auch nur auf Grund eines solchen erfolgen.

2. Eine unmittelbar auf die Verfassung gestützte Organisationsgewalt besitzen alle Verfassungsorgane. Ihre institutionelle Autonomie ist verfassungskräftig, soweit dem Gesetzgeber nicht ausdrücklich Regeiungsaufträge erteilt sind.

3. Organisationsgewalt im engeren Sinne betrifft gegenständlich die Organisation der Gerichte, Verwaltungseinrichtungen und Streitkräfte. Das Referat wird nur die Organisationsgewalt der Verwaltung behandeln.

4. Die Verleihung eines öffentlichrechtlichen Status an Religionsgesellschaften sollte nicht als Akt der Organisationsgewalt bezeichnet werden. Dem widerstreitet das staatskirchenrechtliche Interventionsverbot, Religionsgesellschaften organisieren sich selbst. Uberhaupt ist es nicht ratsam, unter einem indifferenten Sammelbegriff Organisationsgewalt ohne Rücksicht auf ihren Gegenstand eine Vielzahl verfassungsunmittelbarer Zuständigkeiten zu vereinen, was $u$. a. für die repräsentativen Kompetenzen des Staatsoberhauptes gilt.

\section{II}

1. Das deutsche Verfassungstecht kennt einen besonderen Typus des rein institutionellen Gesetzesvorbehalts.

2. Dieser Vorbehalt hat in Art. 87 GG eine föderative Funktion, er soll den Ausbau bundeseigener Verwaltung unter der Kontrolle des Gesetzgebers halten.

3. Die Landesverfassungen sind hier stark unterschiedlich, nur einige von ihnen haben diesen Vorbehalt speziell auf die politische (allgemeine) Verwaltung abgestellt. Keine Verfassung kennt einen lückenlosen Vorbehalt, dem alle nur denkbaren Verwaltungseinrichtungen unterfallen. 
4. Auf dem Boden rein institutioneller Gesetzesvorbehalte unterliegt der Gesetzgeber insbesondere nicht dem rechtsstaatlichen Konkretisierungsgebot.

\section{III}

1. Ob das Prinzip gesetzmäßiger Verwaltung und sein primär funktionsorientierter Vorbehalt auch institutionelle Ordnungen einbezieht, kann nicht einheitlich beantwortet werden.

2. Die verfassungskräftige Chance gesetzesfreier Verwaltung (Art. 28 GG) findet ihre notwendige Ergänzung in einer damit ebenfalls verfassungskräftigen Organisationsgewalt im Bereich gesetzesunabhängiger Verwaltungsinitiative.

3. Der Vollzug von Bundesgesetzen bedarf nur insoweit stets einer gesetzlichen Regelung, als er in bundeseigener Verwaltung erfolgen soll.

4. Die Landesverwaltung unterliegt einem solchen Vorbehalt jedenfalls nicht, soweit den Gegenstand des zu vollziehenden Gesetzes gewährende Leistungsverwaltung bildet und das Anliegen daher nicht dem rechtsstaatlichen Gesetzesvorbehalt unterliegt.

5. Die Kritiker der auf Anschütz zurückgehenden Lehre, daß auch die Organisation der Eingriffsverwaltung nicht dem Gesetzesvorbehalt unterliege, vermögen nicht anzugeben, welches das rechtsstaatliche Mindestprogramm auf organisatorischem Gebiet ist. Die Staatspraxis genügt diesen Anforderungen rechtsstaatlicher Kritik in aller Regel nicht.

\section{IV}

1. Die verfassungsrechtlichen Grundlagen der Organisationsgewalt bilden das Recht zur Bewirtschaftung. präsenter Haushaltsmittel und teils beamten- teils arbeitsrechtliche Direktionsrechte gegenüber dem Personalkörper.

2. Die Wechselwirkungen zwischen Dienstrecht und Organisationsgewalt bedürfen besonders sorgsamer Beobachtung.

$$
V \text {. }
$$

1. Organisationsgewalt besitzt jeder Leiter einer selbständigen Arbeitseinheit.

2. Die institutionelle Einheit des Staates beruht nicht zuletzt auch auf einer übergreifenden Organisationsgewalt der Zentrale.

3. Bundesstaat und Dezentralisation begründen hier allerdings Interventionsverbote von unterschiedlicher Stärke. 


\title{
Die Organisationsgewalt
}

\author{
2. Mitbericht von Professor Dr. Felix Ermacora, \\ Innsbruck
}

I.

1. Die Organisation und die Macht, diese zu gestalten, sind nichts typisch Staatliches. In allen Bereichen, wo Gemeinschaften sind oder sich bilden, wo Personenmehrheiten fingiert und Vermögenschaften zu Personen erhoben werden, überall dort, wo es also um die Herstellung einer Ordnung zwischen Personen oder zwischen Personen einerseits und Sachen andererseits geht, bedarf es einer Organisation. Auch ist dann die Macht vorhanden, sie zu gestalten oder diese wird als gegeben allgemein vorausgesetzt. So sei z. B. auf die mannigfaltigen Regeln hingewiesen, die die innere Organisation politischer Parteien bestimmen, sowie auf organisatorische Maßnahmen aufmerksam gemacht, die der politischen Partei erst Gestalt geben ${ }^{1}$ ); von der Organisation der gesetzlich anerkannten Kirchen- und Religionsgesellschaften handelt das Kirchenrecht ${ }^{2}$ ); das technische Kollektiv schließlich verschmelzt Produktionsmittel, Betrieb und Individuum mittels eines noch nie dagewesenen organisatorischen Vorganges unlösbar. Man müßte fast sagen, weltweit und grenzenlos ${ }^{3}$ ). Ein besonderes

1) Vgl. z. B. für Osterreich das OVP-Bundesorganisationsstatut vom 19. Mai 1948, das Organisationsstatut der Sozialistischen Partei Osterreichs vom 11. und vom 13. November 1954, siehe ferner die Verordnung zur Durchführung des Gesetzes zur Sicherung der Einheit von Partei und Staat v. 29. März 1935, RGBl. I, S. 205 oder die Verordnung über die Deutsche Arbeitsfront vom 24. Oktober 1934, oder die österreichischen Bundesgesetze über die „Vaterländische Front" vom 1. Mai 1934 BGBl. II Nr. 4 und vom 20. Mai 1936 BGBl. Nr. 160; siehe ferner für Osterreich: $\mathrm{H} \mathrm{u} \mathrm{r} \mathrm{d} \mathrm{e} \mathrm{s,} \mathrm{Wie} \mathrm{die} \mathrm{österreichi-}$ sche Volkspartei entstand, in: Osterreichische Monatshefte, 1. Jhrg. (1945), S. 9 ff.; ders el be, Ein Jahr österreichische Volkspartei, aaO., S. 269.

2) Siehe darüber die einschlägigen Lehrbücher des Kirchenrechtes oder zum B. die Verfassung der evangelischen Kirche A. u. H. B. in Osterreich vom 26. Januar 1949 ABl. Nr. 57 in: Das österreichische Recht, Loseblattsammlung, Hrsg. v. He in l, L o e benst ei n, Verosta, IV/22, S. $1 \mathrm{ff}$. (bearbeitet v. Klec at sky, Weiler).

s) Vgl. hierzu die grundlegenden Studien von F. G. J ü n g e r, Die Perfektion der Technik, 1953, 3. Aufl., und Bernadik, An der Konsumfront, 1957; vgl. ferner u. a. Gold, Der Betrieb, 
Element im Problemkreis von Macht und Organisation stellt die Organisationsgewalt dar. Das Wort bezeichnet das Spezifische des Problems von Macht und Organisation im Rahmen einer Rechtsordnung, begreift es und erhebt es durch seine eigentümliche Prägung zu allgemeiner Bedeutung. Von der Organisation und der Macht, sie für Rechtsordnungen zu gestalten, soll im folgenden die Rede sein. Der Betrachtung muß aber noch eine Grenze gesetzt werden: die Rechtsordnung erscheint faktisch durch eine Organisation ${ }^{4}$ ). Es ist der Organwalter in Uniform, es ist die als solche bezeichnete Dienststelle, die auffällt; es sind die Organe, die für juristische Personen handelnd auftreten. Mögen Sie sich eine zentralisierte oder eine dezentralisierte - in zahllose Machtträger aufgesplitterte - Rechtsordnung vorstellen, in jedem organisatorischen Teilchen finden Sie eine Gestalt der Organisation und eine Erscheinung der Macht, diese zu ordnen. In der untersten Instanz wie in der höchsten, in der Verwaltung wie bei den Organen der Gerichtsbarkeit und der Gesetzgebung, im Verhältnis von Oberstaat und Gliedstaaten eines Bundesstaates, im Verhältnis von ursprünglichen zu abgeleiteten Rechtsträgern - überall stehen Sie organisatorischen Problemen gegenüber $\left.{ }^{5}\right)$. Sie bilden sich in einem „regressus ad infinitum" fort. Man darf aber die Probleme nicht über einen Leisten schlagen ${ }^{6}$ ), denn die Funktion des Organs bestimmt seine Gestalt. Sie läßt die Organisationsgewalt jeweils in anderem Licht erscheinen. Diese ist in jeder Organisationsstufe von anderer Weise. Thre Bedeutung ist je nach ihrem Auftreten qualitativ und quantitativ verschieden Ich glaube,

Schriftenreihe des österreichischen Gewerkschaftsbundes, Nr. 48; Eu le n b u r , Das Geheimnis der Organisation, 1952; Krä he, Unternehmungsorganisation, 1954; Le h m a n n, Allgemeine Betriebswirtschaftslehre, 3. Aufl., 1956.

) Siehe vor allem Burckhardt, Die Organisation der Rechtsgemeinschaft, 1927, S. $119 \mathrm{ff}$.; K els e n, Reine Rechtslehre, 1934, S. 121, 123 "Der Staat ist Apparat der beamteten Organe“.

5) M e r k 1, A., Allgemeines Verwaltungsrecht, 1927, S. 310: „... Durch diese unökonomisch spezialisierte Problembehandlung (gemeint ist die Behandlung des Organisationsproblems als ein besonderes Problem der Verwaltungsrechtslehre) ist das Mißverständnis nahe gelegt, als ob die Ergebnisse der derart in ihrer Problemstellung beschränkten Organisationslehre nur für das fragliche Teilbereich der Rechtsordnung Geltung hätten, als ob namentlich die von ihr vorgeführten Organisationssysteme nicht eine Eigentümlichkeit der ganzen Rechtsordnung, sondern einer bloßen Teilordnung wären. Insbesondere werden einzelne der vorgeführten Organisationssysteme in dem Sinne behandelt, als wären sie bloße Möglichkeiten der Verwaltungsorganisation ...".

6) Vgl. die treffenden Bemerkungen bei $\mathrm{S} m$ end, Verfassung und Verfassungsrecht, 1928, S. 132. 
man müßte ein stattliches Handbuch füllen, um den Problemen der Organisationsgewalt in einer modernen Rechtsordnung Herr werden zu können.

2. Sie werden von mir nicht erwarten dürfen, daß ich Sie mit den tausend - im konkreten Fall immer gleich bedeutsamen - Fragen vertraut mache. Vielmehr müßten Sie von mir erwarten, daß ich versuche, zur Achse der Orga$n$ is ationsgewalt vorzudringen. Sie ist begriffslogisch bestimmt von der Tauglichkeit oder Untauglichkeit des klassischen Begriffes der Organisationsgewalt, die rechtliche Wirklichkeit $\mathrm{zu}$ erfassen und, staats- bzw. verwaltungsrechtlich gesehen, von der Organisationsgewalt jener Organe, bei denen die Frage nach der Verantwortlichkeit gegenüber der Gesellschaft bzw. gegenüber den Repräsentanten der Gesellschaft aufgeworfen werden kann; also bei der Organisationsgewalt der "Grenzorgane", d. s. im Sinne der herrschenden Lehre unmittelbare Organe ${ }^{7}$ ). Gerade bei der Struktur und den Machtbefugnissen dieser Organe kommt das gesellschaftliche Kraftund Machtverhältnis im Staate, wie es sich in den dynamischen Wandlungen der Staatsorganisation abzeichnet, besonders zum Ausdruck. Wenn ich mich im Folgenden mit der Organ is ationsgewalt in den Staatsfunktionen Gesetzgebung und Verwaltung besonders beschäftige, so deshalb, weil im Verhältnis dieser beiden Staatsfunktionen seit den Anfängen der Lehre von der Organisationsgewalt bedeutende Veränderungen vor sich gegangen sind. Die Fragen der Organisationsgewalt, die im Verhältnis von Oberstaat und Gliedstaaten eine Rolle spielen, sollen keiner systematischen Erörterung unterzogen werden. Das ist aber nicht als Geringschätzung des Problems zu werten. Die Probleme sind, da sie nach der Verfassung selbständige Staaten betreffen, so eigentümlich, daß eine Darstellung, soll sie mehr sein als eine ungenaue Skizze, den Rahmen des Berichtes und des mir gesteckten Zieles sprengen würde.

3. Die Gestalt der Organisation und der mit ihr gedachten Gewalt gibt ein Bild von den in einer konkreten Rechtsordnung herrschenden politischen und sozialen Kraft- und Machtverhältnissen. Die Organisation paßt sich den Staatszielen des jeweiligen Staates an. Daher ist die Organ is ationsgewalt je nach Rechtsordnung, Idee und Epoche variabe ${ }^{6}$ ). Dennoch scheint der Versuch nicht

7) Uber diesen Begriff siehe G. J ell in ek, Allgemeine Staatslehre, 3. Aufl., 1914, S. $548 \mathrm{ffl}$.

8) Vgl. z. B. für die UdSSR G r ot t i a n, Das sowjetische Regierungssystem, 1956, 2. Bd., siehe auch die laufenden organisations- 
gewagt, vom österreichischen Anschauungsmaterial her Allgemeines, auch für die Bundesrepublik Deutschland Gültiges, über die Organisationsgewalt zu entwickeln. Die Substanz in beiden Rechtsordnungen ist gleichartig: Die eine wie die andere Rechtsordnung ist fast in gleichen Zeitläufen durch dieselben Staatsformen geschritten ${ }^{9}$ ). Die Baugedanken der Verfassungen sind verwandt. Da wie dort soll die Staatsfunktion "Verwaltung" nach denselben Grundsätzen geführt werden. $\mathrm{Da}$ wie dort ist sie an das Gesetz gebunden ${ }^{10}$ ). So sehr sich die Wissenschaft vom öffentlichen Recht in Deutschland wie in Osterreich wechselseitig befruchten, sind rechtwissenschaftliche Forschungsergebnisse über die Organisationsgewalt in Osterreich grundlegend verschieden von denen in Deutschland. Die Organisationsgewalt wurde bei Thnen unablässig als Problem erkannt, als solches behandelt und in weite rechtstheoretische Zusammenhänge gehoben. Hierdurch wurde die rechtliche sowie die politische Bedeutung des Problems augenscheinlich ${ }^{11}$ ). In der österreichischen Rechtswissenschaft hinjegen nahm man sich der Grundfragen der Organisations!ewalt kritisch nur bis zum Zusammenbruch der Monarchie $\mathbf{i n}^{12}$ ). Später wurde den Problemen nur von Herrnitt

rechtlich bedeutsamen Artikel in der von amerikanischen Stellen herausgegebenen Zeitschrift (Bad Godesberg) "Ost-Probleme“.

-) Beide Staaten endeten als konstitutionelle Monarchien im Herbst 1918, in beiden Staaten verlor im Jahre 1933 schon die demokratisch-freiheitliche Verfassung ihre Wirksamkeit, in beiden Staaten herrschte von 1933 bis 1945 eine mehr oder minder diktatorische Staatsführung.

10) Und zwar: Bekenntnis zur Demokratie (Art. 1 B-VG; Art. 20 GG), Bekenntnis zur bundesstaatlichen Staatsform (Art. 2 B-VG; Art. $20 \mathrm{GG}$ ), Bekenntnis zu rechtsstaatlichen Grundsätzen (Art. 18 B-VG und vor allem StGG RGBl. Nr. 142/1867; Art. 20 GG und Art. 1 bis 19 GG), Bekenntnis zur Trennung der Gewalten und zu ihrer Balancierung (Art.94 B-VG, Aufbau des B-VG an sich, 6. Hauptstück des B-VG; Art. 20 Abs. 2 GG, Aufbau des GG, Art. $92 \mathrm{ff}$. GG), Bekenntnis zur Trennung von Staat und Kirche Art. 15 StGG RGBl. Nr. 142/1867, Art. 140 GG), Bekenntnis zur monokratischen Geschäftsführung in der obersten Bundesverwaltung (Art. 76 B-VG, Art. 65 GG), u. a.

11) Vgl. unter vielen: A n s c h ü $t z$, Die gegenwärtigen Theorien über den Begriff der gesetzgebenden Gewalt und den Umfang des königlichen Verordnungsrechts nach preußischem Staatsrecht, 2. Aufl. 1901; A r ndt, Das selbständige Verordnungsrecht, 1902; F orsth off, Lehrbuch des Verwaltungsrechts, 6. Aufl., 1956, S. 356 ff.; L a b a n d , Das Staatsrecht des Deutschen Reiches, 2. Bd., 1878, S. 207 ff.; M a u n z, Verwaltung 1937, S. 74 ff.; $R$ i c h t e r, Die Organisationsgewalt, 1926; O b e r m a y r, Verwaltungsakt und innerdienstlicher Rechtsakt, 1956, S. $116 \mathrm{ff}$.

12) S p i e g e 1, Die Verwaltungsrechtswissenschaft, 1909, S. $59 \mathrm{ff}$; L. v. Ste in, Handbuch der Verwaltungslehre, 1870, S. $14 \mathrm{ff}$;; 
und Merkl besonderes Augenmerk geschenkt ${ }^{13}$ ). Melich a $r$ berührt in einer ausgezeichneten Abhandlung ${ }^{13 a}$ ) Fragen der Organisationsgewalt. Für die in der heutigen Verwaltungspraxis gebräuchlichen Werke von Adamovich und Antoniolli scheint die Organisationsgewalt jedoch kein Problem zu bilden ${ }^{14}$ ).

Wo hierfür Grund und Ursache liegen, kann ich nur vermuten:

Kelsen hat in seinen "Hauptproblemen"15), entgegen Anschü $z^{16}$ ) zu begründen versucht, daß die von der deutschen Lehre als typisches Mittel der Organisationsgewalt angesehene Verwaltungsverordnung ebenso wie die Rechtsverordnung und das Gesetz Rechtsnorm ist. Sie dürfte nur auf Grund der Gesetze ergehen. Die Ausübung der Organisationsgewalt müßte daher wie jede andere Gewaltausübung gesetzesgebundene Verwaltung sein. Das in dem Sinne, daß sie nicht sein darf, wenn kein Gesetz ist. Diese Auffassung Kelsens findet im Artikel 18 BVG. ${ }^{17}$ ) und in der diesen Artikel handhabenden Spruchpraxis der Gerichtshöfe öffentlichen Rechts ihren positiv-rechtlichen Niederschlag. Der Artikel 18 gilt auch für die Erlassung sogenannter Verwaltungsverordnungen ${ }^{18}$ ). Damit gäbe es für Österreich keine Freistellung der österreichischen Exekutive vom Gesetz in Belangen des Organisations-

T ezner, Der Kaiser, 1909, S. 23 ff.; U $1 \mathrm{~b}$ ri ch, Lehrbuch des österreichischen Vervaltungsrechtes, 1904, S. $70 \mathrm{ff}$.

19) Herrnitt, Grundlehren des allgemeinen Verwaltungsrechtes, 1921 , S. $17 \mathrm{f}$.; d e rsel be, Osterreichisches Verwaltungsrecht, 1925, S. 66 ff.; M e r k 1, A., 2aO., S. 308 ff.

1sa) Meli char, Institutionelle und personelle Zuständigkeitsordnung, in: Gegenwartsprobleme des Rechts (Ebers-Festschrift), Bd. II, 1950, S. 214 ff.

14) A d a m ovi ch, Handbuch des österreichischen Verwaltungsrechts, I. und II. Bd., 1954 und 1953, geht auf die Problematik der Organisationsgewalt nicht ein; Ant on i olli, Allgemeines Verwaltungsrecht, 1954, S. 142, zieht sich auf einen rein formalen Standpunkt zurück.

15) Kelsen, Hauptprobleme der Staatsrechtslehre, 2. Aufl., 1923, S. 537 ff.

16) Anschütz, Die gegenwärtigen Theorien ... aaO.

17) Art. 18 Abs. 1 und 2 lauten: „Die gesamte staatliche Verwaltung darf nur auf Grund der Gesetze ausgeübt werden. (2) Jede Verwaltungsbehörde kann auf Grund der Gesetze innerhalb ihres Wirkungskreises Verordnungen erlassen."

$18 \mathrm{Vgl}$. die in der österreichischen Rechtswissenschaft abgeführte Diskussion über diesen Gegenstand bei $R$ in $g h$ of er, Zur Rechtsüberleitung reichsdeutscher Erlässe, JBl. 1953, S. 558 ff. und $591 \mathrm{ff}$. und $\mathrm{E}$ r m a cor a, Uber die derogatorische Kraft der Verwaltungsverordnung, JBl. 1955, S. 185 ff. sowie die dieser Diskussion zu Grunde liegende Rechtsprechung der österr. Gerichtshöfe öffentlichen Rechtes, die in den Aufsätzen zitiert ist. 
rechtes. Die Spannung ist dem Problem, wie es herkömmlich gestellt wird, genommen. Es wurde von den führenden österreichischen Rechtslehrern durch Stillschweigen in die Versenkung gestellt $\left.{ }^{19}\right)$. Wenn die österreichische Rechtswissenschaft mit dem Begriff nicht arbeitet, die Praxis in ihm etwa nur eine belastende Erfindung der Gelehrten erblickt, so beweist die rechtliche Wirklichkeit aber, daß die Organisationsgewalt auch in Osterreich nach wie vor ein staats- und verwaltungsrechtliches Problem ersten Ranges ist, so daß der Begriff der Organisationsgewalt tauglich sein kann, bedeutende organisatorische Erscheinungen ordnend zu erfassen. Nur so kann die tatsächlich existierende Organisationsgewalt - ist das Problem in seinem ganzen Umfang erkannt - in kontrollierbare Bahnen gelenkt werden; nur so kann das rechtsstaatliche Gedankengut auch die Organisationsgewalt formen.

4. Die Erkenntnis von Organis a $t$ i on und Macht, sie zu gestalten, öffnet viele Seiten des Fragenkomplexes. Die Organisation soll im Großen gesehen niemals Selbstzweck sein, sondern ihrer Idealform nach immer Mittel zum Zweck - hier: den Staat wirksam werden zu lassen. Sie ist als solche auch eine technische Einrichtung. Nicht von ungefähr finden sich daher in den Betrachtungen der Organisation des Staates Ausdrücke, die aus dem Vokabular der technischen Wissenschaften entnommen sind. Die Verwendung von Worten wie „Funktionär“20), „technischer Apparat“21), "Verwaltungsapparat", „Staatsmaschinerie“, „Arbeitsvorgang“22), „Arbeitsteiliger Vollzug“, „Mechanisierung der

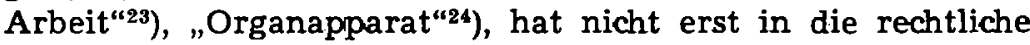
Terminologie Eingang gefunden, seit Techniker zum Personalstand der Staatsorgane zählen' ${ }^{25}$ ), sondern war schon in den Lehren von den Regalien heimisch $\left.{ }^{26}\right)$. Besonders aufschlußreich

19) Gleichartiges konnte ich in meinem Aufsatz „Die besonderen Gewaltverhältnisse in der österreichischen Rechtsordnung", in: DOV 1956, S. 529 ff. für die „besonderen Gewaltverhältnisse“ feststellen.

20) Z. B. Art. 147 Abs. 4 B-VG.

21) Kels en, Reine Rechtslehre aaO., S. 121.

22) Forsth of $f$, aaO., S. 364.

23) $\mathrm{M}$ el i c h a r, aaO., S. 213.

24) B r ockhausen, Osterreichische Verwaltungsreform, 1911, S. 77.

25) Vgl. F. G. Jüng e r, aaO, S. $98 \mathrm{ff}$. siehe ferner die Anstellungserfordernisse für gewisse Sparten im öffentlichen Dienst in der österr. Dienstzweigeverordnung BGBl. Nr. 164/1948 i. d. g. F.

26) L. v. S te in z. B. spricht in "Die Verwaltungslehre“ 7. Teil, 1868, auf S. 61, daß die ,Verwaltungsorgane der Regalien fast ausnahmslos technische Beamte" sind. 
ist der Satz bei Brockhausen, a.a. O. S. 62: „Mit einer solchen Dampfmaschine möchte ich die ganze bureaukratische Arbeitsleistung vergleichen." Der tiefere Blick in die Organisationsgewalt müBte jedenfalls die technische Seite des Problems - die Selbstbewegung der Organisation - erhellen. Insbesondere die anglo-amerikanische Verwaltungswissenschaft versucht diese Seite der Organisation zu begreifen ${ }^{27}$ ). Auf die Bemühungen des Brüsseler "Institut international des Sciences administratives", das mit dem "Comittee on administrative Practices of the Institute for the UNO" zusammenarbeitet, sei aufmerksam gemacht ${ }^{28}$ ). Gewiß reflektiert diese technische Seite der Organisation auf die Organisationsgewalt ${ }^{29}$ ), veranlaßt sie zu Maßnahmen organisatorischer Art, die ohne Kenntnis der technischen Seite nicht von vorneherein geplant werden konnten. Dennoch verschließt eine ausschließliche Beobachtung dieser Seite des Problems den Blick in seine Grundstruktur. Diese ist vielmehr im Rechtlichen und Rechtspolitischen gelegen. Denn dort ist die Macht, die die Organisation gestaltet, die die Selbstbewegung des technischen Apparates ordnet. Die Kenntnis dieser Seite der Organisation scheint mir Voraussetzung für das sinnvolle Begreifen der technischen Seite der Organisationsgewalt. Dem rechtlichen und rechtspolitischen Aspekt des Problems sei daher mein besonderes Augenmerk zugewandt.

27) Siehe z. B. G 1 a d e e n, Introduction to the principles of public administration, 1955 .

28) Vgl. z. B. folgende von diesem Institut herausgegebenen Schriften: $M$ il es und $D$ e a n, Issues and problems in the administrative organization of national governments (1950, I); L ef a $s$ u. a. Structure et attributions des administrations centrales de l'Etat (Paris, 1950); Dovey, Handbook of organization and method techniques (1951, VII); ferner siehe den Kongreßbericht über den VII. Kongreß (1947) des Internationalen Verwaltungskongresses 1947 und zwar besonders: „Der Regierungschef und die Organe seiner Dienststellen“, S. 246 ff.; „Die Mitwirkung des Beamten an der Verwaltungstätigkeit im zentralisierten oder regionalen Staate sowie in der Gemeinde", S. 334 ff.; siehe ferner die Berichte in der Revue internationale des sciences administratives Brüssel, hrsg. vom Institut des Sciences administratives; in diese Kategorie der Untersuchungen ist auch die „statistische Methode" s piegels in der Verwaltungsrechtswissenschaft zu stellen, aaO. Siehe die modernen und grundlegenden Betrachtungen Peter s, Lehrbuch der Verwaltung, 1949, S. 49 ff. Auf diese Ausführungen ist auch bei der Darstellung des Berichtes Bedacht genommen worden (insbesondere S. 226 des Berichtes).

29) Z. B. der Grundsatz, daß das Verhältnis der speziellen Aufgaben zur toberwachungskapazität der überwachenden Einheit richtig sein muß. 
5. a) Nun noch zur Methode, von der die Untersuchung getragen sein soll, einige Erinnerungen. Ich hatte oben ${ }^{30}$ ) hervorgehoben, daß ein neuralgischer Punkt in der Lehre von der Organisationsgewalt in der Frage liegt, ob der Begriff der Organisationsgewalt noch imstande ist, die Wirklichkeit richtig zu erfassen. Will ich den Problem-Komplex nicht mit einem analytischen Urteil steuern - das glaube ich vermeiden zu müssen, mir aber auch ersparen zu können ${ }^{31}$ ) - so muB der hergebrachte Begriff der Organisationsgewalt auf seine Entsprechung für die Wirklichkeit mit induktiver Methode geprüft werden. D. h. die Organisationserscheinungen in den Staaten sind auf den Begriff der Organisationsgewalt zuzuteilen. Dieses Vorgehen ist notwendig. Denn der zum Ausgang des vergangenen Jahrhunderts geprägte Begriff der Organisationsgewalt muB einer Bewegung unterworfen sein: einerseits einer dialektischen Bewegung, die dem Begriff selbst eigen ist ${ }^{32}$ ), andererseits einer Bewegung, die durch die Beziehungen mit dem Anschauungsmaterial der Organisationsgewalt - den Staat und dem Verhältnis der Staatsfunktionen zueinander - entstanden ist. Dieses Anschauungsmaterial ist seit dem Entstehen und Vergehen der konstitutionellen Monarchien in unseren beiden Staaten in eine neue innere Ordnung getreten. Diese begreift $\mathrm{man}^{33}$ ). $\mathrm{Da}$ die Organisationsgewalt immer in Beziehungen zu den Staatsfunktionen - Gesetzgebung und Verwaltung - gesetzt wurde und auch steht, kann sich die Organisationsgewalt verändert haben. Das wäre bei der Begriffsbildung zu berücksichtigen.

b) Hierbei ist die sogenannte normative Methode der $\mathrm{Kelsen}$ 's chen Lehre ${ }^{34}$ ) nur bedingt verwendbar. Das Problem der Organisationsgewalt ist - wie sich noch zeigen soll - normativ auf das Wesen der Verwaltungsverordnung in ihrem Verhältnis zum Gesetz rückführbar ${ }^{35}$ ). Von der eigen-

30) S. 193.

31) Ersparen deshalb, weil „im Vortrag analytische Urteile unter der Voraussetzung anzuwenden sind, daß der, zu dem geredet wird, den Subjektivbegriff nicht so vollständig kennt oder gegenwärtig hat, wie der, welcher redet", S ch o p e n h a u e r, Parerga und Paralipomena, II. Bd., S. 23; das ist aber hier nicht der Fall.

32) Ich glaube hier $\mathrm{H}$ e g e l, Wissenschaft der Logik, erster Teil, 2. Aufl., Jubiläumsausgabe in 20 Bd., IV. Bd., 1836, S. 50 ff. folgen zu müssen.

33) Vgl. vor allem C. Schmitt, Verfassungslehre, 1928. $\mathrm{S} m$ end, aaO. und Forsth of $f$, aaO. sowie die Ausführungen in den vorangegangenen Referaten.

34) Vgl. K el s e $\mathrm{n}$, Hauptprobleme der Staatsrechtslehre, aaO., S. $38 \mathrm{ff}$.

35) Vgl. die Ausführungen auf der S. 220 sowie die Betrachtungen bei A s c $h \ddot{u} t z$, Die gegenwärtigen Theorien, aaO.; ders elbe 
tümlichen Kennzeichnung der Verwaltungsverordnung als gesetzesfreie (selbständige) Verordnung bezog die Organisationsgewalt ihre Freiheit ${ }^{36}$ ). Die Frage, ob die Verwaltungsverordnung als Staatsakt tatsächlich gesetzesfreie Verordnung sein kann, ist eine "normative“. Denn sie betrifft ausschließlich das rechtliche Verhältnis von Rechtssätzen. Anschütz, L ab and, G. Jellinek hatten für inhaltlich bestimmte Staatshandlungen organisatorischer Natur, aus einer Betrachtung ihres Seins und historischen Werdens (nämlich als „eigengesetzliche" Handlungen juristischer Personen und als gewohnheitsrechtliche Prärogative der Krone) den Begriff der Verwaltungsverordnung geprägt ${ }^{36}$ ) und diese aus jenen Gründen zur selbständigen Verordnung ${ }^{87}$ ) erhoben. Hierzu hat Kelsen mit den Mitteln der reinen Rechtslehre Grundlegendes hervorgehoben. So weit es also dieses Problem im Gegenstande noch zu erfassen gilt, wird man sich des Verhältnisses Anschütz'scher und Kelsen'scher Ausführungen entsinnen müssen ${ }^{36}$ ). Im übrigen aber versagt die normative Methode. Das unter der Voraussetzung, da $B$ bei der Erörterung der Organisationsgewalt Ergebnisse erzielt werden sollen, die die rechtliche und rechtspolitische Bedeutung der Organisationsgewalt in der konkreten Staatsordnung erfaßt werden und der in Rede stehende Begriff eine ordnende Wirkung im öffentlichen Recht ausüben soll ${ }^{30}$ ).

II.

6. Der Sinn des Wortes Organisationsgewalt knüpft an zwei Begriffe an, die in der Wissenschaft vom

Lehrbuch des deutschen Staatsrechts, 1914, 7. Aufl., S. 670; d e r se I b e in: Enzyklopädie der Rechtswissenschaft, IV. Bd., 1914, S. $163 \mathrm{ff}$; ; bei A r n d t, Uber die verfassungsrechtliche Grundlage des preußischen Unterrichtswesens, in Arch.föR, Bd. 1 (1886), S. $512 \mathrm{ff}$.; d e r s e 1 b e, Das selbständige Verordnungsrecht, 1902; d e r s e l b e, Noch einiges über das selbständige Verordnungsrecht, ArchföR Bd. 16 (1901), S. 192 ff.; und in zahlreichen anderen bei $A$ nschütz, Die gegenwärtigen Theorien, 2. Aufl., S. 55 zitierten Werken; Ge r b e $\mathbf{r}$ in der Besprechung von Richters, Die Organisationsgewalt in: ArchföR, Bd. 13 NF (1927), S. 450 ff.; G. J el l i n e k, Gesetz und Verordnung, 1887, S. $366 \mathrm{ff}$; L a b a n d, aaO., S. 222 ff.; H. K els e n, aaO., S. 537 ff.; L. R i c h t e r, aaO.

36) Vgl. insbesondere G. J ell in ek, aaO. und A n s cütz, Die gegenwärtigen Theorien, aaO., S. 153 ff. (176!).

37) Siehe z. B. G. J e 11 i n e k, aaO., S. 386: „... Daher hat jede verwaltende Persönlichkeit ein selbständiges Verordnungsrecht.“

38) Vgl. die Ausführungen $\mathrm{H}$. K e l s e n s, aaO.

s9) Siehe u. a. He ck, Begriffsbildung und Interessenjurisprudenz, S. 22, S. $129 \mathrm{ff}$; D a h m, Deutsches Recht, 1951, S. $73 \mathrm{ff}$. und C. Schmit t, Uber die drei Arten des rechtswissenschaftlichen Denkens, 1934, S. $11 \mathrm{ff}$. 
öffentlichen Recht eingehend behandelt werden. Das Wort setzt die Begriffe der Organisation und der Gewalt wohl als geklärt voraus. Das Wort Organisation wird in jeder Betrachtung über den Gegenstand gebraucht ${ }^{40}$ ). Allerdings wird es in der Regel einer näheren Würdigung nicht unterzogen. Ausnahmen: L a b a nd, aaO. S. 207. Kels e n setzt die Organisation der Rechtsordnung bzw. der Teilrechtsordnung der Summe von Normen, die Zuständigkeits-Komplexe der Behörden bilden, gleich $\left.{ }^{11}\right)$. Von dieser Gleichsetzung scheint auch $\mathrm{H}$ an S Juli u s Wolf $\mathrm{f}^{42}$ ) auszugehen. Die mittels normativer Methode vorgenommene Gleichsetzung von Organisation und Rechtsordnung muß aber - auch wenn dadurch das normative Gesicht des Problems getrübt würde - im Sinne Burck$\mathrm{h}$ ard t s${ }^{43}$ ) zumindest ergänzt werden. Nur so kann das die Normen Bewegende erfaßt werden, nur so wird in das staatsrechtliche Problem, das der Praxis zu schaffen macht, eingedrungen. Sollte das aber nicht auch mit der Kels en's chen Lehre von der Zurechnung ${ }^{44}$ ) in Einklang stehen? Zurechnungspunkte - um die es sich bei den einzelnen Organen im Sinne Kels en s handelt - würden aus ihrer linearen Position, die sie durch die Kels en' sche Lehre erhalten haben, ins Mehrdimensionale gerückt werden. Sieht man von der Identifizierung der Rechtsordnung mit der Organisation ab und zugleich den technisch faßbaren Apparat des Staates (Rechtsträger), so kann unter Organisation folgendes verstanden werden: Organisation ist die Summe der für das Funktionieren der Machtausübung eines Rechtsträgers jeweils vorhandenen Mittel, deren Handhabung darauf abzielt, eine Ordnung bei der Machtausübung herzustellen, um bestimmte Zwecke mit einem adequaten Minimum an Arbeit und Kosten zu erreichen.

Der zweite Bestandteil im Wort "Organisationsgewalt" ist das Wort „Gewalt". Hier über den Begriff "Gewalt" abzuhandeln, würde ins Uferlose führen. Es kann aber festgestellt werden, daß es sich im Sinne des herkömmlichen Sprachge-

40) Es erübrigt sich wohl jede nur auffindbare Stelle in der Literatur hier anzuführen, an der das Wort Organisation verwendet wird. Auf einige moderne Werke sei verwiesen: F or st h of f, aaO., S. $356 \mathrm{ff}$;; Meli char, aaO., S. 213; Turegg, Lehrbuch des Verwaltungsrechts, 3. Aufl., S. 238.

11) Reine Rechtslehre, 1934, S. 55.

42) Juristische Person und Staatsperson, I. Bd., 1933, S. 202.

4) Burckhardt, aaO., S. 17: „Die Organisation bezeichnet auch die durch Menschen gehandhabte, verkörperte, aktionsfähig gemachte Zuständigkeitsordnung.“

44) Reine Rechtslehre, 1934, S. 119 ff. 
brauches um die Staatsgewalt bzw. um die Macht der Rechtsträger handelt. Es beziehen sich unter anderen ausdrücklich darauf L. v. Stein ${ }^{45}$ ), Loening ${ }^{46}$ ), Herrnritt ${ }^{47}$ ), L. Richte ${ }^{46}$ ), und Forsth of $f^{40}$ ). Insbesondere ist es Richter zu verdanken, ausdrücklich klargestellt zu haben, da $B$ die Organisationsgewalt kraft ihres Wortbestandteiles "Gewalt" in allen Funktionen des Staates auftritt; wenngleich dieser Gedanke schon bei $\mathrm{L}$ a b a nd, Staatsrecht des deutschen Reichs, II. Bd., 1878, S. 207, aufscheint.

Der Wortsinn des Wortes Organisationsgewalt erfaßt somit, die Macht eines Rechtsträgers durch Organe der Gesetzgebung Verwaltung und Gerichtsbarkeit, je nach Zuständigkeit, die Organisation in jeder Staatsfunktion in allen Belangen zu gestalten. Sie steht - um mit Burckhard t, aaO., S. 140, zu sprechen, „mit der gesamten staatlichen Rechtsordnung im Zusammenhang".

7. Wie aus zwei Sätzen, wenn sie syllogistisch zu Prämissen verbunden werden, mehr folgen kann, als in jedem einzelnen Genommenen liegt $\left.{ }^{50}\right)$, so kann aus zwei Begriffen, soferne sie zusammengezogen werden, mehr bzw. weniger folgen, als in jedem von beiden liegt; so beim Begriffe der Organisationsgewalt. Der hergebrachte Begriff der Organisationsgewalt ist enger als der Sinn der den Begriff bildenden Worte. Wo in der Rechtslehre der Begriff der Organisationsgewalt entweder ausdrücklich definiert ${ }^{51}$ ) oder doch über ihn abgehandelt wird ${ }^{52}$ ), ist folgendes zu erkennen: Die Organisationsgewalt wird als eine besondere

45) Handbuch der Verwaltungsiehre, 1870, S. 15: „Als Inhalt der vollziehenden Gewalt nennen wir sie die Verordnungs-Organisations- und Zwangsgewalt. ... sie bilden ein Ganzes und heißen ... die Staatsgewalt."

46) Lehrbuch des deutschen Verwaltungsrechts, 1884, S. 28/29: „Das Staatsoberhaupt vereinigt ... alle Rechte der Staatsgewalt in sich und übt sie unter den in der Verfassung festgesetzten Bestimmungen aus."

47) Grundlehren des Verwaltungsrechtes, 1921, S. $17 \mathrm{f}$; Österreichisches Verwaltungsrecht, 1925, S. 66: „Der Staat ist Träger der Verwaltung vermöge der ihm zustehenden obersten Gewalt, welche auch die Zuständigkeit zur Organisation der Verwaltung (Organisationsgewalt) in sich schließt."

48) aaO., S. 7.

49) aaO., S. 359 unter Hinweis auf M. v. Seydl (Anm. 4).

b0) Schopenhauer, aaO., $\$ 24$.

51) Anschütz, Die gegenwärtigen Theorien, 2. Aufl., aaO., S. $153 \mathrm{ff}$.; d e r s e l b e, Deutsches Staatsrecht in: Holtzendorff aaO., S. 163; H a t s chek, Institutionen des Verwaltungsrechts, 1919, S. 74; Herrnritt, aaO.; C. S c h m itt, aaO., S. 74.

s2) In allen Systemen. 
Funktion in der Verwaltung angesehen, die innere Organisation der Verwaltung, innerhalb bestimmter Grenzen, die nicht stabil zu sein scheinen, zu gestalten ${ }^{53}$ ).

Die herrschende Lehre sieht in der Organisationsgewalt ein Problem, das die interne Seite der Verwaltung betrifft und das nur soweit diese hoheitlich auftritt $\left.t^{54}\right)$. Sie setzt eine feste Staatsordnung, daher Rechtsträger, eingerichtete Organe ${ }^{53}$ ) und bestehende materielle Regierungsrechte voraus $\left.{ }^{56}\right)$.

8. Soferne die Organisationsgewalt im Sinne der herrschenden Lehre als eine Tätigkeit der Staatsfunktion "Verwaltung" angesehen wird, ist sie der historischen Auffassung treu geblieben. Sie hat einen Begriff übernommen, der vor allem in den parlamentarischen Monarchien bewußt geworden ist. Ein Bewußtsein, das mit dem Für und Wider herrschaftlicher Prärogative auf organisationsrechtlichem Gebiet als Träger der Staatsgewalt zusammenhing. Je mehr diese eingeschränkt oder erweitert wurde, desto lebhafter wurde über sie diskutiert. Die Idee vom Verfassungsstaat ${ }^{57}$ ) hat ebenso wie die Idee von der parlamentarischen

58) F orsth of $f$, aaO., S. 359 verweist darauf, daß der Umfang der Organisationsgewalt strittig sei; $R$ i c $h$ te $r$ wendet sich gegen die herrschende Auffassung und behauptet, daß die Organisationsgewalt dem Gesetzgeber zukommen müsse, in noch schärferer Form Ge r b e $r$ aaO. siehe hierzu auch $N$ e b in g e $r$, Verwaltungsrecht, 2. Aufl., 1919, S. 192, er spricht von „Dienstgewalt", der bayr. VerfGH in Verw.Rspr. Bd. 4 Nr. 61, S. 274 von "Ordnungsgewalt"; Turegg, aaO., 241. Geradezu klassisch sind die Ausführungen eines Ministerialvertreters vor dem preußischen Herrenhaus, die in der Kontroverse Arndt-Anschütz eine Rolle spielen. Aus A n s chütz, Die gegenwärtigen Theorien, aaO., S. 155: „Die Behördenorganisation ist an und für sich Verwaltungs- und nicht Gesetzgebungssache“ ... "... der Landtag habe auf die Handhabung der Organisationsgewalt nur aus dem Titel des Budgetrechtes einen Einfluß, sonst keinen“, aaO., S. 156: „Ausfluß der vollziehenden Gewalt ist notwendig die Organisationsgewalt. Die vollziehende Gewalt muß die Behörden und Organe selbst schaffen können, um die Gesetze ausführen zu können. Es gehört also zu einer solchen Organisationsgewalt die Befugnis zur Einsetzung von Behörden, zur Bestimmung ihres Wirkungskreises und ihrer inneren Einrichtung", siehe auch aaO., S. 158.

b4) Forsth off, aaO., S. $364 \mathrm{ff}$. scheint eine Ausnahme zu bilden, desgleichen ist auch L. v. Ste in, Die Verwaltungslehre, 7. Teil, 1868 , S. 61 ff. sehr modern.

s5) L a b a nd, aaO., S. 207.

so) Ans chütz, aaO., S. 159.

57) Hierüber siehe S a r w e y, Das öffentliche Recht und die Verwaltungsrechtspflege, 1880, S. 23 ff.; L e m a y e r, Der Begriff des Rechtsschutzes im öffentlichen Rechte, Grünhuts Zeitschrift, Bd. 29 (1902), S. 151 ff. 
Monarchie ${ }^{57 a}$ ) der Prärogative des Herrschers im Grundsätzlichen keine nennenswerten Abstriche auferlegt ${ }^{56}$ ). $\mathrm{Zu}$ den Prärogativen der Krone zählten nach übereinstimmender Auffassung auch die Rechte, welche sich auf die Einrichtung der Staatsbehörden bezogen, zählte die erst später sogenannte Organisationsgewalt. Die Behauptung bedarf keiner weiteren Begründung, daß vor der Wandlung der absoluten Monarchien zu parlamentarischen, die Organisationsgewalt uneingeschränkt zu den „Souveränitäts-, Regierungs-, Hoheits-, Majestäts- und Herrscherrechten" gehörte ${ }^{50}$ ). Erst der Zustand in den parlamentarischen Monarchien hat auf Grund des in ihnen herrschenden natürlichen Gegensatzes von Herrscher und Parlament eine Wandlung im Denken über den Umfang der Herrschergewalt und damit der Organisationsgewalt herbeigeführt, ja die Organisationsgewalt selbst erst zu einem Problem werden lassen. Die Krone war nach wie vor aus mancherlei Gründen ein selbständiger Machtfaktor geblieben $^{60}$ ). Daher hatte ihr Träger auch die aus der vorkonstitutionellen Ära stammenden Befugnisse besessen, wo nur eine Ubung erweislich und soweit sie mit der Verfassung vereinbar und auch sonst durch nachfolgende Gesetze nicht aufgehoben war ${ }^{61}$ ). Das auf die Organisationsgewalt angewendet, bedeutet somit: die Organisationsgewalt oblag dem Herrscher, soweit nicht Verfassung und Gesetze einen Vorbehalt machten. Diesen Gedanken finden Sie in der damals herrschenden deutschen und österreichischen Rechtslehre übereinstimmend.

Um die Namen einiger Träger dieser Meinung zu nennen, sei auf folgende verwiesen:

Lorenz v. Stein, Handbuch der Verwaltungslehre $1870^{62}$ );

57a) Siehe da über G. Jellinek, Allgemeine Staatslehre, 3. Aufl., 1914, S. $702 \mathrm{ff}$.

58) Siehe für Osterreich das StGG über die Regierungs- und Vollzugsgewalt RGBl. Nr. 145/1867 und die Theorien hierzu bei Ulb rich, Lehrbuch des österreichischen Staatsrechts, 1883, S. 122 ff., Tez ner, aaO.; siehe für die deutschen Monarchien A ns c h üt z, Die gegenwärtigen Theorien, 1. Aufl., S. $12 \mathrm{f}$.

38) $\mathrm{Z}$ a c h a ri a e spricht in seinem Werk "Deutsches Staats- und Bundesrecht", 3. Aufl., 1865, S. 72 davon, daß zu diesen Rechten solche gehören, die sich auf die Organisation der Staatsbehörden beziehen.

60) A r ndt, Noch einiges über das selbständige Verordnungsrecht, ArchföR, Bd. 16 (1901), S. 197.

61) An s chütz, Die gegenwärtigen Theorien, 2. Aufl., aaO., S. 156 ff.; G. Jelli nek, Gesetz und Verordnung, 1887, S. 373, Anm. 12; T e z n e r, aaO., S. 23.

62) S. 16: „Das Prinzip des Rechtes ist die Unterordnung desselben in Verordnung, Organisation und Zwang unter das Gesetz, 
U lb rich, Lehrbuch des österr. Staatsrechtes $1883^{\circ 5}$ );

L oen ing, Lehrbuch des deutschen Verwaltungsrechtes $\left.1884^{64}\right)$;

U $1 \mathrm{~b}$ rich, Handbuch der österr. politischen Verwaltung, I. Band, 1888'5);

G. J elli in e k, Gesetz und Verordnung, a. a. $0 .{ }^{\text {(6) }}$;

A r ndt, Das selbständige Verordnungsrecht, 1902;

Anschütz, Deutsches Staatsrecht in: Enzyklopädie der Rechtswissenschaft 1914, IV. Bd., Die gegenwärtigen Theorien, 1. Aufl. a. a. O., S.6, S.79, 8987); 2. Aufl. S. $156 \mathrm{ff} ., 175$.

Sowohl in der deutschen wie in der österreichischen monarchischen Rechtsordnung setzten die Verfassungen der Organisationsgewalt der Krone manche Schranke ${ }^{68}$ ). Die Nachgiebigkeit des Parlaments, die politische Bedeutung der Krone aber verhalf in Osterreich der hergebrachten Organisationsgewalt der Exekutive ein eigentümliches, um nicht zu sagen verfassungswidriges Eigenleben. Dieses formte die Organisationsgewalt zu einem unleugbaren, wenn auch verfassungswidrigen Gewohnheitsrecht. Laband und Anschütz haben sich vorsichtig, T e z n e r vehement mit diesem im gegebenen Um-

soweit eben ein Gesetz vorhanden ist; daß aber die vollziehende Gewalt - also auch die Organisationsgewalt (d. V.) - das Gesetz da $\mathrm{zu}$ ersetzen hat, wo es notwendig ist, und dennoch fehlt. Dies sind die Grundlagen des Rechts der vollziehenden Gewalt."

63) S. 140/141: "Die Organisation des Behördenapparates in seinem Detail ist Verwaltungssache; die Verfassung beschränkt jedoch den Monarchen nach 2 Richtungen..."

4) S. 29.

65) S. 55: „Die Regierungsgewalt umfaßt: a) die Amtshoheit, d. i. das Recht, die zur Ausführung der Gesetze erforderlichen Behörden zu errichten, den Wirkungskreis, Sitz und die Geschäftsordnung derselben zu bestimmen, insoferne nicht die Gesetze etwas anderes normieren."

66) aaO., S. $373 \mathrm{ff}$.

67) Deutsches Staatsrecht: S. 52, 163: „Diese (die Organisationsgewalt - d. V.) gehört nach der verfassungsmäßigen Gewaltenteilung nicht zur Legislative, sondern zur Exekutive, steht daher ... der vollziehenden Gewalt nur insoweit nicht zu, als die Organisation bestimmter Arten von Behörden gesetzlich festgelegt oder dem Gesetzgebungsrecht durch ausdrückliche Bestimmung vorbehalten ist" u. aaO.; weitgehend zurückhaltender schon im Handbuch des deutschen Staatsrechtes (A n s h ütz-Thom a), II. Bd. 1932, S. 223.

08) Art. 7 Z. 2 RV, Art. 53 RV, § 11 lit. i des österr. StaatsGG über die Reichsvertretung v. 21. Dezember 1867, RGBI. Nr. 141; zum letzteren vgl. Tez ner, aaO. 
fang bedenklichen Gewohnheitsrecht der Exekutive auseinandergesetz $\mathrm{t}^{69}$ ).

9. Rückblickend kann man, gemessen an den einschlägigen Maßnahmen und Verhältnissen, vorbehaltlich der verfassungsrechtlichen Einschränkungen, folgende Belange des Organisationsrechtes im großen und ganzen als für die Exekutive zurückbehalten ansehen ${ }^{70}$ ).

a) Die Errichtung von Anstalten, Stiftungen und Fonds und anderen Körperschaften ${ }^{71}$ ), ihre Erhebung in den öffentlichbzw. öffentlich-rechtlichen Status, ihre innere Organisation;

04) L a b a nd, Staatsrecht des Deutschen Reiches, I. Bd., 1876, S. 303; Anschütz. Lehrbuch des Deutschen Strafrechtes, aaO., S. 670; und derselbe in Gegenwärtige Theorien, aaO., Tezner, aaO., S. 24 f.

70) Für das deutsche Staatsrecht siehe hierzu Beispiele bei A n s ch üt z, Die gegenwärtigen Theorien, 2. Aufl., S. 66 ff. Beispiele für die österreichische Staatenpraxis werden in den nachfolgenden Anmerkungen angeführt.

71) Siehe hierzu: Hubrich, Entstehung öffentlich-rechtlicher Korporationen, in: Arch. f. bürg. Recht, Bd. 33 (1909), S. 39: „Die bei weitem überwiegende Mehrheit der Rechtslehrer hat sich dafür ausgesprochen, daß der konstitutionelle Hohenzollernkönig allein durch einen Akt der Exekutive jedesmal die Korporationsrechte verleihen kann." G. M e y e $r$, Lehrbuch des deutschen Verwaltungsrechts, 1910, 3. Aufl., 1. Hälfte, S. 112; siehe ferner Herr n $r$ it $t$, in seinem grundlegenden diesbezüglichen Werk, Das österreichische Stiftungsrecht, 1896; de r s el be, Grundlehren, aaO., S. 212 ff., 221, 230 (Anm. 3); der letztgenannten Arbeit entnahm ich den aufschluBreichen Bericht über den Hauptausschuß für Kriegsund Ubergangswirtschaft v. 21. März 1918, in dem ein Bericht über die Errichtung von Wirtschaftsverbänden mit hoheitlichem Einschlag abgegeben wurde (Wiener Zeitung v. 22. März 1918, Nr.67, S. 2). Uber die Errichtung von Stiftungen siehe ferner $M$ a y erh of er, Handbuch für den politischen Verwaltungsdienst, 1903, insbes. Bd. V, S. 190 ff., S. 198: „Die Behörde nimmt die Verleihung selbst vor". Uber die Errichtung von Fonds siehe Mayerh of er, aaO., Bd. VI, S. 748; für Anstalten siehe gleichfalls M a y e r h of er, aaO., Bd. VI, S. 749 ff.; über die Einrichtung von Hoch schulen siehe Herrnritt, Grundlehren aaO., S. 238 (Anm. 3), über die Einrichtung von $S \mathrm{ch}$ u len gleichfalls Herrn r it t aaO., S. 244 (Anm. 15). Uber gewerbliche Genossenschaften siehe M a yer h of e r, aaO., Bd. VI, S. 1029; über die Errichtung von Verbänden siehe die Verordnung des Handelsministers mit den beteiligten Ministerien und im Einverständnisse mit dem Kriegsminister vom 26. August 1919, RGB1. Nr. 273, betreffend die Errichtung eines Kriegsverbandes der Baumwollindustrie (der Verband hatte Rechtspersönlichkeit, $\S 3$ !!), desgleichen die V. RGBl. Nr. 315 und 316. Ferner siehe mannigfaltige Beispiele aus der Handhabung der Organisationsgewalt bei $\mathrm{S}$ p i e g e l, aaO., S. $59 \mathrm{ff}$. 
b) die Errichtung, Auflassung und Umwandlung von Organen in der Verwaltungsorganisation, insbesondere die Errichtung, Auflassung und Änderung von Ministerien ${ }^{72}$ );

c) die Begründung von sachlichen, räumlichen, personellen und zeitlichen Zuständigkeiten der Organe und die Gliederung der Zuständigkeitsverteilung innerhalb der einzelnen $\left.\operatorname{Organe}^{73}\right)$;

d) die Besetzung von Organen durch Organwalter bzw. die Vergebung von Dienstposten ${ }^{74}$ );

e) die Regelung des inneren und äußeren Amtsdienstes wie der Dienststunden, des Parteienverkehrs, die Erledigung der Geschäfts-Korrespondenz, die Art und Weise der Aktenerledigung, der Fertigung von Akten, der Stellvertretung des Ministers durch Beamte bei Aktenerledigungen und ähnliches $\left.{ }^{75}\right)$;

f) die interne Wahrnehmung der Gesetzes-Initiative ${ }^{75}$ );

g) die Systemisierung und zeitweilige Regelung der Bezüge für die Dienerschaft außer den Beamten ${ }^{75}$ );

h) die dienstrechtliche Behandlung des Beamten;

i) die Heeresorganisation und die Befehlsgewalt im Heere, die Organisation der bewaffneten Exekutive ${ }^{70}$ );

j) die Grundsätze für die Erstellung des Budgets ${ }^{77}$ );

k) die Einrichtung von Verordnungsblättern ${ }^{78}$ );

l) die freie Verwendung der den Organen der Verwaltung zur Verfügung gestellten Budgetmittel im Rahmen des Finanzgesetzes;

m) die Einrichtung von „technischen, wirtschaftlichen und fiskalischen Behörden" $" 79$ ).

Wenngleich die österr. Verfassung (Art. 11 lit. j des StGG RGB1. 143/1867) dem Gesetzgeber vorbehalten hatte, die

72) Vgl. hierzu die Ausführungen bei T e z n e r, aaO., S. 24 f. und bei $\mathrm{M}$ a yerh of er, aaO, Bd. I; U l b r i ch, Lehrbuch des österreichischen Verwaltungsrechtes, 1904, S. $70 \mathrm{ff}$.

73) Siehe die in Anm. 72 angeführten Hinweise, insbesondere U l b r i ch, aaO., S. 72.

74) Siehe $M$ a yerhofer, aaO.

75) Siehe die bei M a y erh of er, aaO., Bd. I, S. 276 ff. abgedruckte Instruktion vom 12. April 1852, die wichtige organisatorische Regelungen enthält.

70) Siehe M a y erhofer, insbesondere aaO., Bd. VII, S. 361 (Disziplinarvorschriften für Ángehörige des Heeres sind durch V. getroffen worden) vgl. hierzu für das deutsche Staatsrecht A n s c h ü t z, Die gegenwärtigen Theorien, aaO., 2. Aufl., S. $75 \mathrm{ff}$.

77) Siehe $\mathrm{M}$ a y e $\mathrm{rh}$ of e r, aaO., Bd. I.

78) Siehe M yerh ofer, aaO., Bd. I.

79) Siehe Ulbrich, aaO., S. 72; für das deutsche Staatsrecht: A ns chütz, aaO., S. $66 \mathrm{ff}$. 
Grundzüge der Organisation festzulegen, so ist er hierbei über das heute noch geltende Gesetz vom 19. Mai 1868, RGBl., Nr. 44, über die Einrichtung der politischen Verwaltungsbehörden und das ebenfalls heute noch geltende Reichsgemeindegesetz RGBl. Nr. 18/1862 nicht hinausgekommen. Diese Gesetze allerdings beziehen sich nur auf die Gestalt der Organisation der politischen Verwaltung in den Königreichen und Ländern. Aus der oben gegebenen Ubersicht ist hingegen deutlich zu erkennen, daß sich die Organisationsgewalt des Herrschers (der Exekutive) auf die Ausgestaltung von drei wesentlichen Organisationserscheinungen in der Verwaltung bezogen hat; nämlich

a) auf die umfassende Einrichtung und Ausgestaltung vor allem der unmittelbaren Staatsorgane in der Verwaltung;

b) auf die umfassende Gestaltung der bewaffneten Körper, wie Landwehr und Gendarmerie, und

c) auf die Erstellung einer absoluten Ordnung für die staatliche Dienstnehmerschaft.

Rechnet man noch die Befugnis des Herrschers hinzu, entscheidend am Wege der Gesetzgebung mitzuwirken - womif ihm auch ein bemerkenswerter Einfluß auf die innere Organisation der gesetzgebenden Körperschaften ${ }^{80}$ ) sowie der Gerichte offen stand -, dann war beim Chef der Exekutive bzw. bei den für ihn tätig werdenden Ministern die Gewalt konzentriert, Herr aller Machtmittel des Staates zu sein.

III.

10. Die Rechtstheorie hat auch nach dem Zusammenbruch der Monarchien an dem Begriff der Organisationsgewalt als einem mehr oder minder gesetzesfreien Raum festgehalten an dem Begriff der klassischen Organisationsgewalt.

Von ihm zehrt die Verwaltung heute noch. Man hat sich in jeder Herrschaftsform des Begriffes bedient. Seine Verwendung während der autoritären Herrschaft konnte begriffslogisch nicht tauglich sein. Der Begriff war damals ohne Spannung. Die dem Begriff eigene Spannung ist in der parlamentarischen Monarchie ebenso wie in den modernen Demokratien aus den Gegensätzen von Gesetzgebung und Verwaltung sowie von formellem Gesetz und materieller Verordnung ${ }^{81}$ ) gewachsen. Nur wo eine solche Spannung denkbar ist, kann man mit Recht zur Organisationsgewalt als Reservat der Ver-

80) So in Osterreich das Gesetz vom 12. Mai 1873, RGBI. Nr. 94, im Betreff der Geschäftsordnung des Reichsrates.

81) Siehe hierüber G. J e 11 i n e k, Gesetz und Verordnung, aaO., S. 385 und Ans chütz, aaO., S. $20 \mathrm{f}$. 
waltung Zuflucht nehmen. Wo die Spannung nie bestanden hat, wie in der absoluten Monarchie, oder erschlaffte, wie im nationalsozialistischen Deutschland und im autoritären Osterreich, da mag es gleichgültig sein, von wem und wie die Organisationsgewalt gehandhabt wird. Auch nach $M$ a u n $z^{82}$ ) sei es klar geworden, daß „die Regelung der Organisation mittels Gesetzes nichts anderes ist, als ein Ausfluß der Organisationsgewalt des Führers". Die Organisationsgewalt kann als Vorbereitung für die Gewaltausübung und somit als Machtfaktor in der staatlichen Kräfteverteilung nur in einem Staate Problem sein, dessen Staatsfunktionen vom System der Gewaltenteilung beherrscht werden. Nur das sind der Form nach unsere freiheitlich-demokratischen Rechtsordnungen.

11. Nach dem Jahre 1918 und nach 1945 hat sich die Ge stalt der Organisationsgewalt grundlegend ge w andelt. Erlauben Sie mir - nicht ohne auch die Verhältnisse in der BRD vorbedacht zu haben - dies zunächst festzustellen, dann zu bestimmen und schließlich zu begründen.

Man hatte in den Jahren 1918/19/20 Regelungen getroffen, die die Zuständigkeiten des Kaisers auf die neugeschaffenen republikanischen Organe überleiten sollten. $\S 4$ des deutschen Uberleitungsgesetzes vom 4. März 1919, RGBl. I S. 285, bestimmt, daß die Befugnisse, die nach den Gesetzen des Reiches dem Kaiser zustanden, auf den Reichspräsidenten übergehen. Art. 3 des österreichischen Gesetzes vom 12. November 1918, StGBl. Nr. 5, über die Staats- und Regierungsform von Deutschösterreich bestimmt, daß „alle Rechte, welche nach der Verfassung der im Reichsrat vertretenen Königreiche und Länder dem Kaiser zustanden . . . . . auf den österreichischen Staat übergehen"83). (In der Folgezeit wurden im Zusammenhang mit der Neuorganisation der Republiken weitere Utbergangsbestimmungen getroffen.) Die gesetzlich nicht festgelegten Befugnisse zur Handhabung der Organisationsgewalt schlüpften so durch die Maschen des Gesetzes und blieben gewohnheitsrechtlich bei republikanischen Organen als Nachfolger jener mon. Organe haften $\left.{ }^{84}\right)$, die diese Befugnisse auch

82) $\mathrm{M}$ a u nz, aaO., S. 77.

83) Die österreichische Staatspraxis lehnte es unter dem Einfluß der Kelsenschen Lehre immer ab, in dieser Bestimmung auch eine Norm zu erblicken, mit der etwa nicht normierte Prärogativen des Herrschers - also monarchisches Gewohnheitsrecht - auf die republikanischen Organe übergegangen seien. Unter Berufung auf Art. 18 Abs. 1 B-VG (siehe Anm. 17) folgert man, daB jedes nicht gesatzte Recht untergegangen sei.

B4) Das nimmt nicht wunder, wenn z. B. von Ans chütz, aaO., S. 175 behauptet wird: "... die durch vorkonstitutionelle Gesetze 
unter der Macht des Herrschers ausübten. Nämlich bei den Organen der Exekutive im besonderen. Das allerdings soweit sie ihnen nicht ausdrücklich entzogen wurden:

a) Die Errichtung und Einrichtung von Anstalten, Stiftungen und Fonds, sowie anderer sogenannter rechtsfähiger Verwaltungseinheiten ${ }^{85}$ ) - ursprünglich wie nachgewiesen, ein Ausfluß der Macht der Exekutive übernahm im weitesten Umfang der Gesetzgeber $\left.{ }^{86}\right)$. Er ist es nun, der in der Regel den öffentlich-rechtlichen Status zuteilt und entzieht. Unter Heranziehung des wissenschaftlich gebildeten Unterschiedes von selbständigen und unselbständigen Anstalten, schied man zwischen Anstalten, die nur der Gesetzgeber, und Anstalten, die auch die Verwaltung errichten durften. So haben sich z. B. die einzelnen Bundesversuchsanstalten oder das Dorotheum auf der Basis verwaltungsrechtlicher Anordnungen erhalten ${ }^{87}$ ). Andererseits wurden die kraft herrschaftlicher Stiftungsakte oder allerhöchster Entschließungen geschaffenen Universitäten nach dem österr. Hochschulorganisationsgesetz BGBl. Nr. 154/1955 zu mehr oder minder selbständigen - in der Regel jedoch unselbständigen - Anstalten gemach $\left.{ }^{88}\right)$. Der Gesetzgeber regelt eingehend alle Voraussetzungen, die gegeben sein müssen, damit die Verwaltungsbehörde Offentlichkeitsrechte verleihen kann. Das trifft insbesondere für die Krankenanstalten nach dem Krankenanstaltengesetz BGBl. Nr. 1/1957 zu. Der innere Betrieb der

ausgesprochenen Spezialvorbehalte zu Gunsten der königlichen Entschließungen sind bestehen geblieben."

85) Uber diesen Begriff grundlegend Köttgen, Die rechtsfähige Verwaltungseinheit, 1939.

80) „Volksbildungsanstalten z. B. leiten ihre innere Struktur ohne gesetzliche Grundlage nach wie vor von einem Erl. des Unterrichtsressorts v. 30. Juli 1919 Z. 16 450, ,Volkserziehung' Nr. 45 ab." Die Errichtung von Schulen fiel in der monarchischen Rechtsordnung in den Aufgabenkreis des Landesschulrates, siehe hierüber $\mathrm{H}$ e r r n r it t, aaO., S. 244 (Anm. 15), heute hingegen ging die Praxis dahin, Hauptschulen mit Landesgesetz einzurichten. Das neue Schulerrichtungsgrundsatzgesetz BGBl. Nr.163/1956 läßt hingegen die Frage nach der Art der Errichtung offen.

87) Das Versatz-, Verwahrungs- und Versteigerungsamt Dorotheum in Wien ist mit Verwaltungsakt errichtet (siehe das Statut des Dorotheums, 1946).

88) Siehe hierüber E r m a c or a, Ostereichisches Hochschulrecht, 1956, S. 20 ferner die in Anm. 71 bezogene Auffassung Herrnritts. Bemerkenswert ist hierbei, daß auch heute noch gewisse Eigenheiten klassischer Organisationsgewalt die Hochschulen beherrschen, so insbesondere die Tatsache, daß noch immer auf dem Verwaltungswege die Verknüpfung der katholisch-theologischen Fakultät der Universität Innsbruck mit der Societas Jesu effektuiert wird. Siehe hierzu auch Ermacora, aaO., S. 360 ff. 
Krankenanstalten soll durch Anstaltsordnung geregelt werden. Jedoch zeichnet auch hier der Gesetzgeber den Inhalt der Anstaltsordnungen im großen und ganzen eindringlich vor $\left.{ }^{80}\right)$.

Fonds wurden ursprünglich in der Regel kraft Herrschermacht errichtet $\left.{ }^{90}\right)$. Auch derzeit existieren noch Fonds, die sich auf eine Verwaltungsmaßnahme gründen ${ }^{91}$ ). Neben ihnen jedoch wurden mit Gesetz neue Typen von Fonds geschaffen ${ }^{92}$ ). Ihre Geldmittel dienen in der Regel dazu, wirtschaftslenkende und fürsorgende Maßnahmen zu steuern, und zwar hoheitlich zu steuern. Fonds als Rechtsträger mit hoheitlicher Macht, das ist vor allem die Parole der Wirtschaftsgesetze ${ }^{93}$ ).

89) Z.B. für die Krankenanstalten im Krankenanstaltengesetz BGBl. Nr. 1/1957 im $\S 6$ bzw. in den entsprechenden Landesgesetzen, u. a.

90) Siehe hierüber M a y e $r$ h of e r, aaO., Bd. VI, S. 748, ferner $S$ c h m id, Fonds (öffentliche) in: $M$ i s c h l er-U I b r i c h, Österreichisches Staatswörterbuch, 2. Aufl., 1906, II. Bd., S. 126 ff. (insbesondere S. 127 und 129); siehe auch Herrnritt, aaO., S. 232 Anm. 5.

91) So z. B. Bundesgendarmerie-Massafonds (Beschaffung von Dienstkleidern für Angehörige der Bundesgendarmerie), Min-Ratsbeschluß v. 6. Dez. 1949; Polizeimassafonds (Beschaffung von Dienstkleidern für Wachbeamte der österr. Bundespolizei), Min-Ratsbeschluß v. 6. Dez. 1949; Massafonds der Justiz (Beschaffung von Dienstkleidung für Beamte der Justizwache), Min.-Ratsbeschluß v. 6. Dez. 1949; Kulturfonds für Volksbildungszwecke MinRatsbeschluß vom 10. Februar 1948; Kulturfonds zwecks Vertiefung kultureller Beziehungen, Min-Ratsbeschlüsse aus dem Jahre 1948; Florianifonds (Unterstützung des Feuerwehrwesens) Min-Ratsbeschluß aus dem Jahre 1937; es handelt sich von vom Bund eingerichteten Fonds, denen Rechtspersönlichkeit zukommt und die ich einer Ubersicht aus den Erläuternden Bemerkungen zum Bundesfinanzgesetz 1956, zu 625 d. B. zu den stenographischen Protokollen d. NR VII. GP, S. 178/179 entnommen habe. Darüber hinaus existieren auch Fonds in den Ländern, die durch Verwaltungsmaßnahme errichtet wurden.

92) Z. B. als Bundesfonds: Salzburger Festspielfonds BGBl. Nr. 147/1950; Bergbauernhilfsfonds BGBl. Nr. 233/1937; land- und forstwirtschaftlicher Wiederaufbaufonds BGBl. Nr. 176/1946; Milchwirtschaftsfonds, Milchwirtschaftsgesetz 1956; Viehverkehrsfonds, Viehverkehrsgesetz 1956; Getreideausgleichsfonds, Getreideausgleichsgesetz 1956; Leibrentenfonds BGBl. Nr. 6/1927; Reservefonds nach dem Arbeitslosenversicherungsgesetz BGBl. Nr. 184/1949 i.d. g. F.; Ausgleichstaxenfonds, StGBl. Nr. 459/1920; Bundeswohn- und Siedlungsfonds BGBl. Nr. 252/1921; Wohnhaus-Wiederaufbaufonds, BGBl. Nr. 130/1948; Ausgleichsfonds für Familienbeihilfen BGBl. $\mathrm{Nr} .18 / 1955$; Kinderbeihilfenfonds BGBl. Nr. 31/1950; ReligionsfondsTreuhandstelle BGBl. Nr. 169/1955; Handelskammer-Altersunterstützungsfonds BGB1. Nr.115/1953; Hilfsfonds zur Hilfeleistung an politisch Verfolgte BGBl. Nr. 25/1956; Stickereiförderungsgesetz 1957 u. a.

99) Vgl. das Getreidewirtschaftsgesetz, das Milchwirtschaftsgesetz, das Viehverkehrsgesetz u. a. 
Während die monarchische Rechtsordnung frei konstituierte Berufsgenossenschaften, insbesondere im Gewerberecht voraussetzte ${ }^{94}$ ), die einen Verbandscharakter hatten, wurden sie in der republikanischen Rechtsordnung vom Gesetzgeber umgewandelt. Nach 1945 wurden auch Bewirtschaftungsstellen und andere Körperschaften öffentlichen Rechtes z. B. auf dem Gebiet des Fremdenverkehrs oder des Feuerwehrwesens oder der Verstaatlichung(5) - vom Gesetzgeber eingerichtet.

Diesen Körperschaften fehlten jedoch die durch natürliche wirtschaftliche Verhältnisse gegebenen Mitglieder. Der $\mathrm{Ge}-$ setzgeber ordnete ihnen erst solche $z u$. Diesen Verbänden wurden zum Teil auch die Vollziehung staatlicher Aufgaben übertragen. Der Gesetzgeber hat es so im steigenden Maße in Konkurrenz zur Exekutive in die Hand genommen, den inneren Verwaltungsaufbau zu gliedern, obschon die verfassungsrechtliche Grundlage hierzu kaum gegeben sein dürfte. Rechtsträger wurden geschaffen, um der Erfüllung moderner Staatsaufgaben zu dienen. Wenngleich in diesen Belangen dem Verordnungsgeber die Aufgabe zugewiesen wird, die innere Organisation der Verbände näher zu gestalten (vgl. z. B. §2 Abs. 6 des Werksgenossenschaftsgesetzes BGBl. Nr. 169/1946) bzw. den neu geschaffenen Rechtsträgern es selbst überlassen wurde, sich weiter zu organisieren, so darf man darin nicht etwa ein Residuum der klassischen Organisationsgewalt erblicken. Es handelt sich um eine delegierte Organisationsgewalt, die den Verbänden nicht kraft ihrer Rechtspersönlichkeit oder ihres Verwaltungsauftrags, sondern nur kraft Gesetzes zusteht. Andererseits wieder kommt gerade diesen neu geschaffenen Verwaltungseinheiten beträchtliche Organi-

94) Vgl. z. B. die Formulierungen der $\$ \S 115$ ff. der österr. Gewerbeordnung in ihrer ursprünglichen Fassung.

95) Hier sind vor allem die Fremdenverkehrsverbände und Feuerwehrverbände zu nennen, die in Osterreich entsprechend der bundesstaatlichen Kompetenzverteilung von den Ländern eingerichtet werden. Siehe ferner das Werksgenossenschaftsgesetz BGBl. Nr. 169/ 1946. Allerdings setzte diese Entwicklung schon im ersten Weltkrieg ein. Die durch Verwaltungsmaßnahmen errichteten Kriegsoder Wirtschaftsverbände sind zu nennen. Siehe hierzu die in Anm. 71 zitierten Verordnungen und den aufschlußreichen Bericht, des Sektionschefs $\mathbf{R}$ i ed 1 vor dem Hauptausschuß für Kriegsund Ubergangswirtschaft des österr. Parlamentes in der Wiener Zeitung vom 22. März 1918 Nr. 67, S. 2 wiedergegeben. Aber die Besonderheit war damals eben die, daß die Errichtung solcher Verbände der klass. Organisationsgewalt zugerechnet werden konnte, während sie heute der Gesetzgeber besorgt. Siehe auch die Anm. 96 a u. 109; beachte auch das Wirtschaftsverbändegesetz StGBl. Nr. 171/1945. 
sationsgewalt zu (vgl. das Erk. des öVfGH, Slg. 2500 und den Vortrag von Spanner, „Probleme der Verwaltung durch besondere nichtstaatliche Rechtsträger", gehalten vor der Wiener Jur. Gesellschaft am 23. Nov. 1950).

b) In der Monarchie wurde es der Organisationsgewalt der Exekutive zugerechnet, Organe $\mathrm{zu} s \mathrm{ch}$ affen, insbesondere Ministerien und ihnen zugeordnete Stellen. Diese Funktion ist kraft der Bundesverfassung nahezu völlig beseitigt. Die Norm des Art. 77 B-VG bestimmt, daß Wirkungskreise und Zahl der Bundesministerien durch Bundesgesetz zu regeln sind. Da Unterbehörden mit dem Ressort eine Einheit bilden, ist jedenfalls auch die Errichtung solcher Organe von der Norm des Art. 77 Abs. 2 erfaßt. Darüber hinaus gebietet es die Verantwortlichkeit der Minister, daß sie allein berufen sind, die obersten Verwaltungsgeschäfte zu führen. Der ö. Verfassungsgerichtshof hat diesem Grundgesetz entsprechend schon im Jahre 1932 (Erk. Slg. 1454) und dann wieder im Jahre 1952 erklärt, daß neben den Ministern keine entscheidungsbefugten Kollegialbehörden treten dürften, die nicht die im Art. 133 Z. 4 B-VG vorgezeichnete Struktur aufweisen. Diese Verfassungsbestimmung gibt jedoch - nach herrschender Auffassung - den Gesetzgebern die Möglichkeit, Kollegialbehörden bestimmter Struktur in Konkurrenz zu den obersten Organen der Verwaltung einzurichten ${ }^{95 a}$ ). Der Gesetzgeber hat von dieser vermeintlichen Kompetenz reichlich Gebrauch gemacht $\left.{ }^{96}\right)$. Während in der Monarchie der Minister seine beratenden Organe ernannte ${ }^{98 a}$ ), hatte es sich der moderne Gesetzgeber nicht nehmen lassen - ähnlich wie in der von $\mathrm{K}$ öt $\mathrm{tg} \mathrm{e} \mathrm{n}^{07}$ ) für Deutschland aufgezeigten Art - die Berater der Minister zu bestimmen. Im steigenden Maße

Dsa) Art. 133 Z. 4 B-VG fordert für die Zusammensetzung der Kollegialbehörden unter den Mitgliedern wenigstens einen Richter, die übrigen Mitglieder dürfen in Ausübung ihres Amtes an keine Weisungen gebunden sein, die Bescheide der Behörde dürfen nicht der Aufhebung und der Abänderung im Verwaltungswege unterliegen.

96), So z. B. Disziplinarkommissionen, Grundverkehrskommissionen u. a. bei Adamovich, Die Bundesverfassungsgesetze, 8. Aufl., 1953 , S. 155 genannte.

96a) So hatte die Reg i e r u g Wirtschaftsverbände errichtet, die ihr beratend zur Seite stehen sollten. Vgl. die diesbezügliche Fundstelle in Anm. 95. Siehe für Deutschland auch $\mathrm{S} \mathrm{ch} \mathrm{oe} \mathrm{n,} \mathrm{Die}$ Verordnungen, in: Handbuch der Politik, Hrsg. v. Anschütz u. a., 3. Aufl.

97) Köttgen, Der Einfluß des Bundes auf die deutsche Verwaltung und die Organisation der bundeseigenen Verwaltung, in: JöR Bd. 3 NF (1954), S. 103 ff. Vgl. meine Besprechung in den JBl. 1957, S. 383. 
werden die Minister verpflichtet, vor Erledigung ihrer Amtsgeschäfte, andere Organe zu hören. „Beiräte" heißen diese modernen organisationsrechtlichen Errungenschaften. Insbesondere sind zu nennen: die Wirtschaftskommission, das Wirtschaftsdirektorium, die Opferfürsorge-Kommission, der Invalidenfürsorge-Beirat, die Wohnbauförderungsbeiräte, Landesplanungskommissionen, der Landesverteidigungsrat, die $\mathrm{Be}-$ schwerdekommission für militärische Angelegenheiten, die Kommission für die Begutachtung der Anträge von Waffendienstverweigerern, der akademische Rat, u. a..8). Allen diesen Kommissionen ist eigentümlich, daß ihre Zusammensetzung ein Spiegelbild der politischen Kraftverhältnisse im Staate sein muB und daß sie an die Seite der unmittelbaren Staatsorgane zu treten haben.

c) Die Begründung von Zuständigkeiten der Organe war Ausfluß der klassischen Organisationsgewalt. Das österreichische Finanzministerium - eingedenk dieser Tradition - richtete Finanz-Strafämter mit Verwaltungsverordnung ein ${ }^{\text {paa }}$. Der Verfassungsgerichtshof hat hierzu in seinem Erk. Slg. 2650 folgendes festgestellt:

„Da der Erlaß ein bisher nicht vorhanden gewesenes Finanzamt für Strafsachen schafft, ist er eine typische Rechtsverordnung organisatorischer Art.

Bei der Prüfung der Frage der Gesetzmäßigkeit dieser Verordnung ist davon auszugehen, daß die Schaffung neuer Behördentypen mit einem besonderen, ressortmäßig abgegrenzten Wirkungsbereich nur durch Gesetz erfolgen kann, weil darin in jedem Fall eine Änderung der bestehenden Rechtslage gelegen ist. Dagegen ist die innere Einrichtung der Behörden, ihre Gliederung in Sektionen, Abteilungen usw. eine Angelegenheit der Verwaltung, die durch interne Verwaltungsmaßnahmen geregelt werden kann.

Unabhängig davon ist die Frage zu beantworten, wie der Sitz und der Sprengel der Behörden zu bestimmen sind. Soweit der Gesetzgeber selbst den Sitz und Sprengel von Be-

98) Diese und noch andere Kommissionen sind durch Gesetz eingerichtet. Vgl. als Typus der Zusammensetzung z. B. den $\$ 69 \mathrm{H}-\mathrm{OG}$ : "(1) Beim Bundesministerium besteht ein aus fünfzehn Mitgliedern zusammengesetzter akademischer Rat. Fünf hiervon entsendet die Bundesregierung nach Maßgabe der Zusammensetzung des Hauptausschusses des Nationalrates ....".

osa) Amtsblatt der österreichischen Finanzverwaltung, VI. Jg. (1953) Nr. 93: „Das Finanzamt für Strafsachen in Graz, dessen Kompetenz sich auf das Bundesland Steiermark erstreckt, wurde eingerichtet. Anschrift: Graz, Konrad-von-Hötzendorf-Straße 14 bis 18." 
hörden festgelegt hat, bedarf auch die Änderung dieser Bestimmungen eines Gesetzes. Dies trifft z. B. hinsichtlich der Finanzlandesdirektion zu (§ 28 Beh.-UG.). Soweit aber eine solche gesetzliche Regelung nicht besteht, der Gesetzgeber diese Aufgabe vielmehr der Verordnungsgewalt einräumt, können Sitz und Sprengel, im besonderen der unteren Verwaltungsbehörden, durch Verordnung bestimmt und geändert werden“" ${ }^{\text {(98). }}$ Es hat sich unter der Sanktion des Verfassungsgerichtshofes auf dem Gebiete der inneren Einrichtung der Behörden ihre Gliederung in Sektionen, Abteilungen durch Verwaltungsverordnung usw. als ein Rest klassischer Organisationsgewalt gewohnheitsrechtlich erhalten. Aber auch dieser Rest klassischer Organisationsgewalt soll abgetragen werden. Nach den Entwürfen eines Bundesgesetzes über die Einrichtung und den Wirkungskreis der Bundesministerien vom 8. 11. 1949, BKA Zl. 48. 591-2a/49 soll die Gliederung der einzelnen Bundesministerien gesetzlich eindeutig vorgezeichnet sein.

Das letzte Reservat, das auch von diesen vorgesehenen Maßnahmen in der Macht der Exekutive verbleiben soll, ist die Aufteilung der Agenden auf Sektionen, Abteilungen und Referate. Aber auch hier sollen gesetzliche Richtlinien gelten.

In den Zeiten der Notlage wird selbst die Frage der Begründung personeller Zuständigkeiten vom Gesetzgeber bestimmt. So bestimmt das Gesetz v. 7. 8. 1945, StGBl. Nr. 115, über die Ordnung der Staatsverwaltung in der sowjetischen Besatzungszone von Oberösterreich den Ökonomierat Plöchl zum Staatsbeauftragten. Melichar hat das Problem grundlegend behandelt und auf die Bedeutung der personellen und institutionellen Zuständigkeitsordnung hingewiesen ${ }^{100}$ ).

e) Die Regelung des inneren und äußeren A $m$ tsdienstes ist vorläufig in der Hauptsache noch Domäne der Exekutive. Hiezu gehört die wichtige Frage, inwieweit sich der Minister bei seinen Amtshandlungen durch Bedienstete seines Ministeriums vertreten lassen darf. Eine Frage, die in Form eines "regressus in infinitum" bis zur Frage nach der Machtbefugnis des letzten Konzipisten zu stellen ist. Das Problem führt zur Rivalität der Macht der

99) Vgl. hierzu paradigmatisch OVG Rhld.-Pf. U. v. 21. 11954 (teilweise abgedruckt in DVBl. 1954, S. $745 \mathrm{ff}$.) siehe hierzu ferner O berm a yer, aaO., S. $126 \mathrm{f}$.

100) Melichar, aaO., (Anm. 13 a); siehe ferner die Kundmachung über die Errichtung der provisorischen Staatsregierung StGBl. Nr. 2/1945, die als Akt der Organisation unmittelbarer Staatsorgane (bevor die vorläufige Verfassung beschlossen war) die Funktionäre namentlich benannte! 
Beamtenschaft und der des Ministers. Auch da bahnen sich gesetzliche Regelungen an $^{101}$ ). Das ist verständlich, handelt es sich doch hiebei um eine eminente Frage staatlicher Machtverteilung und Machtausübung. Jede Ermessensentscheidung, die ein Organ zu treffen hat, kann je nachdem, ob der Beamte oder Minister den Akt fertigt, verschieden ausfallen. Die Regelung anderer grundlegender Fragen, die nach außen wirken, jedenfalls aber immer den Dienstnehmer berühren, wie die Einteilung der Dienststunden, die Urlaubsregelung der Bediensteten, der Geschäftsverkehr zwischen den Ministerien, die Amtssprache, die Verwendung von Amtssiegeln und Formularen, bleibt vorderhand der Organisationsgewalt der Verwaltung überlassen. Doch auch hier greift der Gesetzgeber durch das AVG 1950 BGBl. Nr. 172 in die Organisationsgewalt ein. Die Beglaubigungsverordnung BGBl. Nr. 445/1925, die Verwaltungsformularverordnung, BGBl. Nr. 219/1951 Maßnahmen des inneren Amtsdienstes - sind Verordnungen, auf Grund des AVG erlassen. Die Regelungen sind solche "delegierter Organisationsgewalt". Darüber hinaus bahnen sich weitere Wandlungen auf Grund des oben bezeichneten Entwurfes an.

f) Auf dem dienstrechtlichen Gebiet ist die Verwaltung nach wie vor, von einzelnen gesetzlichen Grundsätzen abgesehen, im patrimonialen Fahrwasser: Im Rahmen der Organisationsgewalt werden Beförderungsrichtlinien statuiert und gehandhabt, Disziplinar- und Qualifikationskommissionen zusammengesetzt. Prüfungskommissionen gebildet, das Einvernehmen mit Gewerkschaften gepflogen, Personalvertretungen geheim ins Leben gerufen ${ }^{102}$ ).

g) Auch die Organisation des Heeres liegt nicht mehr in der ausschließlichen Macht der Verwaltung. Wehrorganisatorische Fragen sind nunmehr im Wehrgesetz geregelt. Das Disziplinarrecht ist durch das Disziplinargesetz BGBl. Nr. 151/1956 festgelegt. Neben den verantwortlichen unmittelbaren Staatsorganen hat ein Landesverteidigungsrat mitzubestimmen. Er ist in seiner Zusammensetzung Spiegel des Gesetzgebers. Selbst die allgemeine Dienstvorschrift (ADV) ist von der Bundesregierung im Einvernehmen mit dem Haupt-

101) Vgl. den oben genannten Gesetzentwurf.

102) Siehe die diesbezüglichen Verwaltungsmaßnahmen, nämlich den Erl. des BKA, v. 17. Juli 1946, Z1. $47538-3 / 46$ u. v. 27. Februar 1952, Zl. 67. $361-3 / 51$, des BMfsV v. 19. Februar 1954, Zl. I-II. 823-1/54 alle veröffentlicht in: Probleme des öffentlichen Dienstes, Die Interessenvertretung; hrsg. von der Sozialwissenschaftlichen Arbeitsgemeinschaft, Wien I, Sonnenfelsgasse 19. 
ausschuß des Nationalrates zu beschließen. Das Streben der Machthaber, auch eine parlamentarisch zusammengesetzte Personalkommission der Bundesregierung zur Seite zu stellen, wurde nicht verwirklicht, hingegen fungiert eine parlamentarische Beschwerdekommission ( $\$ 6$ WG). Ein Recht klass. Organisationsgewalt liegt in der Handhabung der Kommandound Befehlsgewalt der zuständigen Behörden, die Organisation und Formation des Heeres und der Wachkörper zu regeln ${ }^{108}$ ).

h) Nach wie vor werden die Grundsätze für die Erstellung des Budgets von den für die Finanzverwaltung zuständigen Verwaltungsorganen festgelegt. Besonders merkwürdig ist hiebei, daß die Regierung eine Pflichtinitiative hat, den Entwurf des Bundesfinanzgesetzes vorzulegen (Art. 51 B-VG).

i) Während man die Systemisierung technischer, wirtschaftlicher und fiskalischer Behörden der Exekutive überließ die Post- und Telegraphendirektion, die Domänendirektion, die Finanzprokuraturen, waren nicht vom Gesetzgeber, sondern von der Verwaltung organisiert $\left.{ }^{104}\right)$ - ist auch in diesen Belangen die Organisationsgewalt der Verwaltung zusammengeschmolzen: die Errichtung von Post- und Telegraphendirektionen hat - auch soweit sie nur wirtschaftliche Aufgaben besorgen sollen - nach dem 27. April 1945 der Gesetzgeber übernommen ( $\$ 52$ des Behörden-UG). Die innere Organisation dieser Organe wird von der Verwaltung besorgt - soweit nicht das moderne Postgesetz BGBl. Nr. 58/1957 anders bestimmt. Der selbständige Wirtschaftskörper "Österreichische Bundesforste" - eine unselbständige Anstalt des Bundes - wurde schon im Jahre 1925 durch Gesetz errichtet (BGBl. Nr. 282/1925), im Jahre 1945 der Wirtschaftskörper wiederum durch Gesetz (\$ 45 Behörden-UG) reorganisiert. Die Finanzprokuratur des Bundes wurde erst nach 1945 durch Gesetz eingerichtet ${ }^{105}$ ). Ferner möge man das Augenmerk auf die Bestimmungen des Behörden-ƯG lenken, nach denen zahlreiche Organe der klassischen Wirtschaftsverwaltung ${ }^{108}$ ) -

103) Vgl. die Bestimmungen der $\S \S 20 \mathrm{ff}$. des österr. Wehrgesetzes, BGBl. Nr. 181/1955; siehe gleichartige Bestimmungen im deutschen Wehrpflichtgesetz. v. 21. Juli 1956 BGBl. I, S. 436, §§ $14 \mathrm{ff}$. Vgl. für die Rechtslage in den Monarchien auf dem Gebiete des Wehrrechtes die Hinweise in Anm. 76.

104) Siehe z. B. U l b r i ch, aaO., S. 72.

105) Siehe den § 30 des Behörden-Uberleitungsgesetzes StGBl. Nr. 172/1945 sowie das Prokuraturgesetz StGBl. Nr. 172/1945.

100) So z. B. die \$ 33 (Postsparkassenamt), § 36 (Salinen), § 38 (Hauptmünzamt), $\$ 39$ (Punzierungsamt) u. a. 
auch wenn sie keine behördlichen Aufgaben zu besorgen gehabt hatten - durch Gesetz eingerichtet worden sind; nicht, wie es der klassischen Organisationsgewalt entsprochen hätte, durch Akte der Verwaltung.

j) Der Staat als Leistungsträger ${ }^{107}$ ) schafft Organisationsformen, die bislang nur der privaten Unternehmersphäre bekannt waren. Hand in Hand mit der Sozialisierung - in Osterreich Verstaatlichung genannt ${ }^{108}$ ) - wird kraft der Natur der verstaatlichten Objekte auch inre Organisation gewandelt.

Was sich vor der Verstaatlichung der Objekte noch nach dem Grundsatz der freien Organisation gestaltete, wandelt sich nach gesetzlicher Maßgabe zur gelenkten Organisation ${ }^{109}$ ). Man wird nicht übersehen dürfen, daß sich hier vollkommen neue Formen der Handhabung der Organisationsgewalt entwickeln. Einerseits ist die Gestalt der Organisationsgewalt von der Natur des Unternehmens als technische Einheit bestimmt, andererseits ist sie nach wie vor bestrebt, Staatsmacht auszuüben ${ }^{110}$ ). Ein merkwürdiges $\mathrm{Z}$ wittergebilde entwickelt sich so. Es würde in diesem Rahmen zu weit führen, die organisatorischen Eigentümlichkeiten verstaatlichter Unternehmen im einzelnen auseinanderzusetzen. Nur soviel sei hervorgehoben: der Staat, und zwar der Gesetzgeber, bestimmt die Rechtsform des Unternehmens $\left.{ }^{111}\right)$. Dieses gestaltet seine innere Einrichtung einerseits selbständig, andererseits werden

107) Uber diesen Begriff siehe bahnbrechend F or s th of $f$, aaO., S. 340 ff.

169) Siehe z. B. das 1. Verstaatlichungsgesetz BGBI. Nr. 168/1946 und das 2. Verstaatlichungsgesetz BGBl. Nr. 81/1947. Zu diesen Problemen hat schon Herrnritt, aaO., S. 232 ff. (Anm. 6), über das "Unternehmen" grundlegendes entwickelt und hierbei schon auf die modernen Aspekte des Problems hingewiesen. Von ebensolchem Interesse dürften die Ausführungen $\mathbf{S}$ te ins, Innere Verwaltung, 7. Teil sein.

100) Siehe über den Begriff der ,gelenkten Organisation“ den eindrucksvollen Grundriß von $\mathbf{E}$ u l e n b u r g, Das Geheimnis der Organisation, 1952.

110) In Osterreich nahm das durch die Errichtung von Kriegsoder Wirtschaftsverbänden (siehe Anm. 95) seinen Anfang. In dem in dieser Anm. zitierten Bericht heißt es u. a.: Die Aufgabe dieser Wirtschaftsverbände ist eine doppelte: Sie sind beratende Organe der Regierung, haben über Befragung Gutachten zu erstatten oder aus eigenem Antrieb Gutachten zu erstellen, und sie sind gleichzeitig Verwaltungsorgane in allen Fällen, in denen ihnen durch eine besondere Verfügung des Handelsministeriums oder durch eine generelle Bestimmung ihrer Statuten die Durchführung kriegswirtschaftlicher Verwaltungsmaßnahmen übertragen werden.

111) So z. B. die $\$ \S 3,4,5,6$ des 1. Verstaatlichungsgesetzes (Anm. 108), der § 4 des Gesetzes BGBl. Nr. 134/1956. 
bestimmte organisatorische Handlungen, die das Unternehmen setzen soll, vom Gesetzgeber vorgezeichnet112). So entwickeln sich organisatorische Einrichtungen des Staates in der Gestalt privatrechtlicher Unternehmerformen. Sie sollen weniger der ökonomischen Nutzung des Unternehmens dienen, als staatlicher bzw. politischer Machtausübung. Für sich spricht z. B. die Bestimmung des $\S 7$ des Bundesgesetzes BGBl. Nr. 134/1956, über die Neuordnung des Wirkungskreises einiger Bundesministerien. Danach sind bei der Bestellung von Organen einer Gesellschaft $\mathrm{m}$. b. H. für verstaatlichte Unternehmungen die Kräfteverhältnisse und die Vorschläge der im Nationalrat vertretenen politischen Parteien zu berücksichtigen.

k) Zahllose Eigentumsbewegungen sind im Zuge der Liquidierung der Folgen des zweiten Weltkrieges einerseits und der NS-Besetzung andererseits eingetreten. Der Staat hat die Ordnung dieser Bewegung in die Hand genommen. Das Rechtsinstitut der öffentlichen Verwaltung wurde mit dem Verwaltergesetz BGBl. Nr. 157/1946 in der geltenden Fassung geschaffen. Dieses Gesetz enthält organisatorische Vorschriften ersten Ranges. Es gestaltet die Organisation der öffentlichen Verwaltung ohne auf die Organisationsgewalt der Exekutive Bedacht zu nehmen; ausgenommen sind gewisse individuelle Maßnahmen, die in das Ermessen der Verwaltung gelegt werden.

Die damals freie Verfügungsmacht der klassischen Verwaltung über die Haushaltsmittel ist einer delegierten Verfügungsmacht gewichen. Vgl. so das Verwaltungsentlastungsgesetz BGBl. Nr. 277/1925, die Bundeshaushaltsverordnung BGBl. Nr. 118/1926 u. a. Bemerkenswert ist auch hier wiederum, da $B$ die neu entstandenen rechtsfähigen Verwaltungseinheiten einen relativ weiten Spielraum genießen.

Es zeigt sich, daß die Organisationsgewalt sowohl vom Gesetzgeber als auch von der Verwaltung ausgeübt wird. Die Entwicklung läßt aber erkennen, daß die klassische Organisationsgewalt, die man der Verwaltung zuerkennt, stetig abbaut. Eine Verlagerung der Handhabung der Organisationsgewalt von der Verwaltung auf den Gesetzgeber ist im Gange. Wenngleich die Verlagerung auch nicht systematisch erfolgt, so ist sie doch stetig. L a b a n d hatte schon im Jahre 1878 festgestellt: „Die Entwicklung des modernen Staates ist darauf ge-

112) Siehe den $\S 3$ Abs. 6 des 2. Verstaatlichungsgesetzes und den $\$ 7$ des 1. Verstaatlichungsgesetzes. Hierzu die Erläuterungen in: Das Osterreichische Recht, hrsg. He in l-L o e bens tein-Ver os t a, (Lose-Blatt-Slg.) Bd. VIII d (Kastner). 
richtet, das gesamte Behördensystem und die Zuweisung bestimmter Geschäftskreise an die einzelnen Ämter immer vollständiger und ausschließlicher durch die Gesetzgebung zu regeln..." und Herrnritt, Grundlehren des Verwaltungsrechts; aaO. S. 18 (Anm. 5): „Was die Organisationsgewalt anbelangt, so ist sie zwischen Gesetzgebung und Vollzugsgewalt geteilt." Wo Organisationsgewalt noch von der Exekutive selbständig ausgeübt wird - insbesondere solange das für Österreich vorgesehene Organisationsgesetz nicht erlassen ist, im inneren Amtsdienst - , da hielt sich die klassische Organisationsgewalt infolge unklarer pasitivistischer Formulierungen der Bestimmungen, die den Utbergang von Kompetenzen des Kaisers auf die republikanischen Organe festlegte, als Gewohnheitsrecht. Der Gesetzgeber ist jedoch imstande, dieses dann zu beseitigen, wenn er die Macht der klassischen Organisationsgewalt erkannt hat. Wo Organisationsgewalt sonst noch vorliegt, ist sie eine vom Gesetzgeber delegierte. Das gilt im weiten Umfang auch für die Organisationsgewalt über die Wirtschaftsbetriebe des Staates (Bund und Länder) - nicht hingegen aber für die anderer Rechtsträger. Die Organisationsgewalt ruht somit nicht mehr ,in dem verfassungsmäßigen Dasein der Regierung selbst" (G. Jellinek) oder „sie folgt nicht mehr aus dem allgemeinen Verwaltungsauftrag des Staatsrg." (Anschütz).

IV.

12. Vom Staatsrechtlichen her gesehen, müßten die Gr $\mathrm{r}$ u $\mathrm{d}$ e und Ursachen für diese Verschiebung in der Handhabung der Organisationsgewalt in der deutschen und österreichischen Rechtsordnung in der selben Weise zu finden sein. Das deshalb, weil die Rechtsentwicklung da wie dort gleichartige Stufen durchschritten hat und zu gleichartigen Ergebnissen gelangt ist.

a) Das Schwergewicht der Organisationsgewalt lag in den monarchischen Rechtsordnungen nicht nur deshalb bei der Exekutive, weil die Staatsrechtslehre dieser faktischen Macht wissenschaftliche Unterstützung lieh, sondern weil auch die Kraft- und Machtverhältnisse in den Monarchien der Exekutive trotz sich anbahnender rechtsstaatlicher Durchbildung eine Vorrangstellung verlieh. Ging doch die staatliche Gewalt nach wie vor vom Monarchen aus. Der Zusammenbruch der Monarchien war geistesgeschichtlich Revolution. Er manifestierte sich nicht zuletzt im verfassungsmäßig verankerten Bekenntnis zur Volkssouveränität. Nach der Weimarer Reichsverfassung sollte alle Gewalt vom Volke ausgehen, nach dem GG geht alle Staatsgewalt vom Volke aus. Sie wird aber von selbständigen Organen der Gesetzgebung, Verwaltung 
und Rechtsprechung ausgeübt. Nach dem B-VG geht „das Recht der Republik" vom Volke aus. Gleichgültig wie man die Dinge in dieser Sphäre benennt, die Gewaltverschiebung war unleugbar. Und das vom Grunde auf! Die Äußerungsform der Volkssouveränität liegt ausschließlich im Gesetz; ihm sollen Akte der Vollziehung jedenfalls untergeordnet sein. Die Lehre vom Stufenbau der Rechtsordnung - durchaus eine Theorie im Sinne Kant'scher Rechtsphilosophie ${ }^{113}$ ) wurde im demokratischen, gewaltenteilenden Staat ungeschriebene Maxime. Die Folge war: keine Verwaltung im gesetzesfreien Raum. Der aus dem Verhältnis von Gesetzgebung und Verwaltung in der Monarchie geborene Begriff des „Vorbehaltes des Gesetzes“114) hat seine Bedeutung verloren. Das mußte auch auf die Organisationsgewalt zurückwirken.

b) Dieses in erster Linie konsequent und ohne konservativer Scheu von der Wiener Schule erarbeitete Prinzip vom Stufenbau der Rechtsordnung fand in der österreichischen Bundesverfassung vom Jahre 1920 seinen positiv rechtlichen Niederschlag. Nach Art. 18 B-VG darf die gesamte staatliche Verwaltung nur auf Grund der Gesetze geführt werden und jede Verwaltungsbehörde darf nur auf Grund der Gesetze Verordnungen erlassen. Diesen Normen kann, entsprechend ihrem Wortlaut, sowohl die Forderung nach „Gesetzmäßigkeit im weiteren Sinne des Wortes" (Rechtmäßigkeit)115), als auch nach "Gesetzmäßigkeit im engeren Sinne" unterlegt werden. Beachten Sie den gleichartigen Artikel 20 Abs. 3 GG, so müssen Sie erkennen, daß sich hiebei im Vergleich mit der österreichischen BV Geister und Rechtsordnungen scheiden. Je nachdem, wie eng oder wie weit man die Begriffe zieht, wird die Exekutive bei Ausübung der Organisationsgewalt durch Verwaltungsverordnungen Handlungsfreiheit haben. Nur dann wird man der Organisationsgewalt Handlungsfreiheit zugestehen können, wenn die gesetzesgebundene Verwaltungsverordnung das Mittel hierfür sein darf. Die österreichische Verwaltung wird vom Verfassungsgerichtshof (vgl. z. B. Slg. 2650)

118) Uber diese Lehre siehe zunăchst die grundlegenden Arbeiten von $M$ erkl, die $K e l s e n$ in seiner 2. Aufl. der Hauptprobleme aaO., S. XV anführt, dann aber schon $\mathrm{K}$ a $\mathrm{n} t$, Metaphysische Anfangsgründe der Rechtslehre, 1797, \$ 45.

114) Vgl. hierzu grundlegend $O$. M a yer, Deutsches Verwaltungsrecht, I, S. 74 fif.

115) Merk l, Allgemeines Verwaltungsrecht aaO., S. $157 \mathrm{ff}$.; Thoma, Der Vorbehalt der Legislative und das Prinzip der Gesetzmảßigkeit der Verwaltung und Rechtsprechung, in: A n $\mathrm{s} \mathrm{ch} \mathrm{utz}$ - T h om a , 2. Bd., 1932, S. 227 ff., siehe auch die folgenden Austilhrungen des Berichts. 
enger, als es den Vertretern dieser Staatsfunktion oft wünschenswert ist, an das Gesetz gebunden.

c) Man muß also - auch heute noch - dem Gedanken G. Je 11 ineks beipflichten ${ }^{116}$ ): „Das Wesen der Verwaltungsverordnung, von Laband auch als materielle Verordnung bezeichnet, erheischt eine eingehendere Untersuchung, die auf die Grundprobleme des Staatsrechtes zurückführt." Um diese eingehendere Untersuchung hat sich die Wissenschaft bemüht. $\mathrm{Zu}$ einer einhelligen Lösung der Frage ist sie jedoch nicht gekommen.

Arndt, Anschütz und andere ${ }^{117}$ ) schoben mit tiefgründigen Uberlegungen, denen politische Aspekte nicht abgingen $\left.{ }^{116}\right)$, der Verwaltung das Sprungbrett für eine vom Gesetz freie Handhabung der Organisationsgewalt in Form der Verwaltungsverordnung hin. Sie hätte keine Normqualität. $\mathrm{Ke}$ l s e $\mathrm{n} \mathrm{u.} \mathrm{a.}{ }^{119}$ ) sehen hingegen auch in der Verwaltungsverordnung im Zusammenhalt mit Disziplinarregelungen $u$. ä. Normen. Nach Kelsen bedürfen auch sie der gesetzlichen Delegation.

$\mathrm{Ob}$ diese Forderung normativ richtig ist oder nicht, hängt von der Lösung dreier Grundfragen ab:

aa) Ist es richtig, mit Anschütz und der herrschenden Lehre zu folgern; "Rechtsnorm ist nur die Norm, welche mit Gebot oder Verbot in die Freiheit oder das Eigentum der Individuen eingreift ${ }^{\text {"'i20 }}$ ) oder die Rechtsnorm als ein hypothetisches Urteil anzuerkennen? Bejaht man das erste, dann ist die Verwaltungsverordnung möglicherweise frei von gesetzlicher Bindung.

bb) Wie weit darf man den Begriff der Gesetzmäßigkeit der Verwaltung, der sowohl aus dem Art. 18 B-VG als auch aus

116) Gesetz und Verordnung, aaO., S. 385.

117) Anschütz, Die gegenwärtigen Theorien, 1. Aufl., S. 79, 89; Arndt, selbständiges Verordnungsrecht, 1901 und die in Anm. 35 angeführten Werke beider, sowie die anderen noch bezogenen Autoren.

118) Aufschlußreich ist die Apologie A n chütz'. Er verwahrt sich gegen Arndt, demokratische Auffassungen zu vertreten.AaO., 2. Aufl., S. 57: „Rechnete ich mich bisher noch immer zu den ernstlich Gutgesinnten, wähnte ich doch, mit keinem Tröpfchen demokratischen Ols gesalbt zu sein!"

119) $\mathrm{Ke} 1 \mathrm{~s}$ e n, aaO., S. 558 in Verbindung mit S. $491 \mathrm{ff}$. Bemerkenswert ist auch das Ergebnis des von A r ndt, aaO., vielfach herangezogene Urteil des Reichsgerichtes für Zivilsachen vom 26. März 1901 in: Entscheidungen des Reichsgerichtes in Civilsachen, 48, S. 85. Es kommt der Kelsenschen Auffassung nahe. Siehe auch $\mathrm{N}$ a w i a s y, Allgemeine Rechtslehre, 2. Aufl., 1948, S. $111 \mathrm{ff}$.; B u r c k h a rd t, aaO., S. $123 \mathrm{ff}$.

120) Gegenwärtige Theorien, 2. Aufl., aaO., S. 97. 
dem Art. 20 Abs. 3 GG hervorleuchtet, spannen? Spanne ich ihn weit, so ist es denkbar, die Verwaltungsverordnung ohne detaillierte gesetzliche Grundlage $\mathrm{zu}$ erlassen.

cc) Liegt es im Wesen des Staates als personifizierte Rechtsordnung begründet, daß sich ihre Funktionen - ohne eingehende gesetzliche Grundlage selbst - gesetzesfrei gestalten dürfen?

$\mathrm{Zu}$ aa) schließe ich mich der Auffassung $\mathrm{Kel}$ ls ens an. Die Frage bb) kann logisch nur in Verbindung mit der Frage cc) gelöst werden. In der juristischen Arbeitspraxis hält man den Staat für eine Juristische Person. Kraft seiner Personqualität erachtet man ihn und seine Funktion „Verwaltung" für delegiert, gesetzlose Verwaltungsverordnungen zur Handhabung dẻr Organisationsgewalt zu erlassen. Vor allem Ans chü tz, $\mathrm{L}$ ab and und Jelline $\mathrm{k}$ neigten dieser Auffassung $\mathbf{z u}^{121}$ ). $\mathrm{Ob}$ diese Auffassung richtig ist, ist aus der Lehre vom Wesen der Juristischen Person als Normenkomplex ${ }^{122}$ ) sowie aus der jeweiligen Rechtsordnung $\mathrm{zu}$ ermitteln. Ohne hier auf jene Seite der Frage näher eingehen zu können, sei das Augenmerk auf diese gerichtet.

Für Osterreich verbietet die Verfassung, die Gestalt der Rechtsträger ohne $\mathrm{n}$ äh e re Bestimmungen in der Verfassung oder in Gesetzen durch den Verordnungsgeber mittels Verwaltungsverordnung zu bestimmen. Das ist in der Ordnung der Ausübung der Staatsgewalt begründet. Für die Bundesrepublik Deutschland jedoch halte ich eine andere Auffassung für vertretbar.

In Österreich sind die Organe der Gesetzgebung wie auch die Organe der Vollziehung Erscheinungen einer einheitlichen Staatsgewalt, die - demokratischen Grundsätzen gemäß vom Volke ausgeht (Art. 1 B-VG). Doch sind die Organe der Vollziehung nicht wie nach dem GG (Art. 20 Abs. 2) von der Verfassung unmittelbar delegiert, Staatsgewalt - wozu auch die Organisationsgewalt als ein Teil derselben zu zählen ist auszuüben. Vielmehr hat diese Delegation in jedem Falle das Gesetz zu besorgen Denn gemäß Art. 18 B-VG und Art. 83 B-VG sind verfassungsmäßige Verwaltung und Gerichtsbarkeit nur

121) Gegenwärtige Theorien, aaO., S. 76: „Soweit die Anstaltsordnung nicht legislativ festgelegt ist, folgt es aus dem allgemeinen Verwaltungsauftrag der Staatsregierung ... die Anstaltsordnung durch organisatorische und instruktionelle Vorschriften zu erlassen, abzuändern, aufzuheben." L a b a nd, aaO., S. $207 \mathrm{f}$.; G. J e 11 i n ek, aaO., S. 385.

122) Vgl. grundlegend $\mathrm{K}$ e ls e $\mathrm{n}$, Reine Rechtslehre, aaO., S. 119 ff. und $H$. J. W o $1 \mathrm{f}$, aaO. 
denkbar, wenn sie auf Grund der Gesetze geschehen. Hingegen sind nach dem GG die Organe der Gesetzgebung und der Vollziehung wie auch der Gerichtsbarkeit un m it telb a r durch Art. 20 Abs. 2 GG delegiert, Staatsgewalt auszuüben. Der Abs. 3 dieses Artikels bewirkt - nicht wie der gleichartige Art. 18 B-VG - keine Delegation zur Ausübung der Staatsgewalt. Er weist der Vollziehung nur eine Schranke für die Ausübung der Staatsgewalt.

Daher müßte in Österreich die Ausgestaltung der in n e re n Struktur der Rechtsträger der Gesetzgebung obliegen, die natürlich die Verwaltung delegieren kann, ihrerseits Organisationsgewalt auszuüben. In der Bundesrepublik Deutschland hingegen, braucht eine solche Delegation nicht zu sein, soferne man nur dem Art. 20 Abs. 3 GG die vorgetragene Auslegung gibt und die Frage bejaht werden kann, daß es im Wesen einer Juristischen Person begründet liegt, ihre innere Struktur selbst zu gestalten.

Wenn in Österreich Fakten Gegenteiliges zeigen, so spricht $\mathrm{k}$ e in e $\mathrm{N}$ or $\mathrm{m}$ für sie: Die Kompetenzverteilungsbestimmung betreffen nur die Frage, ob eine Angelegenheit dem Bund oder den Ländern "gehört". Sie regeln hingegen nichts darüber, ob ein Rechtsgebiet durch die Verwaltung oder durch die Gesetzgebung gestaltet sein soll. Anderes könnte aus der Rechtslage in den Monarchien geschlossen werden ${ }^{128}$ ). Wo das B-VG Bestimmungen enthält, die den Gesetzgeber im besonderen berufen, Vorschriften zu erlassen ${ }^{124}$ ), da sind solche Normen auf das Verhältnis von Bund und Länder abgestellt.

$\mathrm{DaB}$ die Handhabung der Organisationsgewalt in Österreich grundsätzlich vom Gesetzgeber zu besorgen ist, ist die Regel. Sie wird durch Ausnahmen bestätigt: GemäB Art. 102 Abs. 6 $\mathrm{B}-\mathrm{VG}$ ist die Bundesregierung berufen mit Verordnung Polizeibehörden einzurichten; gemäß Art. 8 Abs. 5 lit. d. VerfƯG 1920 i. d. Fassung v. 1925 dürfen die Landesregierungen und die Bundesregierung mit Verordnung Sprengelgrenzen verändern u. ä.

O b e r m a y e $\mathbf{r}$, aaO., S. 119 vermeint, daß der ,institutionelle Zweck" als normativer Faktor geeignet sei, die nicht von der Legislative ableitbare Organisationsgewalt der Verwaltung zu

128) Anschütz, Die gegenwärtigen Theorien, aaO., 1. Aufl., S. 35 oder für Ơ s te r r e i c h StGG RGBl. Nr. 141/1867; hier hatten die Vorschriften nicht nur die Aufgabe, Kompetenzen zwischen Reich und Länder zu verteilen, sondern auch Kompetenzen ausdrücklich der Gesetzgebung vor der Verwaltung vorzubehalten.

124) Siehe z. B. Art. 3, 10 Abs. 2; 11 Abs. 5; 12 Abs. 2; 19 Abs. 2; 21 Abs 1, 3 und 5; 23 B-VG usw. 
rechtfertigen. Im Hinblick auf seinen normativen Gehalt sei er einem Ermessentatbestand gleichzuhalten. Was für das Ermessen im republikanischen Rechtsstaat zu gelten hat, hat Klecatsky in einer literarischen Kontroverse mit Melichar zu begründen versucht ${ }^{125}$ ). Auf diese Darstellung verweisend, schließe ich mich der Meinung Klec atsk y an.

d) Aus all dem folgt, daß die Gründe für das Abbröckeln der klassischen Organisationsgewalt in der Verschiebung der Kraftund Machtverhältnisse innerhalb der Staatsfunktionen und den hinter ihnen liegenden politischen Kräften sowie in den damit verbundenen Änderungen des Verfassungsrechtes liegen. Organisationsgewalt der Verwaltung ist nicht, soweit die Verfassung oder Gesetze nicht anderes bestimmen, sondern soweit die Verfassung und das Gesetz die Verwaltung ermächtigen, die Organisationsgewalt auszuüben ${ }^{125 a}$ ).

Nicht übersehen werden darf, daß die Handhabung der Organisationsgewalt immer wieder von der Lösung der Fragen, wie ist die Verwaltungsverordnung zu werten und wie hat die juristische Person Gestalt zu gewinnen, abhängt. Es sind Phänomene, die von der Wissenschaft der Praxis bewußt gemacht worden sind und nur von der Wissenschaft richtig gelöst werden können. Wenn eine übereinstimmende Lösung der Fragen aber nicht gelingt, dann wird sich die Praxis die eine oder die andere Meinung zu Nutze machen müssen. Aber sprechen wir realistischer, wenn dem Wissenschaftler die übereinstimmende Lösung nicht gelingt, dann werden sich der Jurist der Praxis und der Politiker die Lösung selbst zu suchen haben. Es wird dann vielleicht eine theoretisch falsche, systemlose Lösung sein, aber es wird eine Lösung sein. Nicht in der Problemstellung gehen die deutsche und die österreichische Wissenschaft auseinander, sondern in der Lösung der Rechtsfragen, die das positive Recht bietet, das anders gelagert ist (Art. 18 B-VG und Art. 20 GG). Hiezu kommt natürlich noch ein methodischer Unterschied, der in der Lehre Hans $\mathrm{K}$ e l s e n s begründet liegt, von dem sich die österr. Theorie, aber auch die österreichische Praxis nicht ganz freimachen kann.

Wenn die Gesetzgebung in Österreich die organisationsrechtlichen Fragen uneinheitlich löst, der Verwaltung manches überläßt, was mittels Gesetz geordnet werden müßte, so hat das nicht in dem Bewußtsein des Gesetzgebers, etwa nicht

125) K lecatsky, Die Köpenickiade der Privatwirtschaftsverwaltung, JBl. 1957, S. 333 ff.

125a) Siehe neuerdings $S p$ a $n$ ner, Organisationsgewalt und Organisationsrecht, in: Die öffentliche Verwaltung, 1957, S. $640 \mathrm{ff}$. 
legitimiert zu sein, Organisationsgewalt auszuüben, seinen Grund, sondern in der Unkenntnis der wahren staatsrechtlichen Bedeutung der Organisationsgewalt.

V.

13. Die Folgen und Wirkungen der a ufgezeigten Verschiebung in der Handhabung der Organisationsgewalt für die Organisationsgewalt selbst scheinen mir zu sein:

a) die Organisationsgewalt ist an sich nicht vernichtet, nur ihre Handhabung hat sich entsprechend der Verschiebung der modernen Gewaltverhältnisse zum Gesetzgeber hin verlagert ${ }^{120}{ }^{127}$ ). Daß diese Verlagerung von $\mathrm{L}$ a b a nd schon im Jahre 1878 ins Auge gefaßt wurde, habe ich bereits vermerkt (vgl. S. 218). Diese Verlagerung der Handhabung der Organisationsgewalt erhöht die Kraft der Organisationsgewalt bedeutend.

b) Ein Gesetzgeber, der die Organisationsgewalt geschickt ins Treffen führt, kann den verfassungsmäßig veranlagten Staatsaufbau auf kaltem Wege vernichten. Die zunehmende Schaffung rechtsfähiger Verwaltungseinheiten ${ }^{128}$ ), die Zersplitterung der Budgeteinheit durch die Schaffung rechtsfähiger oder auch nichtrechtsfähiger Fonds, die Konkurrenzierung der obersten Staatsorgane in Bund und Ländern durch die Einrichtung "unverantwortlicher" Kollegialorgane und Beiräte, die Ubernahme privatrechtlicher Organisationsformen zur Besorgung staatlicher Aufgaben, bewirken zwar keine substanzielle Änderung im Umfang der Staatsgewalt. Bei normativer Betrachtung des staatlichen Aufbaus, wie er durch das Bonner Grundgesetz und das B-VG gesichert ist, kann es keine Tätigkeit rechtsfähiger Verwaltungseinheiten geben, die letzten Endes nicht zur Verwaltung des Bundes und der Länder zu rechnen wäre. Denn alle die Verwaltungseinheiten, die hier in Betracht kommen, sind es nur kraft Bundes- oder landesrechtlicher Delegation. Sie sind nicht wie Bund und Länder ursprüngliche, sondern abgeleitete Rechtsträger und damit Ausläufer der staatlichen Zentrale. Ihr Bestand hängt vom

120) Diese Frage hat schon $B$ urckhardt, aaO., S. 140 angeschnitten: "Welche organisatorischen $X$ nderungen die Folge dieser Anderungen der Rechtsordnung ... sein müßten, ist hier nicht auszuführen."

127) Ohne auf die dargestellte staatsrechtliche und normative Problematik eingehend setzt Obermayer, aaO., S.117 den aufgezeigten Wandel voraus.

128) S. 209 ff. 
„Willen" des Bundes und der Länder $\mathrm{ab}^{129}$ ). Doch können (oder wollen) Bund und Länder es nicht verhindern, daß durch die organisatorischen Bewegungen faktisch neue, vom Staat auch in der Substanz verschiedene Machtkörper entstehen, die Staaten im Staate sind. Sie haben besondere Verwaltungsziele, betreiben besondere Personalpolitik, führen eine besondere Budgetierung, gründen besondere Gewaltverhältnisse u. ä. - das alles in einem "regressus ad infinitum".

c) Wachsen durch die Handhabung der Organisationsgewalt vom Gesetzgeber politisch und ständisch orientierte Satelliten heran, so wächst die gesetzlich unkontrollierte Restorganisationsgewalt der Verwaltung in die Bürokratie aus. Ihr Kennzeichen ist die Vermehrung staatlicher Ämter innerhalb bestehender Organe ohne sachliche Rechtfertigung, wennschon das Sonderbehördenwesen den Umfang nicht angenommen hat, auf den in der Bundesrepublik Deutschland verwiesen wird ${ }^{120 a}$ ).

d) Es mag zunächst wohl scheinen, als ob die Vielzahl der Organisationsformen, die ihrer Form nach demokratisch organisiert sind, kraft ihrer $n$ a $t \ddot{u} r l i c h$ en Reibungen, die Vehemenz der staatlichen Gewalt mindert. Dann und wann ist es auch so. Doch in Osterreich nicht von vornherein. Die besondere Einheitlichkeit der politischen Struktur in Bund und Länder - getragen von der "großen Koalition“130) - dirigieren die "Organisationsgewalt der Gesetzgebung". Während man in den absoluten Monarchien von der Kanzlei des Monarchen mit ihren Kommissionen, Abteilungen und Ämtern gesprochen hat, wird man heute bei manchen rechtsfähigen Verwaltungseinheiten von einer Abteilung dieser oder jener politischen Partei zu sprechen haben! Wie wir in den Referaten des Vortages erfahren konnten, massieren sich trotz formaler Scheidung von Gesetzgebung und Verwaltung die staatlichen Machtmittel. Was für die Gewaltausübung im allgemeinen gilt, gilt für die Bereitstellung der Mittel zur Gewaltausübung für die Organisationsgewalt - im besonderen.

Die dargelegten Verschiebungen in der Handhabung der Organisationsgewalt berühren aber dennoch die Substanz der staatlichen Gewalt. Und zwar deshalb, weil „unverantwortliche" Organe den "verantwortlichen" Organen den Rang abzulaufen beginnen, weil diese in ihrer Zusammensetzung ein

129) Vgl. Köttgen, aaO.

128a) Siehe Peters, Lehrbuch der Verwaltung, 1949, S 49.

130) Siehe den in der Wiener Zeitung vom 27. Juni $1956 \mathrm{Nr} .147$ erstmals veröffentlichten Koalitionspakt der Regierungsparteien!

131) Vgl. diese Bemerkung bei $B$ rockhausen, aaO., $S .16$. 
Spiegelbild der Kraftgruppierungen im Parlament sind, weil ihnen unter anderem Begutachtungsaufgaben im Gesetzgebungsverfahren oder gegenüber Verordnungsentwürfen zustehen. Diese Begutachtungen werden infolge der faktischen Macht der rechtsfähigen Verwaltungseinheiten beachtet. Der Gesetzgeber schaltet die an dem Werden des Gesetzesinhaltes so maßgebend beteiligten Verwaltungseinheiten schließlich entscheidend in die Gesetzesvollziehung ein ${ }^{132}$ ). Das kann sich bei Ermessensmaßnahmen zu Lasten des Einzelnen auswirken. Der einheitliche Rechtswille erscheint geschwächt.

14. Dadurch, daß sich die Handhabung der Organisationsgewalt auf den Gesetzgeber verlagert hat, haben sich auch die rechtlichen Grenzen für die Handhabung der Organisationsgewalt verändert. Für die klassische Organisationsgewalt sind sie wohl gleichartig geblieben ${ }^{135}$ ). Das allerdings mit umgekehrten Vorzeichen: Klassische Organisationsgewalt ist nur insoweit, soweit die Verfassung oder das Gesetz zu ihr ausdrücklich ermächtigt. Für die Handhabung der Organisationsgewalt durch neu geschaffene Verwaltungseinheiten wiederholen sich - da ihre gesetzlichen Grundlagen nicht unproblematisch sind - auch in der Grenzziehung die Fragen, die einstmals für die klassische Organisationsgewalt gegolten haben (S. 208). Die Organisationsgewalt der neuen Verwaltungseinheiten scheint die Position der klassischen Organisationsgewalt $\mathrm{zu}$ besetzen. Insbesondere wird ihre Organisationsgewalt durch die Zwecke, die die Verwaltungseinheit zu erfüllen hat, begrenzt sein. Das entnehme ich dem Leitsatz 6 der Entscheidung des bayr. VfGH in: Verw.Rspr. 4. Bd., S. 262.

Für den Gesetzgeber aber sind die Grenzen weiter hinaus gesteckt; nämlich bis zur Verfassung. Da sich aber die Verfassungen wohl mit der Organisationsgewalt im Verhältnis von Bund und Ländern, nicht aber mit ihr schlechthin befassen, gibt es praktisch keine unmittelbar erkennbaren und rechtlich wirksamen Grenzen für die Handhabung der Organisationsgewalt durch den Gesetzgeber. Die Verwirklichung der Forderung nach der Stabilität des Budgets hängt nur von außerrechtlichen Gesichtspunkten ab. Eine Zuständigkeitsgrenze, die etwa für die Verwaltung und die Gerichtsbarkeit maßgebend wäre, ist in der Österreichischen Rechtsordnung nicht ohne weiteres erkennbar. So bleiben als Grenzen für die Handhabung der Organisationsgewalt des Gesetzgebers - sieht man

132) Jung wirth, Uber Verwaltungsformen und Wirtschaftsordnung, JBI. 1950, S. 282.

133) Siehe hierüber der sich sehr an An s chü tz, aaO., 2. Aufl., S. $156 \mathrm{ff}$. anlehnende F or s th of $f$, aaO., $S .359 \mathrm{ff}$. 
von jenen ab, die von staatsökonomischen Gesichtspunkten oder technischen Organisations,"gesetzen " gezogen werden, verfassungsrechtliche Grundsätze übrig. Zwei sind besonders augenfällig: die strenge Trennung von Bundes- und Landesverwaltung und der Grundsatz, da $B$ die gesamte staatliche Verwaltung gegenüber der Allgemeinheit verantwortlich getragen vom verfassungsrechtlich normierten Prinzip der Ministerverantwortlichkeit - geführt werden muB. D. $\bar{h}$. rechtsfähige Verwaltungseinheiten sollten nur Hilfsorgane sein, Zwangsbefugnisse dürften nur gegenüber Mitgliedern der Rechtsträger selbst ausgeübt werden; Rechtsträger sollen nur autonome Verwaltung führen dürfen, die genau zu umschreiben wäre. Welche Grenzen für die Organisation staatlichen Unternehmertums im besonderen gelten sollen, das müßte auf Grund der Erfahrung im In- und Ausland, insbesondere in den Volksdemokratien, noch eingehend untersucht werden.

15. Wenn ich im Vorangegangenen als Ursache der Entwicklung die Gewaltverlagerung angesehen habe und mich bemühte die rechtlichen und rechtspolitischen Folgen zu skkizzieren, so drängen sich als weitere Folge Forderungen auf; Forderungen, die in rechtsstaatliche Postulate münden. Die Verfassung steht der Organisationsgewalt des Gesetzgebers mangels näherer Ordnung der Organisation des einzelnen Rechtsträgers derzeit machtlos gegenüber. Sie müßte dem staatlichen Organisationsrecht mehr Augenmerk zuwenden als bisher. Die Organisationsgewalt der Verwaltung aber sollte vom Gesetzgeber näher vorbestimmt sein. Somit teile ich im Ergebnis die rechtspolitischen Auffassungen von $L$. $R$ ichte ${ }^{194}$ ) und Spanne $\left.{ }^{125 a}\right)$. In diesem Zusammenhang muß ich es bedauern, den Auffassungen F orsth of $f s$ nicht folgen zu können, mit denen er die Thesen Richters ablehnt $\left.{ }^{135}\right)$. Und zwar aus folgenden Gründen:

aa) Die Handhabung der Organisationsgewalt hinsichtlich des inneren Amtsdienstes berührt in den Fällen, die politisch bedeutsam sind, das rechtliche Interesse jedes einzelnen. Die Frage inwieweit sich der Minister bei einer Amtshandlung durch Bedienstete seines Ministeriums, ob durch Beamte oder gar nur durch Vertragsbedienstete vertreten lassen darf, die Frage ob ein Akt „für den Bundesminister" gezeichnet ist, oder ob ihn "der Bundesminister" gezeichnet hat, oder ob etwa ein Organwalter ,in Vertretung für den Bundesminister" gezeichnet hat, werfen subtile Rechtsprobleme auf. Sie münden letztlich

134) AaO.: Organisationsgewalt soll gesetzlich geordnet sein.

135) F or sth of $f$, aaO., S. 362. 
in die Frage, ob die zuständige Behörde im konkreten Falle überhaupt entschieden hat.

bb) Es kann für die Allgemeinheit nicht gleichgültig sein, wer vor Entscheidung über einen Verwaltungsakt oder vor Wahrnehmung der Gesetzesinitiative der Regierung „gehört wird“. Ob das zuständige Bundesministerium allein entscheidet, oder ob es "vor Abfertigung" eine Personalmaßnahme etwa einer Interessenvertretung oder einem andern Ministerium zuzuleiten hat. Insbesondere bei Ermessensentscheidungen oder aber bei Regierungsakten kann sich die Entscheidung nach Befassung mehrerer Stellen grundsätzlich wandeln. Die Offentlichkeit hat aber ein Recht von der Manipulation der Behörden Kenntnis zu erlangen, denn die Staatsgewalt geht vom Volke aus.

cc) Es kann nicht gleichgültig sein, ob die Zentralstellen mangels geeigneter Rechtsgrundlagen - in Angelegenheiten des Beamtendienstrechtes nicht Vertreter der Beamtenschaft, sondern Gewerkschaftsfunktionäre hören, die kraft Organisationserlasses zu pseudo-offiziellen Interessenvertretern gemacht wurden. In diesen Belangen scheint die Gleichheit der Dienstnehmer des Staates, gegenüber anderen Dienstnehmern, die gesetzlich eingerichtete Interessenvertretungen haben, durch Maßnahmen der Organisationsgewalt gefährdet.

dd) Für den Gesamtstaatsaufbau, sowie für die ökonomische Gewaltausübung ist es von entscheidender Bedeutung, daß die Ministerien z. B. richtig gegliedert sind: das Verhältnis der speziellen Aufgaben zur Uberwachungskapazität der überwachenden Einheit müßte wohl abgewogen sein.

ee) In jedem Falle aber betrifft die Regelung des internen Amtsdienstes sowie der internen Personalverwaltung den bislang aus der Diskussion gestellten Dritten: den Bediensteten. Wie und wer die Mitglieder von Disziplinar-, Qualifikationsund Prüfungskommissionen besetzt, wie die Urlaubseinteilung, wie die Verteilung von Auslandsreisen und die Vergebung von Orden und Ehrenzeichen vor sich geht, nach welchen Gesichtspunkten Beförderungsrichtlinien gestaltet sein müßten, das alles trifft das rechtliche Interesse des Bediensteten aus seiner Stellung im Amte.

ff) Das Bedenken, daß es schwierig sein dürfte, die Probleme legistisch einwandfrei gestalten zu können, vermag ich nicht zu teilen. Der Legist wird bei gründlicher Kenntnis des äuBeren und inneren Amtsdienstes und seiner Nahtstellen die Grenze zwischen Haupt- und Nebenproblemen nach Maßgabe rechtsstaatlicher Erfordernisse richtig zu ziehen vermögen und 
der Verwaltung wohl abgewogene Organisationsgewalten delegieren können.

gg) Zumindest für österreichische Verhältnisse vermag ich auch dem Bedenken For $s$ t h of $f s$ nicht zuzustimmen, wonach durch die gesetzliche Gestaltung des Organisationsrechtes eine den Traditionen (deutscher) Verwaltung und des Berufsbeamtentums widersprechende unmittelbare Einwirkung der politischen Partei auf die Interna der Verwaltung eröffnet würden. In Österreich herrscht kraft des Koalitionspaktes ${ }^{130}$ ) der Proporz in Gesetzgebung und Verwaltung. Der Beamte wird einen sichereren Boden unter den Füßen haben, wenn die Organisationsgewalt gesetzlich begrenzt ist.

$\mathrm{Da} B$ die Organisationsgewalt der neu geschaffenen rechtsfähigen Verwaltungseinheiten (S. 209) relativ erheblicher ist, als die klassische Organisationsgewalt, hat seine Gründe in der politischen Machtstellung dieser Rechtsträger, in der mangelhaften verfassungsrechtlichen Grundlagenbildung, in der Neuartigkeit der Satelliten und nicht zuletzt in der "weichen" Judikatur des österreichischen Verfassungsgerichtshofes, die sich nach dem "Gesetz vom geringsten Widerstand" bei der Beurteilung von Rechtsakten solcher Selbstverwaltungskörper den faktischen Verhältnissen fügt. Aber gerade diese Judikatur wäre imstande, in konsequenter Weise die Rechtsfragen zu verfolgen und den Gesetzgeber, d. i. aber die politischen Parteien $\mathrm{zu}$ veranlassen, in einer Generaldebatte reinen Tisch $\mathrm{zu}$ machen. Ein Akt der Balancierung der Gewalten wäre das. Bemerkenswert ist, daß der VfGH solchen rechtfähigen Verwaltungseinheiten im Gegensatz zu den ehrwürdigen Gemeinden selbständiges Verordnungsrecht zuerkannt - also die klassische Organisationsgewalt anerkennt (vgl. das Erk. Slg. 2500 und die rechtswissenschaftliche Diskussion über diesen Problemkreis, dargestellt bei Erm a cor a, Der Verfassungsgerichtshof, 1956, S. $178 \mathrm{ff}$.).

Auch diese Umstände sprechen für eine gesetzliche Handhabung der Organisationsgewalt.

ii) Ich höre die Klage, daß die Vergesetzlichung der Organisationsgewalt die Gesetzesflut vermehre. Auf diese Klage, die an sich ja begründet ist, erlauben Sie mir mit Worten $z u$ antworten, die ich dem Aufsatz K le ca t sk y s, Die Köpenickiade der Privatwirtschaftsverwaltung, JBI. 1957, S. 341, entnehme: "Soweit diese Klage von patrimonialen Verwaltungsromantikern ausgestoßen wird, vermag ich sie nicht zu trösten. Die

196) Siehe hierüber für die österreichische Rechtslage Gedanken bei Melichar, aaO., siehe für die deutsche Rechtsordnung Oberm a yer, aaO., S. 117 . 
,gute alte Zeit' ist halt vorbei. Ernst zu nehmen ist die Sorge allerdings, soweit sie philosophisch geschulte Köpfe bedrückt. So hat Marcic jüngst erst in ... Ansätzen zu einer Fundamentalontologie des Rechtes angemerkt, daß viele Gesetze ein ,Zeichen der Dekadenz' seien. Darin stimme ich Marcic durchaus bei. Allein man beachte, daß es sich bei der Vielzahl von Gesetzen eben nur um ein ,Zeichen', also um ein Symptom handelt, das einen tiefer sitzenden Mangel anzeigt. Dieser Mangel ist transzedenter, und zwar nicht nur metajuristischer, sondern auch metaphilosophischer Natur. Ihn beseitigt man nicht, indem man die symptomatischen Gesetze abschafft oder auch nur vermindert. Im Gegenteil: das Unrecht als ein Element dieses transzedenten Mangels wird dann nur noch tiefer werden." Soweit Klecatsky; die gesetzliche Normierung der Organisationsgewalt bewußt und alle Erfordernisse der Rechtsstaatlichkeit mit denen der Verwaltungsökonomie abwägend, wäre die Ordnungsaufgabe!

16. Die Verschiebung der Innehabung der Organisationsgewalt übt nicht zuletzt auch eine Wirkung a uf den herkömmlichen Begriff der Organisationsgew a 1 t aus. Ich deutete das in den Punkten 1 bis 4 meines Berichtes an. Vom Logischen her muß die Frage untersucht werden, ob es logisch-wissenschaftlicher Zucht entspricht, von Organisationsgewalt noch zu sprechen, wenn man unter ihr bislang grundsätzlich nur eine Funktion der Verwaltung verstand - also Organisationsgewalt und Verwaltungsfunktion identisch waren - aber nun Bewegungen im Raume der Gesetzgebung darin einbeziehen will. Organisationsgewalt ist erst, wenn Erscheinungen des Rechtslebens als solche begriffen werden. Solange nicht die Sonde des Begriffes angelegt ist, ist jedes Sein ungeordnet. Der Begriff der klassischen Organisationsgewalt basiert auf Erscheinungen, die nicht mehr oder nur mehr zum Teil sind. Der Umfang der klassischen Organisationsgewalt wurde vom Gesetzgeber dezimiert. $\mathrm{Er}$ selbst trifft an Stelle der Verwaltung organisatorische Maßnahmen, die sie bislang setzte. Ich bin der Auffassung, daß man das, was die Verwaltung einst als Organisationsgewalt besa $\beta$ und nun vom Gesetzgeber wahrgenommen wird, nach wie vor als Organisationsgewalt ansprechen darf. Es hat sich ja nicht die Qualität der Maßnahmen als "organisatorische Maßnahmen“ geändert, es hat sich nur die Qualität in der Ausübung organisatorischer Maßnahmen geändert. Ich halte es vom Begrifflichen her nicht nur für vertretbar, sondern geradezu für erforderlich, die organisatoischen Maßnahmen des Gesetzgebers (allenfalls auch solche der Gerichtsbarkeit) ${ }^{136}$ ) als Maßnahmen 
der Organisationsgewalt anzusehen. Nur dann ist begriffliche Ordnung möglich, wenn der Begriff nicht erstarrt. Hätte man einen anderen tauglichen Begriff, die von der klassischen Organisationsgewalt abgezweigten organisatorischen Maßnahmen des Gesetzgebers umfassend begreifen zu können, dann wäre mein Ansinnen - nach Revision des Begriffes - aus begriffsökonomischen Gründen abzulehnen. So aber folge ich nur der Wandlung des Begriffes, folge also einer im Begriff liegenden dialektischen Bewegung.

$\mathrm{Da} B$ diese Begriffsbildung, die auch die organisatorischen Maßnahmen des Gesetzgebers mit umfaßt, darüber hinaus gerechtfertigt ist, scheint sich mir dadurch zu beweisen, daß die Organisationsgewalt ein Axiom der Staatsgewalt ist und übereinstimmend auch als ein solches angesehen wird $\left.{ }^{187}\right)$. Die Staatsgewalt ist nach herrschender Auffassung ja eine einheitliche. Erscheinungen der Staatsgewalt sind doch Gesetzgebung, Verwaltung und Gerichtsbarkeit. Es wird daher die Organisationsgewalt nur richtig eingeordnet, wenn man sie, den Verhältnissen entsprechend, auch der Gesetzgebung zurechnet. Eine derartige Zurechnung kommt auch dem Wortsinn (S. 199) näher.

$\mathrm{Ob}$ ich unter Organisationsgewalt auch die Gestaltung der Organisation in der staatlichen Unternehmerschaft verstehen darf, ist eine weitere Frage. Diese wirft aber das Problem auf: Ja wo liegt die rechtliche „differentia specifica“ zwischen Organisationsgewalt in staatlichen oder partiell staatlichen Unternehmen und in privaten Unternehmen? Abgesehen von politischen Merkmalen ist nur dort eine erkennbar, wo das staatliche Unternehmen dem Staat zugerechnet werden kann. Das kann aber kraft normativer Methode nur mittels Rechtsnorm geschehen. Wo diese nicht ist, ist die differentia specifica zwischen den beiden Arten von Unternehmerschaften vielleicht im „besonderen Gewaltverhältnis" zu finden, das die staatliche Unternehmerschaft ausstrahlt. Dieses muß aber nicht immer normativ erkennbar sein. Jedenfalls übt der Staat in seinen Unternehmen Staatsmacht aus wie durch seine Behörden ${ }^{138}$ ). Daher wird im Begriff der Organisationsgewalt auch die organisatorische Macht in der staatlichen Unternehmerschaft mitzuverstehen sein.

"Durch die rechtssatzmäßige Natur unterscheidet sich die staatliche Organisation von derjenigen einer gewillkürten $\mathrm{Ge}-$

137) Siehe z. B. F or sth of $f$, aaO., S. 359 .

138) Siehe z.B. Stas in op oulos, Traité des actes administratifs, 1954, S. 27: „On trouve donc un élément de puissance publique dans tout service publique“. 
meinschaft, wie sie ein Verein, eine Handelsgesellschaft, eine private Anstalt darstellen. Dadurch gleicht sie aber den öffentlich-rechtlichen Organisationen, wie den Anstalten des öffentlichen Rechtes, den Gemeinden, Provinzen und anderen Körperschaften, die, wie er, nicht durch den Zufall einer rechtsgeschäftlichen Entwicklung von Privatpersonen entstehen, sondern durch den Willen des objektiven Rechts, der Rechtsordnung selbst: als Bestandteile des Planes, welcher die Zuständigkeitsordnung, die Verfassung des Landes, ausmacht"139).

17. Zum Begriff der Organis ationsgewalt kann somit folgendes festgestellt werden:

a) Organisationsgewalt ist als Axiom der Staatsgewalt je nach der staatlichen Gewaltenbildung die Macht der zuständigen Organe, unter Voraussetzung unmittelbarer Staatsorgane, die hoheitliche und wirtschaftliche Organisation im Staate mit dem Ziele, eine geordnete Machtausübung herbeizuführen, nach jeder Richtung hin zu gestalten. Umfang, Mittel und Grenzen sowie die Kontrolle der Organisationsgewalt ergeben sich aus der jeweiligen Rechtsordnung. Die Gestalt der Organisationsgewalt ist somit variabel.

b) Die klassische Organisationsgewalt ist folglich der Rest an Organisationsgewalt, der der Exekutive nach den Gewaltenverschiebungen im modernen Staat - faktisch gewohnheitsmäßig oder zu Recht - noch verblieben ist. Rechtlich ist die Organisationsgewalt eine vom Gesetzgeber stillschweigend oder ausdrücklich delegierte. Rechtlich soll sie sein, nicht soweit Gesetz und Verwaltung nichts anderes bestimmen, sondern soweit Verfassung und Gesetz Organisationsgewalt zulassen.

VI.

Abschließend nun Gedanken über die Kontrolle der Ausübung der Organisationsgewalt:

18. Die Gestalt der Organisation im Staate unter der Voraussetzung des Vorhandenseins unmittelbarer Staatsorgane ist Ausdruck für die Kraft der Organisationsgewalt. Diese hält gleichen Schritt mit der staatlichen Machtausweitung. Allerdings ist die Organisationsgewalt nur technische Handhabe zur Erfüllung der Staatszwecke. Die Wucht der Organisationsgewalt ist proportional der den Staatszweck erfüllenden Ausübung der Staatsgewalt. Werden die Staatszwecke beschränkt, müßte die Organisationsgewalt sich in ihrem AusmaB auto-

189) Burckhardt, aaO., S. 147 . 
matisch verringern. Daher ist jede Maßnahme der Verwaltungsreform gleichzeitig Kontrolle der Organisationsgewalt ${ }^{140}$ ).

19. Die faktisch gehandhabte Organisationsgewalt im hoheitlichen Staatsbereich findet je nachdem, von welchen Organen sie getragen ist, ihre rechtliche Kontrolle durch die Gerichtshöfe öffentlichen Rechtes ${ }^{141}$ ). Mittelbar auch durch Organe, die nach der Verfassung berechtigt sind, Anträge auf Rechtskontrolle an die Gerichtshöfe zu stellen. Problematisch an dieser Kontrolle ist aber immer, daß die einer Uberprüfung unterzogene Maßnahme an einem rechtlichen Maßstab zu prüfen ist. Dieser Maßstab ist die Rechtsnorm. Für die Gesetze die Verfassung, für Akte der Verwaltung das Gesetz usw. Die Utberprüfung setzt eine Interpretation der Rechtsnorm voraus. Sie wissen, meine Herren, daß der geschickte Jurist fast immer Mittel findet - dem Auslegungsgrundsatz des österreichischen Verfassungsgerichthofes folgend, daß keiner Norm von vornherein eine Auslegung gegeben werden darf, die sie verfassungswidrig erscheinen läßt -, das Úberprüfte mit der vorgegebenen Rechtsgrundlage in Einklang $\mathrm{zu}$ setzen. Daraus erwächst in Wahrheit mancher Unsicherheitsfaktor, auch für die rechtmäßige Ausübung der Organisationsgewalt. Nur die einwandfreie Rechtsgrundlage hilft die Organisationsgewalt davon zu bewahren, daß sie Hypertrophien erzeugt, die vom Laien mit Verständnislosigkeit und Staunen zur Kenntnis genommen werden.

Die österreichische Rechtsprechung hat ein für die Organisationsgewalt bedeutsames, dem deutschen Rechtsleben unbekanntes Kontrollmittel entwickelt, und zwar wird die klassische Norm: „Niemand darf seinem gesetzlichen Richter entzogen werden "142), auch auf der Verwaltungsebene angewendet. Das führt zu merkwürdigen Kontrollformen der Organisationsgewalt.

140) Vgl. hierzu für Östereich das Verwaltungsentlastungsgesetz BGBl. Nr. 277/1925, die Verordnung über den Wirkungskreis des Ersparungskommissärs BGBl. Nr. 47/1949; siehe den Wirkungskreis des Bundeskanzleramtes - Verfassungsdienst auf dem Gebiete der Verwaltungsreform im jeweiligen Österreichischen Amtskalender; siehe ferner die Schrift von B r o ckhausen, Osterreichische Verwaltungsreformen, 1911. Bemerkenswert ist in diesem Zusammenhang die Diskussion über die Verwaltungsreform in den volksdemokratischen Staaten siehe z. B. den Aufsatz ,Zur Einführung der Volkswirtschaftsräte", in: Ost-Probleme 1957 (Nr. 17), S. $578 \mathrm{ff}$.

141) Utber die Rechtskontrolle siehe Ermacora, Der Verfassungsgerichtshof, 1956.

142) Siehe darüber neuerdings Ermacora, Klecatsky, Ringh of er, Die Rechtsprechung des Verfassungsgerichtshofes im Jahre 1956, OJZ 1957, S. $621 \mathrm{f}$. 
Im Bereich der wirtschaftlichen Verwaltung des Staates und seiner Trabanten kann rechtliche Kontrolle der Organisationsgewalt nur wirksam sein, wenn diese Wirtschaftsverwaltung auf Grund der Gesetze geführt wird. Das liegt - ohne hierauf weiter eingehen zu können - in Osterreich jedoch im argen ${ }^{143}$ ).

Die faktisch gehandhabte Organisationsgewalt findet ihre ökonomische Kontrolle vor allem in der Kontrollfunktion des Rechnungshofes ${ }^{144}$ ), ferner in der Tätigkeit der von den Finanzgesetzen jeweils berufenen Ersparungskommissäre ${ }^{145}$ ) oder der nach dem Verwaltungsentlastungsgesetz vorgesehenen Einrichtungen und Maßnahmen. Nicht zuletzt ist die Publizität von Organisationsmaßnahmen und die freie Meinungsäußerung über sie heilsam.

Wie sehr die Selbstbewegung der Organisation aus sich heraus Kontrolle in ökonomischer Richtung erzeugen kann, das bemüht sich die anglo-amerikanische Rechtswissenschaft ans Licht zu stellen (vgl. die Ausführungen auf S. 197 und in Anmerkung 28).

Muß ich vor Ihnen, meine Herren, noch von der Kontrollfunktion der erkennenden Rechtswissenschaft sprechen? ... Ich glaube nicht.

VII.

20. Wenn Sie, verehrte Zuhörer, die von mir skizzierten Gedanken für richtig halten können, dann folgt, daß die Organisationsgewalt in ihren Extremen ein für die Rechtsstaatlichkeit erschreckender Koloß sein kann. Sie vermag - unkontrolliert - wie Unkraut zu wuchern. Insbesondere deshalb erschreckend, weil sie an sich als Mittel zum Zwecke, Macht zu organisieren, "neutral" ist. Daher können gewisse Produkte der Organisationsgewalt in der freiheitlich-demokratischen Rechtsordnung ebenso wie in der Diktatur verwertbar sein. Erschreckend auch heute deshalb, weil durch die MammutWirtschaftsmacht des Staates und seiner Trabanten Elemente in der staatlichen Organisationsgewalt und Organisation Eingang finden, die bisher nur den technischen Monsterunternehmen eigen waren $\left.{ }^{146}\right)$. Das mit der Wirkung, den Menschen ob Konsumenten oder Produzenten - einem strengen Mechanismus zu unterwerfen. Aber dennoch ist in diesem staatlichen Mechanismus ein grundlegender Unterschied zum technischen erkennbar, wenn jener in einer freiheitlich-demokratischen

143) Siehe Klecatsky, aaO., und die dort angeführte Literatur.

144) Vgl. die Art. 121 ff. B-VG.

145) Siehe die Anm. 140.

140) Siehe F. G. J ü $\mathbf{n g}$ e r, aaO. 
Grundordnung existiert: Der technische Mechanismus ist notgedrungen anonym, der staatliche kann nicht anonym sein, weil die Verantwortlichkeit der die Organisationsgewalt handhabenden Organe in unseren Bereichen offenkundig sein muß. Darüber hinaus kann die Organisationsgewalt des Staates nur durch Organwalter - durch Menschen - in Erscheinung treten, die Recht anzuwenden haben. Die Handhabung derselben ist aber noch nicht, wie in Franz $\mathrm{K}$ a $\mathrm{f} \mathrm{k}$ a' $s$ bedrohlicher Vision der "Strafkolonie“, Urteilsmaschinerie, sondern sittliche Entscheidung. Das wirkt auf die Organisationsgewalt zurück: Sie ist nicht technischen Automationen preisgegeben! 


\title{
Leitsātze des Mitberichterstatters über: Die Organisationsgewalt
}

\author{
I.
}

Abgrenzungder Probleme:

1. Der Bericht bezieht sich nur auf die Organisation und die Macht, diese in der Rechtsordnung zu gestalten.

2. Schwerpunkte des Phänomens der Organisationsgewalt: Fragen nach dem Wert des klassischen Begriffes der Organisationsgewalt und nach der Organisationsgewalt, die den "unmittelbaren Staatsorganen" (Georg Jellinek) zukommt.

3. Gestalt der Organisation und der mit ihr vorausgesetzten Gewalt sind je nach Rechtsordnung variabel. Aus dem österreichischen Anschauungsmaterial kann infolge mancher substanzieller Gleichheit mit dem deutschen Allgemeingültiges entwickelt werden.

4. Mannigfaltige Seiten dieses Fragenkomplexes. Hauptaugenmerk soll auf die rechtliche und rechtspolitische Seite gerichtet werden; darin wird die Grundstruktur des Phänomens offenbar.

5. Der klassische Begriff der Organisationsgewalt ist mit induktiver Methode zu prüfen. Normative Methode nur bedingt anwendbar; einem materiell-teleologisch methodischen Vorgehen soll der Vorzug gegeben sein.

II.

Die klassische Organisationsgewalt:

6. Der Sinn des Wortes "Organisationsgewalt" setzt die Begriffe der Organisation und der Gewalt voraus. Der Wortsinn erfaßt die Macht juristischer Personen, durch Organe jeder Staatsfunktion die Organisation des Staates nach jeder Richtung zu gestalten.

7. Hingegen erscheint der klassische Begriff der Organisationsgewalt enger. Die Organisationsgewalt sei in der Hauptsache Tätigkeit der Staatsfunktion Verwaltung, soweit sie die Hoheitsverwaltung betrifft. 
8. In den parlamentarischen Monarchien ist der Begriff aus der rechtlichen und natürlichen Spannung von Gesetzgebung und Verwaltung erwachsen. Die Organisationsgewalt lag gesetzesfrei in der Hand des Herrschers (Exekutive), soweit nicht Verfassung und Gesetz Vorbehalte machten.

9. Organisationsgewalt bezog sich besonders auf die umfassende gesetzesfreie Einrichtung und Ausgestaltung der Organe - vor allem der unmittelbaren Verwaltungsorgane -, auf die umfassende Gestaltung der bewaffneten Macht und auf die Erstellung einer absoluten Ordnung für die Staatsdienerschaft. Mittel der Handhabung: die Verwaltungsverordnung.

III.

Verschiebungen in der klassischen Organisationsgewalt:

10. Auch nach dem Zusammenbruch der Monarchien hielten Rechtswissenschaft und Rechtspraxis in allen Staatsformen (auch in der Diktatur) an der hergebrachten Organisationsgewalt mit zeitbedingten Varianten fest.

11. Nach dem Zusammenbruch der Monarchien jedoch Wandlung in der Trägerschaft und dem Umfang der klassischen Organisationsgewalt: Abbau zugunsten des Gesetzgebers, Abbau zugunsten neugeschaffener Verwaltungseinheiten. Organisationsgewalt besitzt die klassische Exekutive nur insoweit, als sie ihr gewohnheitsrechtlich unangetastet bleibt.

12. Ursache dieser Verschiebung liegt in der durchgehenden und praktischen Neuordnung des Verhältnisses der Staatsgewalten zueinander, in der dieser folgenden Erfüllung der Forderung der Gesetzmäßigkeit der Verwaltung, in der Unterordnung der Verwaltungsverordnung unter das Gesetz. Organisationsgewalt steht daher der Verwaltung nur zu, soweit sie zur Handhabung durch Verfassung und Gesetz ermächtigt ist (Schwerpunkt in der juristischen Struktur: die Verwaltungsverordnung; die Beantwortung der Frage nach dem Wesen der Verwaltungsverordnung ermangelt eines übereinstimmenden Ergebnisses).

\section{IV.}

Folgen der Verschiebung der Organisationsgewalt:

13. Der Gesetzgeber als Träger der Organisationsgewalt kann den klassischen Staatsaufbau untergraben. Dagegen nur untaugliche Schranken. 
14. Denn rechtliche Grenzen der Organisationsgewalt sind verschoben. Für den Gesetzgeber nur Grundsätze bindend: Trennung von Bundes- und Landesverwaltung und die Norm, die Verwaltung verantwortlich zu führen. Organisationsgewalt im staatlichen Unternehmen ist aber grenzenlos, wenn keine juristische Zurechnungsregel.

15. Handhabung der Organisationsgewalt durch den Gesetzgeber. Wenn schon etwa nicht normativ zwingend, so dennoch begründetes Postulat rechtsstaatlicher Ideologie.

16. Notwendige Begriffswandlung als Folge: klassische Organisationsgewalt und Verwaltungsfunktion sind eins; jedoch nicht schlechthin Organisationsgewalt und Verwaltung. Da die Organisationsgewalt ein Axiom der Staatsgewalt ist, darf begrifflich die Befugnis jedes Organes, organisatorische Handlungen zu setzen, als Organisationsgewalt angesprochen werden. Auch die Ausübung organisatorischer Macht im staatlichen Unternehmertum ist Organisationsgewalt.

17. Daraus folgt, daß umfassende Begriffsbildung notwendig.

$V$.

Kontrolle der Organisationsgewalt:

18. Die Wucht der Organisationsgewalt ist proportional der staatszweckerfüllenden Gewaltausübung, daher besorgt die Verwaltungsreform auch die Kontrolle der Organisationsgewalt und ihrer Ausübung.

19. Rechtliche Kontrolle der Organisationsgewalt im hoheitlichen Bereich durch Gerichtshöfe öffentlichen Rechtes, im staatlichen Unternehmerbereich ist sie nur wirksam, wenn dieser gesetzlich geordnet. Ökonomisch geordnete Selbstbewegung der Organisation trägt in sich Kontrollfunktion.

$V I$.

Zusammenfassender Schlußgedanke:

20. Staatliche Organisationsgewalt und staatliche Organisation sind kein automatischer Mechanismus. 


\section{Aussprache über: \\ Die Organisationsgewalt}

\section{W e b e r - Göttingen:}

Bei dem Vortrag unserer Referenten heute vormittag ist, wie ich meine, sehr bald deutlich geworden, daß das heute behandelte Thema in ziemlich engem Zusammenhang steht mit dem Thema von Mainz („Besonderes Gewaltverhältnis"), aber auch mit dem gestrigen Thema („Regierung und Parlament im modernen Staat"). Der Zusammenhang ist dadurch gegeben, daß es sich auch bei dem Thema "Organisationsgewalt" um die Frage nach der Exekutive, ihrer Eigenständigkeit, ihren Möglichkeiten und der Begrenzung dieser Möglichkeiten handelt, überhaupt danach, wie und in welchen Grenzen der Staat sich durch eine eigenständige Exekutive und in ihr realisiert. Nicht von ungefähr waren deshalb die Bezugnahmen auf das Referat von Herrn Krüger vom vorigen Jahre verhältnismäßig häufig, und an einigen Stellen klangen auch ohne ausdrückliche Bezugnahme Fragen unseres gestrigen Themas an, und zwar Erwägungen, die vielleicht gestern etwas an den Rand gedrängt worden sind und die insgesamt ebenfalls auf die Frage nach den Möglichkeiten einer eigenständigen Exekutive in der modernen Verfassung abzielen. Nun ist das sehr subtile Referat von Herrn Köttgen insofern etwas sperrig gegenüber einer Diskussion, als die Subtilitäten, die seine Arbeitsweise kennzeichnen und die er in diesem Referat besonders stark sich hat entwickeln lassen, den Vergröberungen einer kurz bemessenen Diskussion nicht leicht zugänglich sind. Das müssen wir in Kauf nehmen - das müssen Sie, Herr Köttgen, natürlich auch in Kauf nehmen -, und Sie haben uns das dadurch erleichtert, daB Thre Thesen mehr „holzschnittartig“ formuliert sind, so daß, wenn man nur die Thesen liest, man nicht viel von dem ahnt, was sich an Subtilitäten darin einhüllt.

Mit Herrn Kollegen Köttgen würde ich empfehlen - davon weicht auch das, was Herr Ermacora vorgetragen hat, nicht ab - bei der Begrenzung des Themas, die die Herren Referenten vorgenommen haben, $\mathrm{zu}$ bleiben. Herr Köttgen hat ebenso wie Herr Ermacora betont, daß er sich mit der Orga- 
nisationsgewalt der Verwalt ung oder im Hinblick auf die Verwaltung beschäftigen würde, und er hat insbesondere hervorgehoben, daß er Militärwesen und Gerichte ausklammere. Natürlich würde die Betrachtung der Organisationsgewalt in bezug auf die Streitkräfte unser Thema außerordentlich wirkungsvoll und wesentlich abrunden, aber wir sind hier zur Beschränkung genötigt. Ich empfehle also, bei der Organisationsgewalt der Verwaltung zu verharren, gerade auch im Bewußtsein dessen, daß wir damit nur einen repräsentativen Ausschnitt des Themas behandeln. Herr Köttgen hat sodann darauf hingewiesen, daß ein Problem, das zeitweilig eine nicht unerhebliche Rolle gespielt hat, nämlich das der Verleihung eines öffentlich-rechtlichen Status an Religionsgesellschaften, hier gleichfalls beiseite bleiben soll. Ich möchte nicht meinen, daB dieses Problem nichts mit der Organisationsgewalt zu tun hätte. Ich könnte mir denken, daß es um die Mitte des vorigen Jahrhunderts durchaus etwas mit Organisationsgewalt zu tun gehabt hat. Aber mit der heutigen staatskirchenrechtlichen Lage hat es in der Tat keinen rechten Zusammenhang. Und wenn sich einige unserer Landesregierungen dann, wenn sie meist ziemlich unbedeutenden - Religionsgemeinschaften die Rechte einer Körperschaft des öffentlichen Rechts verleihen, auf die Organisationsgewalt berufen, dann ist das einfach falsch. Das ist nicht Betätigung der Organisationsgewalt, und wir sind uns jedenfalls darüber klar, da $B$ das hier beiseite bleibt.

Herr Kollege Köttgen hat uns insofern die Erörterung des Themas ein wenig erschwert, als er uns eine genaue Beschreibung dessen, was Organisationsgewalt ist, nicht gegeben hat. Er hat allerdings den Tatbestand, der damit gemeint ist, eingegrenzt, wenn ich mich so ausdrücken darf, und zwar schon dadurch, da $B$ er den Bereich des Militärwesens, der Gerichte und der Religionsgesellschaften ausgeklammert hat. Dann sind durch die verschiedenen Abgrenzungen, die sich nachher ergaben, noch einige weitere Präzisierungen herausgekommen. Aber dann hat sich doch wieder gezeigt, daß sich etwas verschwimmende Perspektiven anboten, als er etwa davon sprach, daß zwischen der Dienstherrenstellung und der Organisationsgewalt ein enger Zusammenhang bestehe, und $\mathrm{daB}$ z.B. auch die Mitbestimmung in den Personalräten oder Personalvertretungen zur Organisationsgewalt eine Beziehung habe. Utberhaupt hat er sehr stark unterstrichen, daB die Personalhoheit des Dienstherren mit der Organisationsgewalt in Beziehung stehe oder jedenfalls Auswirkungen auf die Organisationsgewalt habe. Aus diesen Andeutungen ergibt sich eine gewisse 
Schwierigkeit, und vielleicht ließe sich im Verlauf der Diskussion gerade die Frage noch ein wenig vertiefen, womit wir es überhaupt zu tun haben. Herr Kollege Ermacora hat nach dieser Richtung festgestellt - das hat Herr Köttgen nicht ge$\tan -$, daß die Organisationsgewalt sich qualitativ gleich bleibe, gleichgültig, ob sie in der Hand der Exekutive oder in der Hand der Legislative sei. Das setzt nun wiederum ein materielles Verständnis von Organisationsgewalt voraus, das gleichfalls noch einer Präzisierung bedürfte. Ich weiß aber von mir aus darauf keine Antwort zu geben, keine klare Antwort jedenfalls, und möchte nur meinen, daß wir uns damit in der Diskussion zu beschäftigen hätten.

Herr Kollege Köttgen hat sein Referat mit einer Bezugnahme auf eine Äußerung begonnen, die ich in einem Ausschuß des Niedersächsischen Landtages getan habe. Ich sprach damals davon, die Organisationsgewalt entstamme dem Arsenal der preußischen Monarchie von 1850 . Da wollte man nämlich (1951) in die Niedersächsische Verfassung hineinschreiben: Die Organisationsgewalt steht der Regierung zu. Darauf hatte ich gesagt: „So geht das nicht. Ihr könnt nicht das, was Bestandteil der spezifischen Verfassungsproblematik der preußischen Verfassung von 1850 war, so einfach mit einem Federstrich perpetuieren. Die Situation ist heute ganz anders." Sie ist ganz anders, aber in mancher Beziehung doch auch wieder dieselbe. Damals, unter der Herrschaft der preußischen Verfassung von 1850, wußte man ziemlich genau, was Organisationsgewalt war. Das war nämlich etwas, was der Monarch oder der monarchische Beamtenstaat als sein Hausgut in Anspruch nahm, so wie übrigens der Monarch in dieser oder unter dieser Verfassung ferner noch in Anspruch nahm die militärische Kommandogewalt, das militärische Verordnungsrecht und das Recht, Verwaltungsordnungen, insbesondere Anstaltsordnungen zu erlassen, d. h. Rechtssätze in Form sogenannter Verwaltungsverordnungen zu schaffen. Das alles einschließlich der Organisationsgewalt gehörte zum Hausgut dieser beamtenstaatlichen Monarchie und wurde - das hat Herr Köttgen auch hervorgehoben - verteidigt gegen die Versuche der Volksrepräsentation, hier die Position des monarchischen Beamtenstaates aufzubrechen. Bemerkenswerterweise war die Defensive für den monarchischen Beamtenstaat auf diesem Gebiete leicht. Das Hauptinteresse der Volksvertretung konzentrierte sich bekanntlich auf das militärische Verordnungsrecht, auf die Kommandogewalt, auf die Gegenzeichnung dabei, auf das Rechtsetzungsrecht des Monarchen, das sich in Verwaltungsverordnungen einkleidete, während die Organisations- 
gewalt dem Monarchen erst in allerletzter Linie streitig gemacht wurde. Nur daraus ist es zu erklären, daß bei der Erbfolge der Weimarer Verfassung ganz naiv gesagt werden konnte: "Nun, die Organisationsgewalt in dem Bestande, wie sie vorher vorhanden war, geht jetzt auf den Reichspräsidenten über, in Preußen auf das Staatsministerium usf." Erst im Laufe der Zeit haben sich die eigentlichen Einbrüche in die Organisationsgewalt der Exekutive herausgestellt. Aber damals handelte es sich noch darum, in der Organisationsgewalt eine verfassungsmäßige Position der monarchischen Exekutive zu behaupten. Auf diesen Grundtatbestand zurückgeführt, scheint mir die Lage heute doch ähnlich zu sein; auch heute scheint es mir sich darum zu handeln, daB die Exekutive - ich darf mich so ausdrücken, wobei ich wei $\beta$, da $\beta$ das etwas verschwommene Bezeichnungen sind - in Anspruch nimmt, in ihrem Hause, wie Herr Köttgen es ausgedrückt hat, Herr zu sein, und da $B$ die Exekutive Organisationsgewalt als ihr Hausgut in Anspruch nimmt, ein Hausgut, das ihr, jedenfalls sofern es ihr von der Verfassung nicht ausdrücklich abgesprochen ist, zu ihren verfassungsrechtlichen Positionen als Exekutive gehört. Das wird ihr nun heute streitig gemacht, nicht mehr von einer in sich geschlossenen Volksvertretung, die sich in toto der monarchischen Exekutive gegenübergestellt weiß, sondern wird ihr streitig gemacht von dem unmittelbaren Zugriff der Parlamente, besser: der Parteiapparaturen auf die Verwaltungsmacht, die wir heute überall finden und die sich in der verschiedensten Weise äußert.

Die eine Äußerung dieses Zugriffs besteht darin, wie Herr Köttgen m. E. sehr treffend hervorgehoben hat, daß in den Verfassungen ein „institutioneller Gesetzesvorbehalt“" angebracht wird. Ich halte die Individualisierung und Hervorhebung des institutionellen Gesetzesvorbehalts gegenüber dem rechtsstaatlichen Gesetzesvorbehalt in diesem Zusammenhang für eine überaus wichtige Erkenntnis. Natürlich kann die Verfassung solche institutionelle Gesetzesvorbehalte anbringen, und sie tut es in reicher Fülle, übrigens aus den verschiedensten Gründen. Herr Köttgen hat besonders auf die Funktion des Art. 87 GG hingewiesen. Aber solche Vorbehalte werden natürlich auch mit dem klaren Ziele angebracht, den Bereich des von der Exekutive in Anspruch genommenen Hausgutes einzuengen. Etwas anderes ist der rechtsstaatliche Gesetzesvorbehalt, mit dem sich die Kontroversen über die Organisationsgewalt früher in der Hauptsache beschäftigten. Von ihm meint Herr Köttgen, daß er seine Bedeutung eingebüßt habe. Wir haben es ja nicht mehr mit der Problematik des Staates von 
1850 oder auch der Weimarer Republik zu tun, wo - gleichviel nach welcher Konstruktion - noch ein selbständiges Rechtsetzungsrecht des Monanchen und später des Trägers der Organisationsgewalt postuliert werden konnte. Wir gehen vielmehr ohne Einschränkung davon aus, daß die Rechtsetzung vom Parlament monopolisiert ist. Nun ist die Frage die, ob in der Betätigung der Organisationsgewalt auch Rechtsetzungselemente enthalten sind, die infolgedessen der Exekutive als dem Träger der Organisationsgewalt streitig zu machen sind.

Ich stimme Herrn Köttgen darin $z u$, daß die Bedeutung dieser rechtsstaatlichen Vorbehalte stark nachgelassen hat. Die meisten Fälle erledigen sich schon deshalb, weil die großen materiellen Gesetze, die im Verwaltungsrecht heute ergehen, Bundesgesetze zu sein pflegen und diese Bundesgesetze schon durch die Art. 84 ff. GG genötigt sind, das wegen der Durchführung organisations- und verfahrensrechtlich Erforderliche ihrerseits vorzusehen. Aber der rechtsstaatliche Gesetzesvorbehalt hat $\mathrm{m}$. $\mathrm{E}$. auch deshalb an Bedeutung verloren, weil die Generalklausel der Verwaltungsgerichtsbarkeit ja auf jeden Fall dafür sorgt, daß jeder seinen "gesetzlichen Richter" findet und dadurch die Bedeutung der "gesetzlichen Verwaltungsbehörde" - wenn ich mich so ausdrücken darf - für den rechtsstaatlichen Vollzug wesentlich geringer geworden ist. Wenn ich gegen jeden Verwaltungsakt zurückgreifen kann auf die verwaltungsgerichtliche Kontrolle, dann ist es rechtsstaatlich nicht mehr wichtig, daß es gerade die so oder so organisierte Behörde ist, die diesen Akt mir zufügt. Natürlich besagt das nicht, daß der rechtsstaatliche Gesetzesvorbehalt insoweit je d e Bedeutung eingebüßt hätte. Herr Köttgen hat sich nun dahin präzisiert, daß der rechtsstaatliche Gesetzesvorbehalt allenfalls für die Eingriffsverwaltung noch Bedeutung habe, für die Leistungsverwaltung dagegen nicht. Das möchte ich nicht unterstreichen, sondern ich möchte meinen, daß die heutige Leistungsverwaltung, soweit sie sich nicht etwa darauf beschränkt, Anstalten zur Verfügung zu stellen, die man nach freiem Belieben benutzt oder nicht benutzt, sondern soweit sie uns daseinsnotwendige Leistungen erbringt, für uns existentiell so wichtig ist, daB auch für die Exekutierung dieser Leistungsverwaltungsbereiche die Frage der Zuständigkeit von derselben rechtsstaatlichen Bedeutung sein kann wie bei der Eingriffsverwaltung. Ich glaube, darüber können wir uns leicht verständigen.

Herr Köttgen hat nun gesagt, daß der allgemeine Verwaltungsauftrag die Exelkutive auch organisatorisch von gesetzlichen Vorentscheidungen unabhängig stelle, und zwar verfas- 
sungskräftig, daß dabei allerdings Bindungen an Typen möglich seien. Ich glaube, daß diese These richtig ist und $\mathrm{da} B$ sie übrigens der Verwaltung noch einen beträchtlichen Betätigungsraum für ihre Organisationsgewalt gibt. Aber wir dürfen auch nicht verkennen, daß der Aktionsbereich des allgemeinen Verwaltungsauftrags sich in unserem heutigen, von Gesetzen durchgeplanten Verwaltungsstaat stark verringert hat. Freilich wird anderseits immer wieder versucht, neue Aktionsbereiche zu erschließen. Herr Köttgen hat in diesem Zusammenhang, was mir außerordentlich wichtig scheint, darauf hingewiesen, $\mathrm{da} B$ ein zu gering bemessener Spielraum beispielsweise das Ausweichen ins Privatrecht begünstige. In der Tat können wir das in großem Umfange feststellen. Ich möchte das noch um ein paar Bemerkungen ergänzen Man weicht nicht nur aus ins Privatrecht, sondern man weicht auch aus in merkwürdige "graue Zonen“, die unser traditionelles Verwaltungs- und Verfassungsrecht aus den verschiedensten Gründen - meist wegen der föderalistischen Komplikationen - nicht in den Griff bekommen hat. Ich darf in diesem Zusammenhang erwähnen - bei Herrn Ermacora hat ähnliches angeklungen -, daß uns etwa die Verwaltungsabkommen der Länder untereinander und mit dem Bund neue Möglichkeiten der Betätigung freier Organisationsgewalt eingebracht haben. Ich brauche nur an den Zentralrat für Wissenschaft oder an die neue „Konferenz für Raumordnung und Landesplanung" zu erinnern, u. ä. m. Auch im Hochschulwesen betätigt sich freie Organisationsgewalt sehr fruchtbar. Das geschieht etwa in der Weise, da $B$ im Zusammenhang mit den kulturpolitischen Bemühungen des Bundesinnenministeriums, des Auswärtigen Amtes und anderer Bundesministerien schon vorhandene Organisationen wie Deutsches Studentenwerk, Verband Deutscher Studentenschaften usw. oder ad hoc neugeschaffene wie der Deutsche Akademische Austauschdienst in die Rolle offiziöser Verwaltungsstellen des Bundes heraufgehoben werden.

Hier möchte ich als Fazit eine kritische Bemerkung anknüpfen: Meine Herren, sobald wir die Organisationsgewalt in ihrem legitimen Bereich zu stark beschränken, wird man ausweichen und sich auf anderem Wege behelfen. Auf diesem anderen Wege aber gelangt man leicht zu einer solchen Hypertrophie unkontrollierbarer, undurchsichtiger Verwaltungserscheinungen, daB man im Ergebnis keinesfalls eine Begrenzung der Verwaltung erzielt, sondern eine starke Ausweitung, noch dazu verbunden mit einer starken Depravierung des 
eigentlichen Verwaltungsauftrags, vor allen Dingen mit einer Beeinträchtigung des Offentlichkeitscharakters der Verwaltung.

Da meine Redezeit begrenzt ist, woran ich schon erinnert worden bin, möchte ich nur auf die Schlußbemerkung von Herrn Köttgen noch in einem Wort eingehen. Er hat gesagt, die verfassungsrechtlichen Grundlagen der Organisationsgewalt seien zu finden im Recht zur Bewirtschaftung präsenter Haushaltsmittel und in teils beamten-, teils arbeitsrechtlichen Direktionsrechten gegenüber dem Personalkörper. Ich meine, die Bedeutung dieser beiden Ansatzmöglichkeiten für die Betätigung von Organisationsgewalt sei hier insofern ein wenig überdosiert, als darin gerade die verfassungsrecht1 i c h e n Grundlagen der Organisationsgewalt erblickt werden. Ich würde vielmehr meinen, daB es von der Natur der Sache her, d. h. von der Natur des Staates und von der Natur der Aufgaben der Exekutive her im Staate keine Exekutive geben kann, in Ordnung geben kann, wenn sie nicht als eigenes Hausgut auch Organisationsgewalt hat. Infolgedessen ist die Organisationsgewalt der Exekutive schon unmittelbarer Bestandteil der Verfassung, während die haushaltsrechtlichen und die beamten- und dienstrechtlichen Möglichkeiten mehr bloß Bestätigungen und Ergänzungen liefern. Ich will damit schließen und nur noch einmal zurückkommen auf die These von Herrn Ermacora, daß die Organisationsgewalt bestehen bleibe und sich auch in der Qualität nicht verändere, wenn das Parlament sie in seine Obhut nimmt. Wie ich demgegenüber meine, zeigt uns die geschichtliche Entwicklung unseres Problems ebenso wie seine Würdigung in der Gegenwart, daß es sich bei der Organisationsgewalt um die Frage nach dem verfassungsmäßigen Hausgut der Verwaltung (der Exekutive) handelt, und daß, wenn andere (Parlament, politische Parteien usw.) sich dieses ursprünglichen Hausguts der Exekutive bemächtigen, es sich in der Hand des neuen Inhabers nicht mehr um "Organisationsgewalt" handelt, jedenfalls nicht in dem Sinne der von uns hier erörterten Prablematik. Auch der neue Inhaber trifft natürlich organisatorische Maßnahmen, aber der Begriff der Organisationsgewalt verliert dann sein durch die Historie und durch unsere politische Situation geformtes Gepräge. Davon, glaube ich, müssen wir ausgehen, denn sonst müßten wir jedwede Art von Organisationsproblemen schließlich in die Frage der Organisationsgewalt einbeziehen. Das aber würde dem hochpolitischen Moment "Organisationsgewalt" nicht gerecht werden und den Begriff selbst auflösen. 
P et ers-Köln:

Den beiden interessanten Referaten möchte ich in einigen wenigen Punkten widersprechen. Leider fehlt die Zeit, meine Darlegungen ausführlich zu begründen. Ich stehe im Ergebnis den Ausführungen von Herrn Köttgen erheblich näher als denen von Herrn Ermacora. Zunächst einmal müssen wir den zugrunde liegenden Begriff der "GesetzmäBigkeit der Verwaltung " klären. Er bedeutet im bundesrepublikanischen Bereich, $\mathrm{da} \beta$ die Verwaltung an die Gesetze gebunden ist, nicht aber, $\mathrm{da} B$ die Verwaltung sozusagen eine gesetzliche in dem Sinne ist, daB ihr alles gesetzlich vorgeschrieben sei, wie Herr Ermacora meint. Den Satz „keine Verwaltung im gesetzfreien Raum" halte ich für falsch. Ich bin nicht einmal der Meinung, daß sich der gesetzesfreie Raum etwa ständig vermindert. Er verringert sich für den Juristen $s \mathrm{ch}$ e in $\mathrm{b}$ a $r$, weil immer wieder neue Regelungen erscheinen. Aber es wächst unendlich viel jeden Augenblick der Verwaltung zu. Herr Weber hat eben ein paar Beispiele genannt. Wir brauchen ja bloß an die Atomaufgaben zu denken, die die Verwaltung neuerdings hinzu bekommen hat, - vorläufig ohne alle Gesetze - . So zeigt schon dies eine Beispiel, daß immer wieder neue Aufgaben ohne gesetzliche Regelungen an die Verwaltung herantreten.

Dann aber ein Zweites, das meiner Ansicht nach auch a priori berücksichtigt werden muß: Es liegt eine der großen Gefahren für den Rechtsstaat darin, daß man die Zahl der Gesetze noch mit der Forderung vermehrt, die Verwaltungsorganisation sowie alle neu auftretenden Aufgaben der Verwaltung müßten ge setzlich geregelt werden. Herrn Köttgen darf ich dabei zunächst in einem kleinen Punkte, den er wohl übersehen hat, korrigieren: Die Verfassung von Nordrhein-Westfalen stellt nicht die allgemeine Verwaltung in Gegensatz zur S p e z i a l verwaltung. Im Art. 77 ist gesagt, wenn die allgemeine Landesverwaltung, also wenn g e $\mathrm{n}$ e re 11 die Verwaltungsorganisation geändert wird, daß das durch Gesetz zu geschehen habe, also wenn z. B. die Regierungspräsidenten als Behörde generell abgeschafft werden. Wenn jedoch die Regierungspräsidenten von sechs auf zwei vermindert werden, dann wird nur die Einrichtung der Behörden im einzelnen verändert, und das kann die Verwaltung allein anordnen. „Allgemein" ist dort demnach im Sinne von "generell" (Zwischenbemerkung von Köttgen - unverständlich -) gebraucht. Wenn man alle Gewerbeaufsichtsbeamten als Behörden aufheben würde, wäre dazu - trotz der Spezialverwaltung - ein Gesetz nötig. 
Die Gefahr für den Rechtsstaat, die sich aus Herrn Ermacora's Forderung ergibt, liegt eben darin, daß eine Hypertrophie von Gesetzen entstehen muß. Endlich bin ich der Meinung, bei der Verwaltungsreform liege der Fehler, dessentwegen man hierbei nicht weiter kommt, darin, daß die Reformaufgaben primär betriebswirtschaftlich gesehen werden, daß also "rationalisiert" werden soll. Ich habe mich im Ausschuß für Verwaltungsvereinfachung bemüht - allerdings bisher ohne viel Erfolg dagegen zu wirken, und habe am Beispiel des Freiherrn vom Stein gezeigt, daß man so keine Verwaltungsreform machen kann. Verwaltungsreformen müssen vom Grundsätzlichen her aufgezogen werden: z. B. wollen wir den Perfektionismus der Verwaltung oder nicht? Wollen wir den Föderalismus stärken, oder wollen wir mit der Verwaltungsorganisation den Föderalismus schwächen?

Herr Weber hat eben eins meiner weiteren Bedenken schon anklingen lassen: Man sollte erst einige Begriffe klarstellen. Ich habe nicht den Eindruck, daß die Referenten in jedem Falle unter "Organisationsgewalt" das Gleiche verstanden haben. Sie, Herr Köttgen, haben einmal die Behördeneinrichtungen damit gemeint. Darin sind wir wohl einig. Dann aber auch das Dienstrecht. Dieses ist eine ganz wesentliche Frage zumindest der Organisation; ob aber auch der Organisations g ew a lt, ist zweifelhaft. Eine zweite Frage ist, wer das Zeichnungsrecht in der Behörde hat. Es ist für den Bürger wichtig, ob der politische Minister etwa eine Verfügung selbst zeichnet, oder ob es der Amtsrat oder der fachtechnische Beamte tut. Soll aber diese Frage nun etwa auch noch in den Bereich der Organisationsgewalt fallen und damit womöglich dem Parlament zur Regelung übertragen werden? Das geht doch nicht! Also wir müssen zunächst klar erfassen, - das kann ich jetzt nicht versuchen, weil es für die Diskussion zu schwierig ist -, was eigentlich alles zur Organisationsgewalt gehört. Ich bin persönlich der Meinung, daß es neben der allgemeinen Aufteilung zwischen den sogenannten Gewalten auch noch in $\mathrm{n}$ er h a l b der Verwaltung ein Stück Organisationsgewalt gibt; denn zu der Aufgabe, die die Exekutive hat, gehört m. E. auch, ihre Organisation intern zu regeln. Dem stimmen Sie, Herr Köttgen, und Herr Weber ja weitgehend zu mit dem Worte „Hausgewalt". Also diese Besonderheit müssen wir zunächst anerkennen. Dann aber geht es darum, die Organisationsgewalt weiter klar abzugrenzen von der Zuständigkeit. Art. 30 GG, den Sie nannten, und Art. 87 GG bestimmen meiner Ansicht nach nichts anderes als eine Zuständigkeitsabgrenzung zwischen Bund und Ländern. Sie setzen die Organisations- 
gewalt entweder voraus, oder, soweit der Art. 87 sagt, das und das müsse durch Gesetz geschehen, ist das nichts anderés als eine positivrechtliche Zuständigkeitsbestimmung zugunsten des Bundesgesetzgebers. Aber das ist nichts Prinzipielles über die Organiationsgewalt des Gesetzgebers seitens der Verfassung. Man muß also ganz klar trennen die Organisationsgewalt von der Zuständigkeit, wie man ja auch - das ist heute hier zum Ausdruck gekommen - auseinanderhalten muß die Organisationsgewalt und das Haushaltsrecht. Gewiß kann man in der Tat die Organisationsgewalt weitgehend lahmlegen, indem das Parlament die notwendigen Gelder nicht bewilligt. Aber das hat an sich mit der Organisationsgewalt als solcher nichts zu tun. Nun bedarf - wie ich glaube - die Organisationsgewalt einer verfassungsrechtlichen Legitimation überhaupt nicht. Ich bin allerdings so konservativ (oder so reaktionär?), hier auf die hergebrachte Lehre weitgehend zurückgreifen. M. E. hat die Exekutive im Rahmen der Verwaltung auch die Organisationsgewalt. Ich halte es für völlig unmöglich, daß jemand z. B. wegen der Einrichtung einer Krankenanstalt usw. den Gesetzgeber bemüht. Also: Der Inhaber der Exekutive hat die Organisationsgewalt und gleichzeitig das Recht, innerhalb seines Bereichs die Organisation zu gestalten, - wieder mit den althergebrachten Ausnahmen. Die Verfassung kann zunächst in concreto etwas anderes bestimmen, wie sie es ja oft genug tut. Der Gesetzgeber kann ferner eine Sache an sich ziehen; da das Prinzip der Gewaltenteilung nach dem Grundgesetz $\mathrm{m}$. E. nicht ausnahmslos gilt, könnte man diese Ausnahme nicht damit widerlegen, daß, weil die Organisationsgewalt innerhalb der Verwaltung zur Verwaltung gehört, eine Verletzung der Verfassung, nämlich des Gewaltenteilungsprinzips, darin liege, da $B$ sich der Gesetzgeber hier in die Exekutive einmische. Dieses Recht hat er. (Herr Friesenhàhn hat das gestern für andere Probleme auch ausgeführt.) Damit könnte also der Gesetzgeber auf einem bestimmten Gebiet die konkrete Organisation an sich heranziehen. Die gesetzliche Regelung wird im Rahmen der Eingriffsverwaltung häufiger sein als im Rahmen der Leistungsverwaltung. In letzterer ist das aber auch heute gar nicht mehr selten; denken Sie an das Gebiet der Sozialversicherung, wie organisatorisch fast alles durch die Reichsversicherungsordnung und das Selbstverwaltungs gesetz geregelt ist, oder an die entsprechenden Spezialgesetze z. B. über die Bundesanstalten in der Sozialversicherung. Ich enkenne also durchaus an, daB die Organisationsgewalt auch mal vom Gesetzgeber ausgeübt werden kann, aber eben nur, weil es 
keinen Verfassungssatz gibt, der das verbietet, so daß nun der Einfluß desjenigen einströmen kann, der stärker ist als die Verwaltung. Der Gesetzgeber kann auf diese Weise mit einer materiellen Regelung auch die zugehörige Organisation bestimmen. Trotzdem ist klar zu differenzieren: materielle Regelung und Organisation sind verschiedene Dinge. Daher kann man auch nicht irgendwie von der Materie her unterscheiden, indem auf gewissen Gebieten der Gesetzgeber die organisatorischen Vorschriften treffen müsse, im übrigen die Exekutive. Die enge Verbindung zwischen der materiellen und organisatorischen Regelung wird sehr häufig dazu führen, daß der Gesetzgeber in dem ihm verfassungsrechtlich gegebenen Raum - z. B. der Bundesgesetzgeber etwa nach Art. 87, der Landesgesetzgeber in seinem eigenen Raum - auch Dinge an sich zieht, die die Organisationsgewalt betreffen und daher sonst grundsätzlich der Exekutive zustehen.

Damit komme ich auch zu dem Ergebnis: Es gibt für die Organisationsgewalt im Prinzip keinen Unterschied zwischen Eingriffsverwaltung und Leistungsverwaltung. Die Verschiedenheiten sind einfach opportunistisch aus der Praxis entwickelt. Ich glaube, daß es gerade im Sinne des Rechtsstaats liegt, den Gesetzgeber nicht noch weiter zu überfordern. Die Flut der Gesetze schädigt den Rechtsstaat auf das schwerste. Jeder, der irgendwo über Reform redet, klagt schon heute, daß zu viele Gesetze gemacht werden. Wenn man jetzt noch dadurch, daß mit mehr oder weniger vagen Konstruktionen meinetwegen oder auch aus einer angeblichen inneren Logik heraus für den Gesetzgeber die Regelung der Organisation in Anspruch genommen wird, dann kommt man - meiner Ansicht nach - auf solche Abwege, die geradezu den Rechtsstaat untergraben. Die Beispiele, die Herr Ermacora aus der österreichischen Praxis genannt hat, - ich glaube nicht, daß sie sich selbst zur Nachahmung empfehlen. Das Parlament baut sich auf den politischen Parteien auf. Die Verwaltungsorganisation läuft dann Gefahr, nach der Stärke der Parteien nicht bloß formal - aufgeteilt zu werden. Gerade diese naheliegende Möglichkeit scheint mir zu beweisen, daß der Gesetzgeber zur Ausübung der Organisationsgewalt vernünftigerweise kaum in der Lage ist. Man sollte ein Staatsorgan nicht in die Lage versetzen, Aufgaben zu erfüllen, die ihm nicht gemäß sind -, bloß aus einer Theorie heraus, die auf den ersten Blick vielleicht ganz einleuchtend ist, die aber große Gefahren mit sich bringt. 
M e rk - Tübingen:

Ich kann mich nach den Ausführungen der Herren Weber und Peters kurz fassen. Ich bin im Gegensatz zu anderen Meinungen nach wie vor der Auffassung, daß die sogenannte Einrichtungsgewalt (oder Organisationsgewalt) an sich Ausfluß der vollziehenden Gewalt ist und insofern keiner besonderen verfassungsrechtlichen oder gesetzlichen bzw. gewohnheitsrechtlichen Grundlage bedarf, soweit nicht etwas anderes in der Verfassung oder im Gesetz in dieser Hinsicht bestimmt ist oder sich aus sonstigen Gründen ergibt. Grundlage ist die Aufgabe der vollziehenden Gewalt, $d$. h. der Regierung und der Verwaltung, und das besondere Gewaltverhältnis, wie es insbesondere im Beamtenverhältnis gegeben ist. Nur dort, wo durch die Handhabung der Einrichtungsgewalt unmittelbar in den Rechtskreis der Bürger, insbesondere durch die Auferlegung von Pflichten, eingegriffen oder eine Erweiterung oder Änderung der in der Verfassung oder im Gesetz bestimmten obrigkeitlichen Befugnisse des Staates in Frage kommt, wie z. B. auch mittels Einrichtung neuer obrigkeitlicher Ämter oder Behörden sowie mittels Einrichtung staatsunmittelbarer öffentlichrechtlicher Körperschaften und Anstalten, bedarf es einer gesetzlichen Grundlage, von der gewohnheitsrechtlichen Grundlage hier abgesehen. Daß durch die bloße Bestimmung der Zuständigkeit von Behörden oder Ämter die Rechtsstellung der Bürger "berührt" wird, wie z. T. gelehrt wird, genügt m. E. nicht. Es kann also die vollziehende Gewalt hier von sich aus vorgehen, soweit gesetzlich nichts anderes sich ergibt. Ein Regierungspräsident kann so z. B. wenn gesetzlich oder durch Dienstvorschriften vorgesetzter Behörden nichts darüber bestimmt ist, seine Behörde innerlich in Abteilungen usf. gliedern, wie er es für zweckmäßig findet, und ebenso kann die vollziehende Gewalt, unbeschadet der haushaltsrechtlichen Beschränkungen, neue Stellen schaffen, wenn, wie gesagt, es sich nicht um eine Erweiterung oder Änderung der Hoheitsbefugnisse der öffentlichen Gewalt oder einen unmittelbaren Eingriff in den Rechtskreis der Bürger handelt. Ein Ausfluß der gesetzgebenden Gewalt liegt bei der Betätigung der Einrichtungsgewalt nicht vor, da es sich nicht um den Erlaß von Gesetzen im sachlichen Sinne, d. $h$. von Rechtsätzen, handelt und so scheidet auch der rechtsstaatliche Gesichtspunkt hier aus, da und sofern ein unmittelbarer Eingriff in Freiheit und Eigentum der Bürger nicht in Frage steht. So ist $\mathrm{m}$. E. die Rechtsauffassung, die schon die preußische Staatsregierung im Jahre 1869 in einer grundsätzlichen Stellungnahme zu dieser Frage im preußischen Landtag 
abgegeben hat, im wesentlichen auch heute noch als zutreffend anzuerkennen. Ich lehne hiernach die Auffassung ab, daß die Einrichtungsgewalt als solche an sich einer besonderen gesetzlichen oder gewohnheitsrechtlichen Grundlage bedarf. Gewiß, die vollziehende Gewalt bedarf im volksherrschaftlichen Freistaat und sozialen Rechtsstaat mit Gewaltentrennung einer rechtlichen Grundlage für ihre Tätigkeit in der Verfassung oder im Gesetz. Aber diese Ermächtigung für die Aufgaben der vollziehenden Gewalt und ihre Betätigung kann nach deutschem Recht auch ganz allgemein gehalten sein; dadurch unterscheidet es sich vom österreichischen Recht, wo die gesamte staatliche Verwaltung nur auf Grund der Gesetze ausgeübt werden darf, d. h. sie für jede Art ihrer Betätigung, und so auch auf dem Gebiete der Einrichtungsgewalt, der besonderen gesetzlichen Grundlage bedarf. Allerdings zeigt sich in der neueren Zeit, daß die gesetzgebende Gewalt auch abgesehen von dem haushaltsrechtlichen Erfordernis der Bewilligung der für die Einrichtung neuer Ämter und Behörden erforderlichen Mittel durch die Volksvertretung mehr und mehr, auch wegen der Bedeutung der Einrichtung von Behörden und Ämtern für die Bürger, Regelungen auf diesem Gebiete vornimmt, wie das ja auf dem Gebiete des Gerichtswesens schon im GVG und in den Verfahrensgesetzen geschehen ist; das hat dort noch seine besondereBedeutung wegen des sogenannten "gesetzlichen Richters", dem nach Art. 101 GG niemand entzogen werden darf. Dann kann die Einrichtungsgewalt der vollziehenden Gewalt nur noch in diesem Rahmen, soweit ein solcher überhaupt noch verbleibt, ausgeübt werden. So finden sich jetzt verschiedentlich ausdrückliche verfassungsrechtliche Vorbehalte bezüglich der Einrichtungsgewalt. Das GG hat bekanntlich in Art. 86 GG die Einrichtungsgewalt im Bunde der Bundesregierung zugesprochen im Gegensatz zur Zeit des Kaiserreichs, wo sie dem Kaiser, und zur Weimarer Zeit, wo sie dem Reichspräsidenten für das Reich zustand. So ist dann in Art. 87 Abs. 3 GG im Verhältnis zwischen Bund und Ländern bestimmt, daß für Angelegenheiten, für die dem Bund die Gesetzgebung zusteht, selbständige Bundesoberbehörden und neue bundesunmittelbare Körperschaften und Anstalten des öffentlichen Rechts durch Bundesgesetz, und, wenn dem Bunde auf Gebieten, für die ihm die Gesetzgebung zusteht, neue Aufgaben erwachsen, bei dringendem Bedarf bundeseigene mittlere und untere Behörden mit Zustimmung des Bundesrats und der Mehrheit der Mitglieder des Bundestags errichtet werden können. Namentlich aber möchte ich hinweisen auf Art. 70 der neuen Bad.-Württ. Verfassung, 
wonach der Aufbau, die räumliche Gliederung und die $\mathrm{Zu}$ ständigkeit der Landesverwaltung durch Gesetz geregelt wird, die Einrichtung der staatlichen Behörden im einzelnen aber der Regierung oder den von ihr ermächtigten Ministern obliegt. Aber bei diesen sogenannten Einrichtungsgesetzen handelt es sich nach dem früher Gesagten um Gesetze im bloß förmlichen, und nicht im sachlichen Sinne, soweit nicht die oben angeführten zwei Ausnahmefälle gegeben sind. Danach sind die Einrichtungsvorschriften z. T. Verwaltungsvorschriften - Einrichtungsverordnungen - oder Gesetze im bloß förmlichen Sinne, oder aber sachlichrechtliche Vorschriften oder Rechtssätze, nämlich in den eben bezeichneten Ausnahmefällen.

\section{K r üg e r-Hamburg:}

Herr Köttgen hat das Thema "Organisationsgewalt" in Parallele gestellt zu dem Besonderen Gewaltverhältnis und der Unterscheidung zwischen Rechtsverordnung und Verwaltungsanweisung, und er hat demgemäß auch die Angriffe gegen diese drei Institute auf eine gemeinsame Wurzel zurückgeführt. Die Gemeinsamkeit aller drei Gebilde - und damit auch die Gemeinsamkeit der Ursache, die ähnliche Angriffe gegen sie auslöst - , liegt offenbar darin, daß es sich um voroder außerkonstitutionelle Bestände handelt. Die Auseinandersetzung mit der Organisationsgewalt hat gezeigt, daß es sich insoweit überall um das gleiche Problem dreht -, nämlich um die Aufgabe, diese vorkonstitutionellen Bestände in das konstitutionelle Staats-Schema einzuordnen und sie durch solche Einordnung zugleich zu rechtfertigen. Gerade das aber ist es, was offenbar in allen drei Fällen nicht recht gelingen will. Zwar hat heute Herr Ermacora einen Versuch gemacht, die Organisationsgewalt als einen Bestandteil der Staatsgewalt zu erweisen. Das ist natürlich völlig richtig, besagt aber noch nichts für eine v e r $f$ a $B$ te Staatsgewalt und ergibt erst recht keine Placierung der Organisationsgewalt in einem System der Gewaltenteilung.

Wenn man - womöglich vergeblich - nach der Stellung dieser vorkonstitutionellen Bestände im konstitutionellen Schema fragt, so entspringt eine solche Frage nicht der Absicht, diese Bestände als unkonstitutionell zum Verschwinden zu bringen. Es handelt sich also insbesondere nicht darum, die Verwaltung einer Handlungsfähigkeit zu berauben, die weitgehend auf den Möglichkeiten beruht, die diese vorkonstitutionellen Bestände ihr bieten. Genau das Gegenteil trifft vielmehr zu: Es geht darum, die Handlungsfähigkeit der Verwal- 
tung zu erhalten, indem man die bis jetzt von den vorkonstitutionellen Beständen dargebotenen Mittel ins Bewußtsein emporhebt, modern versteht und sich dadurch in die Lage versetzt, sie erfolgreich verteidigen zu können.

Es ist mit Recht hervorgehoben worden, daß es sich hierbei in erster Linie um ein Problem der Grenzziehung handelt. Man kann aber dann nicht von einer Grenzziehung sprechen, wenn man zwei, etwa die Organisationsgewalt beanspruchende Größen wie z. B. die Gesetzgebung und die Verwaltung einander idergestalt zuordnet, daß man der ersten eine unbegrenzte Option auf die Organisationsgewalt zuspricht und die zweite Größe auf das verweist, was nach der Ausübung solcher Option übriggeblieben ist. Ein solches Vongehen könnte man selbst dann nicht gelten lassen, wenn man hinzufügen würde, es müsse auf jeden Fall für den zweiten Falktor nach der Option noch etwas übrigbleiben, er dürfe also nicht ganz leer ausgehen. Eine echte Grenzziehung kann nicht in die Hand eines der zu begrenzenden Faktoren gelegt werden, sie muß vielmehr von dritter Seite her erfolgen, und hierbei wird entscheidend auf die vorgegebenen Sachstrukturen abzuheben sein.

Versucht man im Sinne des letzten Gesichtspunktes einige Andeutungen, dann ist vor allem hervorzuheben, daß es sich bei der Organisationsgewalt um eine formelle Gewalt im Verstande der fruchtbaren Unterscheidung zwischen materiellen und formellen Gewalten handelt, die bis in die Mitte des vergangenen Jahrhunderts gang und gäbe war. Formelle Gewalten sind diejenigen rechtlichen Möglichkeiten, deren die materiellen Gewalten bedürfen, um sich zu verwirklichen. So bedarf z. B. die Rechtsetzung durch das Parlament der Organisationsgewalt, um ein Präsidium zu konstituieren usw. usw. Die Rechtsanwendung benötigt die Organisationsgewalt um der Instituierung der Gerichte willen usw. usw. Das entsprechende gilt für eine als materielle Gewalt verstandene Verwaltung.

Es wäre die Frage zu stellen, ob für die formellen Gewalten nicht deswegen von einer Grundlage in der Verfassung oder im Gesetz abgesehen werden muß, weil sie eine derartige Grundlage bereits in derjenigen der materiellen Gewalt haben, der sie zur Verwirklichung verhelfen. Auf jeden Fall reicht auch eine solche mittelbare Grundlage aus, um die Möglichkeit auszuschließen, da $\beta$ die gesetzgebende Instanz unter Berufung auf den Vorbehalt des Gesetzes organisatorische Fragen regelt, wenn die entsprechende Organisationsgewalt der Natur der Sache nach einer anderen materiellen Gewalt zugeordnet ist. Etwas derartiges könnte als Ausnahme nur 
dann als̉ zulässig angesehen werden, wenn die gesetzgebende Gewalt eine besondere Ermächtigung zu einer solchen Evokation vorweisen könnte: Es ist nicht einzusehen, weshalb nur die Verwaltung einer Ermächtigung bedürfen sollte, wenn sie statt der Gesetzgebung Recht setzt, und das entsprechende nicht für die Gesetzgebung gelten sollte, wenn sie organisatorische Fragen an Stelle der Verwaltung entscheiden will.

Gerade das letzte läßt deutlich werden, worum es der Beschäftigung mit den vorkonstitutionellen Beständen geht: In dem großen Zusammenwirken der materiellen Gewalten der Verwaltung das zu geben, was ihr gerade in einem Verwaltungs- und Wohlfahrtsstaat zukommt.

\section{S p a n n e r - Erlangen:}

Herr Köttgen war heute morgen so freundlich, einleitend auf meinen kleinen Aufsatz in der "Offentlichen Verwaltung"1) hinzuweisen, wobei er freilich erklärte, daß er von meinen dort vertretenen Auffassungen grundsätzlich abweiche. Ich muß gestehen. daß mich dies durchaus gefreut hat, insbesondere auch im Sinne des gestern von Herrn Friesenhahn geäußerten Wunsches, $\mathrm{da} B$ in der Diskussion mitunter auch größere Gegensätzlichkeiten $z u$ Tage treten mögen.

Nun möchte ich aber doch einige Auffassungen aus diesem um einen Ausdruck von Herrn Giese hier zu verwenden vorweggenommenen Diskussionsbeitrag nochmals unterstreichen, zumal sie zusammenhängen mit einer Feststellung, die ich gestern nachmittag im Schlußwort machen durfte. Das ist wiederum die Methodenfrage, auf die auch jetzt mehrfach in dieser Diskussion bereits hingewiesen worden ist. Es will mir nämlich scheinen, daß die Referate des heutigen Vormittags wieder die Notwendigkeit der Besinnung auf die Methodenfrage deutlich werden ließen. Insbesondere im Referat von Herrn Köttgen haben wir mehrere Methoden nebeneinander beobachten können. Ich darf hier nicht ausgehen von der Fiktion, daß vorweggenommene Diskussionsbeiträge in einer Zeitschrift bereits gelesen worden wären und möchte daher darauf hinweisen, daß ich damals schon gesagt habe, daß für die umfassende Erkenntnis der Fragen der Verwaltung und damit auch der Verwaltungsorganisation eine Betrachtung

1) "Organisationsgewalt und Organisationsrecht" (DOV 1957, S. 640 ff.). Im letzten Absatz (S. 634) findet sich übrigens dort ein sinnstörender Druckfehler, indem es statt „Abschaffung einer das Verfahren der Verwaltungsbehörden regelnden gesetzlichen Ordnung" selbstverständlich heißen muß „S c h a f f u n g einer . . .". 
sowohl des Tatsachenbereiches, damit auch des rechtspolitischen Bereiches und andererseits des rein normativen Bereiches notwendig ist, wobei man allerdings dann leicht der Gefahr einer gewissen methodologischen Vermischung unterliegt. Ich möchte aber auf diese Methodenfrage hier nicht weiter eingehen, da sie in Zukunft doch einmal auf die Tagesordnung unserer Tagungen gesetzt werden soll.

Ich möchte aber besonders ein Wort von Herrn Krüger unterstreichen, als er von der Notwendigkeit einer juristischen Sanierung gesprochen hat, die mir auch gerade in diesem $\mathrm{Be}-$ reich notwendig erscheint. Herr Ermacora hat darauf hingewiesen, da $B$ durch die Lehren von Kelsen der Blick für das, was hinter den organisatorischen Maßnahmen steht, vielfach getrübt worden sei. Das mag insofern richtig sein, als man sich mit diesen Dingen wohl etwas zu wenig befaßt hat, zumindest was die österreichische Rechtslehre anlangt. Im übrigen liegen aber tatsächlich die Wesensprobleme dessen, was wir als Organisationsgewalt bezeichnen, vielfach im politischen Bereich, was in den Referaten sehr deutlich geworden ist, so da $B$ hier eine Betrachtung dessen, was hinter den Normen steht, gar nicht vermieden werden kann und soll.

Von besonderer Bedeutung ist die Frage, die, wie mir scheint, durch die Referate und die bisherige Diskussion nicht zufriedenstellend beantwortet werden konnte: Das ist die Frage, wo eigentlich die einwandfreie Rechtsgrundlage für das gelegen ist, was wir Organisationsgewalt nennen. Wir haben da gehört von einem „Hausgut" der Verwaltung. Dann wurde gelegentlich - das war natürlich schon sehr juristisch - auf Gewohnheitsrecht verwiesen. Ich für meinen Teil bï nicht in der Lage, den Begriff des Hausgutes als eine neue Rechtsquelle anzuerkennen. Ich meine jedoch, daB, wenn von der Organisationsgewalt und in Zusammenhang damit von einem Hausgut der Verwaltung oder von notwendigen Befugnissen der Verwaltung gesprochen wird, dies letzten Endes alles Versuche sind, eine einwandfreie Rechtsgrundlage $z u$ finden. Es geht auch mir nicht darum, nummehr der Verwaltung etwas zu nehmen, sondern nur darum, eine einwandfreie Rechtsgrundlage für die organisatorischen Maßnahmen in der Rechtsordnung zu finden, wie sie dem rechtsstaatlichen System entspricht. Es ist vielfach die Rede gewesen von einer Verwaltung im gesetzesfreien Raum. Ich meine, das ist doch in Wahrheit nichts anderes als ein Bereich freien Ermessens der Verwaltung. Eine staatliche Verwaltung in einem völlig rechtsfreien Raum gibt es nicht, denn es muB zumindest eine Zuständigkeitsnorm da sein, die es ermöglicht, die Maßnahmen, die der 
Herr Schulze oder Meier oder die ein Kollegium getroffen hat, als eine Maßnahme des Staates oder eines anderen Trägers von Verwaltungsaufgaben zu erkennen und gelten zu lassen.

Und schließlich noch ein Wort zu dem Begriff der Organisationsgewalt überhaupt: Ich glaube, da $B$ man unter der Organisationsgewalt nichts anderes verstehen kann, als eine $\mathrm{Zu}$ sammenfassung der Kompetenzen, organisatorische Maßnahmen zu treffen, mögen diese Kompetenzen dem Gesetzgeber zustehen oder mögen sie der Verwaltung zukommen. Wenn Herr Peters von der Gefahr gesprochen hat, daß wir auch im organisatorischen Bereich zu viele Gesetze bekommen, so meine ich, daß nichts den Gesetzgeber, noch weniger den Verfassungsgeber hindert, seinerseits der Verwaltung für die Maßnahmen, für die es eben notwendig erscheint, einen weit gespannten Bereich freien Ermessens einzuräumen. AbschlieBend sei aber nochmals betont, daB der Verwaltung keineswegs etwas genommen, sondern ihr auch für organisatorische Maßnahmen nur eine einwandfreie Rechtsgrundlage gegeben werden soll, wie sie dem rechtsstaatlichen System entspricht, so daß sie nicht immer wieder gezwungen wird, auf einer mehr oder meist weniger begründeten Grundlage zu arbeiten, die aus dem vergangenen Rechitssystem des absoluten Staates stammt.

I p s e n-Hamburg:

Es trifft sich glücklich, daß ich sogleich im Anschluß an Herrn S p a n n e r sprechen kann, der die Forderung aufgestellt hat, wir müßten uns um die Ermittlung einer sauberen Rechtsgrundlage der Organisationsgewalt bemühen. Ich halte diese Wendung für einen Widerspruch in sich. Nach meiner Auffassung besteht das Wesen der Organisationsgewalt, wenn ihre Erscheinung einen Sinn behalten soll, darin, daß sie eben keine Rechts g r undlage besitzt, sondern fließt aus der inneren Aufgabe, der - ich bin beinahe geneigt zu sagen - Mission der Verwaltung, sich überhaupt zu betätigen. Wenn wir daran gehen, für die Organisationsgewalt Rechts grundlagen zu ermitteln, fügen wir sie in ein Legalisierungsnetz ein, das der Organisationsgewalt das Wesentliche nimmt. Organisationsgewalt ist sicherlich in jedem Verfassungsstaate rechtsstaatlich gebunden, es gibt Grenzen, innerhalb deren jede Verwaltung ihre Organisationsgewalt wahrzunehmen hat, und wenn sie diese Grenzen verläßt und dadurch möglicherweise die Rechte einzelner verletzt, überschreitet sie damit Grenzen, die auch justiziabel sein können. Aber die Innehabung der Or- 
ganisationsgewalt durch die Verwaltung wird $\mathrm{n}$ i $\mathrm{ch} \mathrm{t}$ durch die Norm begründet, sondern nur begrenzt und be$\mathrm{s} \mathrm{chränkt}$. Und aus diesem Grunde - ich bin ja gestern zum Begriffsjuristen „befördert" worden - will ich auch zu diesem Thema der Begriffsbildung meinen Beitrag leisten

Ich bin nicht der Meinung, da $\beta$ die Organisationsgewalt in dem Augenblick, in dem sie durch Normen parlamentarischen Einrichtungen überantwortet wird, noch dasselbe bleibt, was sie vorher war. Das, was die Verwaltung kraft Organisationsgewalt tut, bleibt nicht dasselbe, wenn es kraft ausdrücklicher gesetzlicher Zuweisung durch das Parlament getan wird. Durch eine solche Legalzuweisung gibt diese Kompetenz ihren Wesensgehalt auf und wird damit eine Befugnis des Parlaments, die wir mit dem Namen "Organisationsgewalt" nicht mehr bedenken sollten. Aus diesem Grunde möchte ich auch Bedenken anmelden zu der These IV 2, die Herr Köttgen entwickelt hat, nämlich für den Zusammenhang des Beamten- und Angestelltendirektionsrechtes mit der Innehabung der Organisationsgewalt. Es heißt in dieser These: Die Wechselwirkungen zwischen Dienstrecht und Organisationsgewalt bedürfen besonders sorgsamer Beobachtung. Wenn wir etwa in der jetzigen Entwicklung des Personalvertretungsrechts erleben, daß Stellen außerhalb der Verwaltung befugt sind, in Kompetenzen mitzuwirken, die bis dahin der Organisationsgewalt ungeschmälert zustanden, dann handelt es sich bei diesen Mitwirkungsbefugnissen von Organen, die selbst nicht Verwaltung sind, um durch Normen eingeräumte Befugnisse, die ihrerseits durch die Normierung sorgfältig umgrenzt sind. Wenn ein Personalrat im Bereich der Verwaltung auf diese Weise mitzuwirken befugt ist, dann we chselt nicht einfach der In haber dieses Teils der Organisationsgewalt, sondern diese Befugnis in Händen der Mitwirkungsinstanzen ist anderer Natur als die Organisationsgewalt, die der Verwaltung zusteht. Ob wir hier die Wendung vom "Hausrecht" der Verwaltung gebrauchen wollen oder ob wir im verfassungsgeschichtlichen Vorspann bis in die Mitte des vorigen Jahrhunderts zurückgehen, dürfte unerheblich sein. Wesentlich ist mir für unsere Begriffsbildung - und das wird uns möglicherweise von unseren österreichischen Kollegen unterscheiden, wenn ich die Bemerkung von Herrn Spanner und das Referat von Herrn E r macor a recht verstehe - : nach den Vorstellungen des deutschen Verwaltungsrechits ist die Organisationsgewalt der Verwaltung etwas, was ohne Legalisierung im Sinne einer B e gründung dieser Kompetenz der Verwaltung aus ihrer Aufgabe ursprünglich zusteht. 
Diese Kompetenz der Verwaltung in rechitsstaatlichen Grenzen zu bewahren, ist mir allerdings ebenso ein Anliegen, wie es nach seinen letzten Worten ein Anliegen von Herrn Krüger ist.

\section{Pf eifer-Wien:}

Die Auffassungen sind, das steht schon fest, geteilt über die Frage, die hier den Gegenstand des zweiten Referates gebildet hat, und sie sind irgendwie vielleicht historisch geteilt, weil sich hier und dort auch die Verfassung anders entwickelt hat. Mir scheint folgendes wesentlich zu sein: Wenn man sich die Entwicklung des Rechtsstaates vom absoluten Staat bis zur Gegenwart vorstellt, so habe ich da immer in der Vorlesung verschiedene Entwicklungsstufen unterschieden, habe da unterschieden die dem absoluten Staat unmittelbar nachfolgende Epoche des liberalen Rechtsstaates. Diese schien mir irgendwie gekennzeichnet durch die Auffassung, wie wir sie etwa bei O t to $\mathrm{M}$ a yer in seinem Lehrbuch des Deutschen Verwaltungsrechts finden, und zu deren Charakterisierung etwa folgender Satz herausgegriffen sein soll: „In der Verwaltung aber begegnet das Gesetz einem auf eigenen Bahnen einhergehenden Staatswillen, der nicht bloß dient, sondern selber herrscht, von mehr oder minder hoher Stelle aus und selber frei bestimmen mag, was rechtens sein soll oder nicht. Hier tritt dann selbständig zu Tage, was dort stillschweigend gilt: Der in Form des Gesetzes geäußerte Staatswille geht rechtlich jeder anderen Staatswillensäußerung vor." Das nennt Otto Mayer den V or r a ng des Gesetzes. Dann kommt er noch zu dem Vorbehalt des Gesetzes und sagt: „Wir nennen den Ausschluß des selbständigen Vorgehens der vollziehenden Gewalt, der bezüglich jener ausgezeichneten Gegenstände" — das sind die Grund- und Freiheitsrechte - „besteht, den Vorbehalt des Gesetzes." Das ist nun so der Typus des liberalen Rechtsstaates, in dem man die Verwaltung noch selbstherrlich auf eigenen Bahnen walten läßt, dann aber sagt: Du, Staatsbürger, du hast einige vorstaatliche Grund- und Freiheitsrechte, und wenn in diese eingegriffen werden soll, dann gilt der Vorbehalt des Gesetzes.

Aber ich glaube, daß wir schon längst weiter sind, und daß diesem liberalen Rechtsstaat, wie er da geprägt ist durch diese Sätze von Otto Mayer, längst eine weitere Periode gefolgt ist, die Periode des demokratischen Rechtsstaates, jenes Rechtsstaates, in dem das Gesetz des Parlamentes alles Grundsätzliche regelt, und in dem die Verwaltung an den Willen dieses demokratischen Gesetzgebers gebunden ist und diesen nur ausführen kann. Das hängt auch zusammen mit dem Thema von 
gestern "Parlament und Regierung", in dem wir hier im Parlament den Gesetzgeber sahen. Auch wenn wir nach der Diktion, in den Verfassungen aber auch in der Staatslehre, die Gewalten unterscheiden, und von der gesetzgebenden Gewalt und dann von der vollziehenden Gewalt oder Exekutive sprechen, so ist mit dieser in der Regel nur die Verwaltung gemeint, im österreichischen Staatsrecht allerdings Verwaltung und Gerichtsbarkeit, da sie beide die dienende Rolle gegenüber dem Gesetz haben, aber so oder so, es kommt zum Ausdruck, daß eben nicht so, wie Otto Mayer es sagte, die Verwaltung noch selbstherrlich auf eigener Bahn einhergeht, sondern daß sie Dienerin ist gegenüber dem Willen des Volkes, wie er im Gesetz ausgeprägt ist. Das ist der demokratische Rechtsstaat, er hat seinen Ausdruck gefunden in dem von Herrn Kollegen E r m a c o r a schon erwähnten Satz der demokratischen österreichischen Verfassung von 1920, der da sagt: "Die gesamte staatliche Verwaltung darf nur auf Grund der Gesetze ausgeübt wenden."

Gewiß, das ist das, was der Herr Kollege Pet e rs ausgeschlossen haben wollte, wenn er sagte, „es muß auch eine gesetzesfreie Verwaltung geben". Nach unserer Auffassung gibt sie es nicht. Und Herr Kollege S p a n n e r hat es schon etwas näher erläutert,das muß ja gar nicht sehr weit gehen, das muß ja gar nicht in Einzelheiten gehen, es kann eine Zuständigkeitsnorm schon genügen, die im übrigen der Verwaltung größten Spielraum läßt. Das ist dann schon der nähere Inhalt der Gesetzgebung, wie weit sie gehen will in der Regelung und Reglementierung, die sie der Verwaltung geben will. Aber - ich meine - der Grundsatz ist: Verwaltung ist Vollziehung des gesetzgeberischen Willens.

Wenn wir nun zur Organisationsgewalt übergehen, so handelt es sich hier um das Recht, um die Befugnis, Verwaltungseinrichtungen zu schaffen und ihre Zuständigkeit abzugrenzen. Was für Verwaltungseinrichtungen geschaffen werden sollen, wie diese sein sollen, ob sie von Juristen oder von Laien besetzt werden sollen, ja, das sind grundsätzliche Angelegenheiten. Die hat sich naturgemäß der Gesetzgeber vorbehalten. Und hier muß ich sagen, daß, in die Verfassungsgeschichte zurückgegriffen, in Österreich schon beim Übergang vom absoluten Staat zum konstitutionellen Staat die klare Erkenntnis bestand, daß das Grundsätzliche der Organisation und damit der Organisationsgewalt in die Hand des Gesetzgebers gehört. Denn schon das Staatsgrundgesetz über die Reichsvertretung von 1867 hat in seinem Art. 11 unter Aufzählung der Aufgaben des Reichsrates gesagt, „Es gehören daher zum Wirkungskreis 
des Reichsrates: 1 . die Gesetzgebung über die Grundzüge der Organisierung der Gerichte und Verwaltungsbehörden". Und es hat das Staatsgrundgesetz über die richterliche Gewalt noch darüber hinausgehend gesagt: „Die Organisation und Kompetenz der Gerichte wird durch Gesetz festgestellit." Die österreichische Verfassung von 1867 ließ also noch immer einen weiten Spielraum für die Gesetzgebung und für die Vollziehung offen.

Die Verwaltung hat zu vollziehen. Meine Herren, auch die Durchführungsverordnung, die ein Gesetz näher ausführt, ist Vollziehung. Es kann sich das Gesetz darauf beschränken, die Verwaltungsorganisation in ihren Grundzügen zu regeln, zu sagen, wir wollen allgemeine Verwaltungsbehörden, diese und diese Sonderverwaltungsbehörden, wir wollen so und so viele Stufen der Verwaltung haben, weil dies zugleich den Rechtszug betrifft. Und damit wird auf Schritt und Tritt auch dieRechtsstellung des einzelnen, der bei der Verwaltung sein Recht sucht, irgendwie mitgeregelt. Man kann also gar nicht immer scharf trennen: materielle Gesetzgebung - organisatorische Gesetzgebung, - ich weiß, daß es eine gewisse Kühnheit ist, wenn man das sagt. Das materielle Gesetz bedeutet eine grundsätzliche Regelung des Gemeinschaftslebens. Diese liegt aber auch vor, wenn ich ein Organisationsgesetz schaffe. Lassen Sie mich schließen mit dem Hinweis darauf, daß unser wichtigstes Gesetz, die Verfassung - vom Grundrechtsteil abgesehen -, ein Organisationsgesetz ist, und da $B$ dieses Organisationsgesetz von Haus aus und unbestritten von einem qualifizierten Gesetzgeber, nämlich dem Verfassunggeber, geschaffen wunde.

S c u p i n-Münster:

Es ist eine Nebenfrage, die ich hier anschneide, wenn ich auf das zurückkomme, was Herr Kollege Weber vorhin schon gesagt hat, als er davon sprach, daß die Entstehung einer Organisationsgewalt in einer "grauen Sphäre" etwas Bedenkliches sei und gerade dadurch hervorgerufen werde, daß man der angestammten Verwaltung ihr ursprüngliches Recht beschneide. Ich stimme ihm darin nachdrücklich zu und möchte nun Folgerungen daraus ziehen, die Herr Weber noch nicht gezogen hat. Es gibt hier doch Gesichtspunikte, die auch an dieser Stelle genannt wenden sollten, denn: nostra res agitur! Ich meine die Maßnahmen nach dem sog. „Honnefer Modell“ als potentielle Grundlage einer Funktions- und Strukturveränderung der Hochschule und ihrer Glieder. Dieser Ansatz zur Wandlung geschieht dadurch, daß Sozialeinrichtungen geschaffen werden, 
die an feste Voraussetzungen geknüpft sind und aus denen ganz bestimmte Folgen hervorgehen, mit anderen Worten, die Veränderungen vollziehen sich durch das, was uns in der Bundesrepublik als die Anfänger- oder die Hauptfönderung nach dem sog. Honnefer Modell bekannt und sogleich zu erläutern ist. Ich glaube, daß das ein recht instruktives Beispiel für die Bildung von Organisationsgewalt ahne gesetzliche Grundlage und außerhalb der Hierarchie der Exekutive darstellt.

Dabei ist eines zunächst zu betrachten: die Frage der Kontrolle der Organisationsgewalt. Herr Kollege Ermacora hat das noch nicht ausgeführt, aber es ist dennoch wohl kein störender Vorgriff, daß ich in dieser Spezialfrage bereits darauf komme; denn hier gibt es eine solche Kontrolle eben nicht. Wenn Herr Weber vorhin auf die Generalklausel der Verwaltungsgerichtsbarkeit hingewiesen und dazu gesagt hat, im Verwaltungsstreitverfahren könne ja nur nachträglich etwas korrigiert werden, zum Leidwesen der Betroffenen könne also nichts vorher, d.h. zur Verhinderung unrichtiger Verwaltungsakte getan werden, so muß man für das neue Feld exekutiven Wirkens feststellen: Hier gibt es gar nichts dergleichen, hier fehlt der Schutz des Rechts. Das aber ist bedenklich, insbesondere dann, wenn ganz unkontrolliert eine Leistungsverwaltung geschaffen wird. Ohne hier auf Einzelheiten eingehen zu wollen, was nicht am Platze wäre, möchte ich eine institutionalisierte Eingriffsmöglichkeit der neu geschaffenen Stellen herausgreifen: Diejenige Universität oder Hochschule, die $\mathrm{n}$ i $\mathrm{ch}$ t folgsam wäre, würde durch entsprechende Zahlungssperre gekennzeichnet. Würde man sich an das Geforderte genau halten, so würde die Lage kritisch werden, Prüfungen dieser Art würden Wochen des Semesters kosten. Wenn man aber Prüfungen nicht kollegial durchführt oder wenn man ferner nicht die Utbungen und Seminare herabwündigt zu Leistungskontrolleinrichtungen in der Richtung, ob der betreffende Student weiterhin förderungswündig sei - das ist die andere kritische Zumutung des Honnefer Modells -, wenn man das also nicht tut, dann bekommt man nichts. Allerdings die Universität selbst soll schon dem Plane nach nichts erhalten, aber das Studentenwerk an der dissentierenden Universität sollte es bekommen; auch ihm wird dann nichts gezahlt. Das Ergebnis ist: In den Augen der Offentlichkeit trifft die Verantwortung dafür, daß diese Gelder nicht fließen, die Hochschule! Damit möchte ich deutlich machen, da $B$ kein Kraut gewachsen ist gegen diese in einer grauen Sphäre eingerichtete Leistungsverwaltung und daß man sich dem, was sie, wenn auch nicht befiehlt, so doch so empfiehlt, schwer entziehen kann. Ich glaube nicht, daß ein Senatsaus- 
schuß für Stipendienbewilligung sich diesem trend zur sozialen Gestaltung des studentischen Daseins und auch unseres Lehrwesens durch kritisch modifizierende Handhabung der Vorschriften auch nur scheinbar zu widersetzen vermag. Führt man das Vorgesehene aber wortgetreu durch, dann gibt man wesentliche alkademische Prinzipien sowohl des Lehrstils wie der Lehrfreiheit preis. Man hätte sich dann allmählich mehr und mehr an das zu halten, was nach jener Ordnung im Hinblick auf das äußere Studienziel der Gegenstand einer Prüfung weit vor Erreichung einer gewissen Reife des Studenten sein müßte, man könnte also nicht mehr frei den Stoff des Kollegs einteilen; diesen Weg droht jedenfalls die Entwicklung zu nehmen. Ubrigens schränkt man zugleich auch die akademische Studierfreiheit der betroffenen Studierenden ein. Doch sind das Einzelheiten, die ich hier nur zur Kennzeichnung der aus einem unkontrollierten und nicht kontrollierbaren Gebrauch der Organisationsgewalt entstehenden Gefahren andeuten wollte.

Das Beispiel birgt noch mehr: Die Kultusminister der Länder haben bei diesen Verhandlungen insoweit die Organisationsgewalt ihrer Länder aus der Hand gegeben. Der Bundesinnenminister hat, mit der Zustimmung der Kultusministerkonferenz, die Richtlinien entworfen, aus denen ich eben einige Punkte herausgestellt habe und auf der Grundlage einer Position des Bundeshaushaltes in die Form einer Verordnung gebracht. Bedeutet dies, daß im Kreise der Träger der Landesorganisationsgewalt in diesem konkreten Fall offenibar keine festen Vorstellungen idarüber vorhanden gewesen sind, welche weittragende Bedeutung jener Entäußerung ihrer Organisationsgewalt und deren unkontrolliertem Gebrauch zukommt? Man muß andererseits feststellen, daß die Durchführung jener großzügigen Hilfsmaßnahmen, die vielleicht Reformen, jedenfalls Strulktur- und Funktionsveränderungen im Hochschulbereich bedeuten, sich in der Sphäre der Organisationsgewalt vollzieht, die den Ländern zukommt. Hier entstünden allerdings bei denkbaren koordinierten Landesregelungen neue Fragen: Wer soll die Organisationsgewalt ausüben? Welche Landesorgane sollen die Grundlagen schaffen und die Einzelnormativierungen treffen: die Kultusverwaltung oder die Parlamente der Länder? Man kann hinsichtlich des Ergebnisses der Betätigung des einen oder des anderen Staatsorgans sehr verschiedener Meinung sein, verschiedene Prognosen stellen. An dieser Stelle sind gar nicht irgendwelche Ratschläge ex cathedra zu geben; vielmehr soll daraus lediglich die allgemeine Folgerung gezogen werden: Es ist zu überlegen, ob nicht 
bei solchen und ähnlichen Anliegen gefondert werden sollte, daß die Schranke des Gesetzes rechtzeitig errichtet wird, ehe in einer abseitigen, nur unter Mitwirkung freier Vereinigungen zu bewältigenden Verwaltungssphäre organisatorisch gehandelt wird, ohne die Folgen vollkommen zu übersehen. Mit anderen Worten: auch dann, wenn Organisationsgrundlagen in der Sphäre der Leistungsverwaltung geschaffen werden, können daraus so starke Eingriffe in die personale Rechtssphäre van natürlichen Personen wie von Rechtsträgern des privaten und öffentlichen Rechts hervargehen, daß eine gesetzliche Ermächtigung dafür gefordert werden muß. Daher vermag vielleicht dieses Beispiel einen Beitrag für Bemühungen zu geben, die Grenzen zwischen der Organisationsgewalt der Exekutive im Bund und der in den Ländern abzustecken, wie auch Notwendigkeiten der gesetzlichen Fundierung und der nicht übereilten, sondern überlegten Einzelregeiung zu unterstreichen.

\section{B a c h of - Tübingen:}

Herr Köttgen und Herr Ermacora haben uns sehr unterschiedliche Auffassungen von der Organisationsgewalt entwickelt. Wenn ich einmal vereinfachen darf, so scheint mir dieser Unterschied in der Auffassung allgemein zwischen den deutschen Kollegen einerseits und den österreichischen andererseits zu bestehen. Es ist wohl der Mühe wert, nach der U r $s$ a $c h$ e für diese verschiedene Sicht der Dinge zu fragen. Sie scheint mir sehr wesentlich mit bestimmt zu sein durch das unterschiedliche Verwaltungsverfahren, das wir in der Bundesrepublik einerseits und in Osterreich andererseits haben. Wenn man, wie in Osterreich, ein stark justizförmiges Verwaltungsverfahren hat und wenn man die Aufgaben der Verwaltung nicht nur (oder doch nicht primär) in deren Gestaltungsfunktion, sondern auch in der Rechtsschutzfunktion erblickt, dann scheint mir in der Tat für eine eigenständige Organisationsgewalt der Verwaltung keine Möglichkeit zu bleiben. Wenn man ein Rechtsschutzverfahren regelt - und das heißt natürlich: gesetzlich regelt -, so bleibt gar nichts anderes übrig, als gleichzeitig auch den A p p a r t, der die Rechtsschutzfuniktion gewährt, gesetzlich zu regeln.

Ich glaube, daß das Nachdenken über solche Zusammenhänge auch für uns in Deutschland von besonderer Bedeutung ist, weil ja auch bei uns schon des öfteren die Frage aufgeworfen wurde, ob nicht die deutsche Verwaltung zu einem stärker 
justizförmigen Verwaltungsverfahren übergehen solle. Erst jüngst hat Herr Ule wieder in einem Aufsatz im Deutschen Verwaltungsblatt ${ }^{1}$ ) die Frage aufgeworfen, ob man nicht zur stärkeren Entlastung der Verwaltungsgerichtsbarkeit nach dem Vorbild der hessischen und rheinisch-pfälzischen Rechtsausschüsse oder nach dem Vorbild des Wehrpflichtgesetzes und des Lastenausgleichsgesetzes in stärkerem Maße weisungsfreie Beschlußbehörden einrichten solle. Ich sehe diese Dinge aus verschiedenen Gründen, auf die ich jetzt nicht eingehen will, etwas anders als Herr Ule; aber ich glaube, die Zusammenhänge als solche, die zwischen Organisationsgewalt und Verwaltungsverfahren bestehen, sollten wir hier nicht übersehen. In dem Augenblick, in dem wir dazu übergehen, das Verwaltungsverfahren mehr oder minder justizförmig zu gestalten, ist es mit der eigenständigen Organisationsgewalt der Exekutive zu Ende. Das würde ich mit Herrn Köttgen bedauern, und es ist dies nur einer der Gründe, weshalb ich Bedenken gegen eine solche justizförmige Gestaltung des Verwaltungsverfahrens habe.

Gerade das Beispiel der Beschlußbehörden ist sehr aufschlußreich: Man kann an sich - jedenfalls wenn kein besonderer institutioneller Gesetzesvorbehalt besteht - das reine Verwaltungsverfahren und die Einrichtung der in einem solchen Verfahren entscheidenden Behörden kraft der Organisationsgewalt regeln. Man kann aber sicher nicht Verfahren und Einrichtung weisungsfrei entscheidender Beschlußbehörden auf diese Weise regeln! Man kann das einmal deshalb nicht, weil die weisungsfrei entscheidenden Behörden aus der hierarchischen Befehlsgewalt der Verwaltung herausgenommen sind; das schließt die Möglichkeit aus, ihnen im Verwaltungswege Vorschriften zu setzen, man bedarf hierzu also eines Gesetzes. Man kann aber, davon abgesehen, auch keine Rechtsfolgen von der Einhaltung eines bestimmten Verfahrens abhängig machen, ohne dieses Verfahren selbst rechtsnormativ zu regeln. Das zeigt das Beispiel des in der BRD allgemein gesetzlich geregelten sog. "Vorverfahrens" (Einspruchs- und Beschwerdeverfahren) als der gesetzlichen Voraussetzung der verwaltungsgerichtlichen Klage, im Gegensatz zu dem weithin gesetzlich u n geregelten ursprünglichen Verwaltungsverfahren. Gestaltet man ein Verfahren überdies noch gerichtsfïrmig, so bleibt nichts anderes übrig, als auch die Organisation der in einem solchen Verfahren entscheidenden $\mathrm{B}$ eh ö rden gesetzlich zu regeln. Denn Verfahren und entscheidende Behörde korrespon-

1) DVBl. 1957 S. 597 ff. Vgl. dazu jetzt auch meine Stellungnahme in DVBl. 1958 S. 6 ff. und die Erwiderung von U l e ebendort S. 9 f. 
dieren einander, ein förmliches Verfahren erfordert auch eine nach Zuständigkeit, Besetzung usw. förmlich geregeite Behörde. Allgemein und zusammenfassend kann man sagen: In dem Umfang, in dem die Verwaltung Rechtsschutzfunktionen übernimmt, tritt an die Seite des "gesetzlichen Richters" notwendig auch der "gesetzliche Verwaltungsbeamte".

Diese hier nur angedeuteten Zusammenhänge zwischen Organisationsgewalt und Verfahren zeigen vielleicht die eigentlichen Ursachen für die unterschiedliche Auffassung der Organisationsgewalt zwischen uns und den österreichischen Kollegen auf. Diesen Zusammenhängen sollte man etwas mehr nachgehen, wenn wir in der Bundesrepublik die Frage nach der Zweckmäßigkeit einer stärkeren Formalisierung des Verwaltungsverfahrens aufwerfen.

E rm a cor a - Innsbruck (Schlußwort):

Ich danke dem Herrn Professor Köttgen für den wertvollen Bericht wie allen Diskussionsrednern für ihre Beiträge, die für mich samt und sonders wertvolle Anregungen enthielten.

Es scheint, daß sich die Diskussion - wie nicht anders zu erwarten war - auf zwei Punkte zuspitzte. Der eine Punkt war schon in den Kontroversen Arndt-Anschütz sowie A n s c h ü tz - K el se n neuralgisch. Nämlich: kann die Organisationsgewalt gesetzesfrei gehandhabt werden oder nicht. Diese Frage läuft nach wie vor auf die Frage nach dem Rechtscharakter der Verwaltungsverordnung hinaus. Muß sie gesetzlich gebunden sein oder nicht?

Die meisten Redner verneinen das. Sie ersetzen aber die gesetzliche Grundlage durch Schlagworte, wenn sie erklären, die Organisationsgewalt entspreche „einem allgemeinen Verwaltungsauftrag", sie sei "in ihrem legitimen Bereich ohne Gesetz statthaft", sie "entspringe der Natur der Sache", sie sei „eine Art Hausgewalt", der "Verwaltung komme mit ihr zu, was ihr zustehen soll", "sie entspreche der inneren Mission der Verwaltung".

Mit solchen Auffassungen verharrt die Rechtswissenschaft im Zeitalter der Pferdebahn und registriert nicht, daß man bereits rüstet, zum Mond zu reisen. Sie bewegen sich mit solchen Erklärungen in Zirkelschlüssen, ohne den tatsächlichen Abbau der klassischen Organisationsgewalt festzustellen. Sie gewinnen auch für die künftige Gestalt der Organisationsgewalt mit ihrem traditionsgebundenen Beharrungsvermögen nichts. Der zweite Punkt ist: Sie wollen es nicht zulassen, da $\beta$ man auch von einer Organisationsgewalt des Gesetzgebers sprechen 
könne. Logisch ist dies jedoch statthaft, auch wenn ich Professor I p s e n zugestehe, daß - wenn sich auch nicht die Qualität einer organisatorischen Maßnahme des Gesetzgebers als organisatorische Maßnahme - sich doch die Kraft der organisatorischen Maßnahme geändert hat. Aber was hat es für einen praktischen Sinn, sich an die klassische Organisationsgewalt zu klammern, wenn sie in Wahrheit auf ein Minimum reduziert wurde?

Professor P eters bedauert meine rechtsstaatlichen Postulate. Aber sind es nicht auch Postulate, die eine demokratische Rechtsordnung erfordert? Der Gesetzgeber müßte heute ein Recht haben, die innere Organisation einer von ihm im Materiellen grundsätzlich abhängigen Staatsfunktion - nämlich der Verwaltung - zu kennen. Ich habe hervorgehoben, daß es dem Legisten gelingen müßte, rechtsstaatliche Forderungen mit verwaltungsökonomischen Forderungen ausgleichend, die Organisationsgewalt so zu regeln, daß das Gesetz die Organisationsgewalt kontrolliert und daß der Verwaltung aber noch genügend Spielraum bleibt, ihrer inneren Mission entsprechend organisatorische Regelungen zu treffen. Wenn Herr Professor Peters in der Vermehrung der Gesetzgeberischen Akte für organisatorische Fragen eine Gefahr für den Rechtsstaat erblickt, so erlaube ich mir zu entgegnen, da $B$ eine derartige Gefahr nur die Folge einer weitaus größeren Gefahr wäre; nämlich der, die durch die Hypertrophie staatlicher Aufgaben erwächst. Wird diese abgebaut, baut sich der Organisationsapparat von selbst ab.

\section{K ö $t$ t g e n - Göttingen (Schlußwort):}

Herr Ermacora hat bereits von der Fülle der Anregungen gesprochen, für die wir zu danken haben. Anregungen, die begreiflicherweise unser Thema von den verschiedensten Punkten aus angepeilt haben. Ich will für meine Person nicht verschweigen, daB ich zuweilen an Erfahrungen aus den letzten Kriegswochen erinnert wurde. Man erwartete einen Angriff aus Osten und er kam aus dem Westen. So habe ich mich gegenüber einigen Diskussionsrednern in einer Lage befunden, auf die ich vielleicht grade deswegen nicht vorbereitet war, weil ich den Widerhall meiner Thesen nicht ohne einen gewissen Pessimismus auf mich zukommen sah.

Wahrscheinlich habe nicht ich allein Herrn Bachof dafür zu danken, daß er in seiner so eindringlichen Weise uns allen am Schluß dieser Diskussion noch einmal deutlich gemacht hat, warum die beiden Referate des heutigen Tages in Ansatz und 
Ergebnis so stark von einander abwichen und, wie ich sagen darf, sogar abweichen mußten Herr Bachof hat auf die unterschiedliche Bedeutung hingewiesen, die dem Verfahrensrecht in der österreichischen und deutschen Tradition zugefallen ist. Organisation und Verfahren sind aber eng zusammenhängende Bereiche, weshalb schon aus diesem Grunde unser Thema für einen österreichischen Kollegen besondere Aspekte bieten mußte. Im übrigen wird damit nur bestätigt, da $B$ die Verwaltungstradition Österreichs sich ganz allgemein von der deutschen bemerkenswert unterscheidet. Sicherlich gibt es hierfür eine Vielzahl der Gründe, aber ich möchte nicht verschweigen, daß mir eigentlich erst heute einer von ihnen so recht klar geworden ist. In einem auch für einen Professor überraschendem Grade hat offenbar Kelsen nicht nur der Theorie, sondern auch der österreichischen Staatspraxis ein bestimmtes Gepräge gegeben.

Damit ist zugleich angedeutet, warum sich hier und heute über den Ausgangspunkt unserer Referate und seine Unterschiedlichkeit kaum diskutieren läßt, da eine solche Diskussion einen uns allen bekannten Dissens der Staatstheorie zu ihrem eigentlichen Gegenstand nehmen müßte. Deshalb darf ich mir nur insoweit eine Bemerkung gegenüber Herrn Ermacora erlauben, als er mit behutsamer Skepsis gegenüber dem deutschen Verständnis der Organisationsgewalt bemerkt hat, diese habe bei Lichte besehen doch eigentlich keinerlei rechtliche Basis mehr. Ganz so scheint mir dies nicht zu sein $\mathrm{DaB}$ insbesondere der allgemeine Verwaltungsauftrag nicht nur ein Produkt theoretischer Spekulationen ist, ergibt sich für die Gemeinden aus dem Art. 28 GG. Aber nicht nur bei diesen ist die Verwaltungsinitiative zumindest nicht durchgehend an gesetzgeberische Vorleistungen gebunden. Ich bin jedenfalls bislang nicht davon überzeugt, daß sich die Länder insoweit in einer anderen Lage befänden als ihre Gemeinden und daB deshalb ihre Staatspraxis in Fragen des Organisationswesens zu verfassungsrechtlichen Bedenken Anlaß gäbe. Inwieweit das gleiche auch für den Bund zu gelten hat, führt in mancherlei bundesstaatsrechtliche Kontroversen, die ich hier nicht vertiefen kann.

Wenn ich nun - mit Rücksicht auf die stark fortgeschrittene Zeit nur kurz - zu einigen Anregungen der Diskussion etwas sagen darf, so glaube ich mit jenem Auftakt beginnen zu sollen, den Herr Weber der Diskussion gegeben hat. Zwar war diesem Auftakt seitens des Vorstandes das Ziel eines „Referates“ gesteckt, das nun einmal gewisse Verzichte auf Seiten des Referenten verlangt. Herr Weber hat uns allerdings nicht nur ein 
sehr wohlwollendes Referat geboten, sondern in dieses auch seine eigene Problemschau verworben, aus der ich nur zwei Punkte herausgreifen möchte. Für mich überraschend hat er sich auf den Standpunkt gestellt, daß die überkommene Unterscheidung zwischen Eingrifts- und Leistungsverwaltung heute aufgegeben werden müßte, nachdem letztere über die Existenz des modernen Menschen ein maßgebliches Bestimmungsrecht gewonnen habe. Ich selbst hatte diese Frage erwähnt, aber offen gelassen, da ihre Beantwortung in dem ja keineswegs nur von Herrn Weber gefordertem Sinne von einer kaum zu überschätzenden - vielleicht sogar bislang kaum übersehbaren - Tragweite ist. Nur aus diesem Grunde hatte ich mich nach Art einer Arbeitshypothese auf den Boden der herrschenden Lehre gestellt, nicht ohne insbesondere die kritischen Einwendungen von Herrn Imboden zu erwähnen. Nicht zuletzt unsere Erfahrungen mit dem augenblicklichen Start des Honneffer Modells, von denen Herr Scupin soeben berichtet hat, haben erneut die vielfältige Problematik einer Leistungsverwaltung beleuchtet, die bei Lichte besehen lediglich eine Position des Bundeshaushalts zur Grundlage hat. Ganz zu schweigen von den bundesstaatsrechtlichen Konsequenzen einer solchen Entwicklung geht es hier auch, und zwar wesentlich um organisatorische Fragen, zumal derart administrative Improvisationen keine geringen organisatorischen Anforderungen zu stellen pflegen.

Man kann mit mancherlei guten Gründen verlangen, daß dieser Staatspraxis Einhalt geboten wird. Aber letztens ist und bleibt es eine rechtspolitische Frage, ob und wie man diese Verwaltungsentwicklung gesetzgeberisch kanalisieren soll. Jedenfalls bin ich bislang noch nicht davon überzeugt, da $B$ wir in Fällen dieser Art verfassungsrechtlich genötigt sind, den heute ja nicht ganz unproblematischen Ruf nach einem ohnehin überforderten Gesetzgeber zu erheben.

Und nun ein zweites. Mit einem leichten Vorbehalt hat Herr Weber über meinen Versuch referiert, eine verfassungsrechtliche Basis der Organisationsgewalt nachzuweisen. Ich selbst war dabei viel zu ängstlich, die altbekannte Vorstellung vom Hausgut der Verwaltung zu beschwören. Gleich Herrn Ermacora habe daher auch ich diesen Terminus peinlich vermieden, der deshalb erst in der Diskussion aufgetaucht ist. Da es nach geltendem Verfassungsrecht keinerlei parakonstitutionelle Prärogative mehr gibt, müssen sich alle Zuständigkeiten zumindesten implicite auf die Verfassung stützen lassen. Herr Krüger hat bereits ähnliche Gedanken unter Anspielung auf die Natur der Sache entwickelt, für die ich ihm besonders zu 
danken habe, zumal unsere beiderseitigen Positionen hiermit einander erheblich genähert sein dürften. Ich selbst habe mich bewußt nicht auf das glatte Parkett der Natur der Sache begeben, sondern versucht, nach einem verfassungsrechtlichen Ansatzpunkt der Organisationsgewalt Ausschau zu halten, den seine Evidenz auch gegenüber skeptischen Vorbehalten bestätigt.

$\mathrm{Zu}$ diesen Ansatzpunkten gehört das unbestreitbare Recht der Exekutive zur selbständigen Bewirtschaftung bereiter Haushaltsmittel sowie ein Direktionsrecht gegenüber dem Personalkörper, das auch das moderne Dienstrecht in seinem Kern respektieren mußte. Von hier aus gesehen stellt sich mir die Organisationsgewalt als eine spezifische Kombination sächlicher und persönlicher Verwaltungsmittel dar und kann sie sich daher auf die zuvor genannten Dispositions- und Direktionsrechte zu ihrer verfassungsrechtlichen Legitimation berufen. Ich wei $\beta$, da $\beta$ ich darin von Herrn Weber differiere, der im übrigen mit Recht vermerkt hat, daß ich eine Definition der Organisationsgewalt schuldig geblieben sei. Obwohl ich damit kaum nur gegen den Stil juristischer Methodik verstoßen habe, habe ich mich zu dieser durchaus als eine solche empfundenen Selbstbeschränkung deswegen genötigt gesehen, weil jede Aussage über die Organisation eine Auseinandersetzung mit der vielschichtigen Problematik des Institutionellen erfordert hätte.

Ich möchte meinen, daß mein Referat zumindest deutlich gemacht hat, welche entscheidende Abhängigkeit nach meiner Sicht zwischen der Organisationsgewalt und dem staatstheoretischen Zentralbegriff der Institution besteht, die dabei ihrerseits eine Gemenglage mit dem Status bildet. Es erschien mir allerdings nicht die Aufgabe dieses Referates, diesen Problemen, die schon unsere Tübinger Tagung an ihren beiden Tagen beschäftigt haben, als solchen hier nachzugehen. $\mathrm{DaB}$ sich mit diesem Fragenkomplex auch für die rein positivrechtliche Gesetzesanwendung höchst intrikate Zweifelsfragen verbinden, möchte ich Ihnen nur an einem einzigen Beispiel zeigen. Sie Kennen den Art. 84 Abs. 1 GG, der für Bundesgesetze die Zustimmung des Bundesrates fordert, falls sie auch das Verwaltungsverfahren und die Behördeneinrichtung regeln. Wann allerdings in concreto nur eine rein materiellrechtliche Regelung vorliegt oder wann der Bundesgesetzgeber seine Hand auch nach den Institutionen der Landesverwaltung ausstreckt, läßt sich bei der Flüssigkeit dieser Grenze oft nur unter großen Schwierigkeiten überzeugend beantworten. Aus den gleichen Gründen ist es auch mir nicht gelungen, immer die 
an sich gewi $\beta$ wünschenswerte Prägnanz der Formulierung zu erreichen. Vielleicht gelingt es uns auf die Dauer, den Komplex des Organisatorischen schärfer in den Griff zu bekommen, ohne daß wir der Selbsttäuschung einer Begriffshülse erliegen.

Darf ich mich nun kurz an Herrn Peters wenden, auf den meine einleitende Bezugnahme auf die Unvorhersehbarkeit taktischer Lagen im speziellen gemünzt war. In der Tat war ich nicht auf den Einwand gefaßt, daß ich nun auch zu denen gehöre, die in einer Situation nach dem Gesetzgeber rufen, die uns eigentlich eines Besseren belehren sollte. Ohne auch dieses Problem vertiefen zu können, darf ich mich auf eine kurze Bemerkung beziehen, die Herr Smend einmal über die Organisationsgewalt gemacht hat. In der Tat glaube auch ich, daß es zur Würde, dem Ansehen oder, wie immer man definieren mag, einer echten Institution gehört, daß sie nicht lediglich nebenbei - gleich dem Honneffer Modell und verwandten Erscheinungen - improvisiert, sondern von einer Gesetzgebung getragen wird, die um den Ernst der Rechtsetzung auch im Bereiche des Institutionellen weiß. Darauf allein kam es mir wesentlich an und ich bitte meine Schlußbemerkung daher nicht im Sinne einer vorsorglichen Konzession an eine von mir erwartete Kritik zu verharmlasen. Das gilt ähnlich auch gegenüber Herrn Ule, der offenbar der Meinung war, ich hätte mit dieser Schlußbemerkung alles zuvor Gesagte wieder zurücknehmen wollen. Davon kann schon deswegen keine Rede sein, weil diese Schlußbemerkung nur im Sinne eines rechtspolitischen Pastulates verstanden sein wollte, ohne daß diese adhortatio an den Gesetzgeber zu der Hypothese eines verfassungsrechtlichen Gesetzesvorbehalts gesteigert werden sollte.

Man könnte mir allerdings den Vorwurf machen, daß der Gedankengang damit insofern vorzeitig abgebrochen worden sei, als die nicht nur staatstheoretisch wichtige Frage unbeantwortet blieb, wo unter solchen, wohlgemerkt nur verfassungspolitischen Gesichtspunkten konkret eine Legalisierung der Institutionen zu fordern ist. Ich möchte meinen, daß auch Herr Smend kaum zufällig auf eine so präzis gestellte Frage bislang die Antwort schuldig geblieben ist. $\mathrm{Da}$ hier noch manches zu tun bleibt, dürfte insbesondere nach den Diskussionsbemerkungen von Herrn Krüger deutlich geworden sein. Diese Ausführungen waren für mich schon deswegen von besonderem Gewicht, weil mein Referat in mancher Beziehung eine Gegenposition insbesondere zu seinem Mainzer Referat über das besondere Gewaltverhältnis bezogen hatte. Wenn ich Herrn Krüger richtig verstanden habe, so bildet für ihn die Organisationsgewalt, die er - kühner als ich - als eine formelle Ge- 
walt definiert, den Gegenpol der verfassungsmäßigen Gestaltung des Staates. Ich muß bekennen - vielleicht lassen mich meine Notizen im Stich oder ich habe Herrn Krüger in dem einen oder gar im anderen Sinne falsch verstanden -, daß ich mich im Augenblick nicht ohne weiteres in der Lage sehe, diesen Gedankengang weiterzuspinnen oder ihm zu widersprechen. Jedenfalls schien mir bedeutsam, daß nach diesen Ausführungen die Organisationsgewalt als im Begriff der Exekutive mitgesetzt und damit als verfassungsrechtlich legitimiert zu gelten hat. Mir scheint, daß Herr Krüger damit seine Stellungnahme zu unserem Problem eng mit der Antithese Regierung und Verwaltung verbunden hat, wie dies ähnlich vor ihm schon Herr Smend getan hatte.

Herr Spanner hat - den gestrigen Appell von Herrn Friesenhahn an das wissenschaftliche Streitgespräch damit aufgreifend - seine soeben in der DÖV vorgelegten Thesen mit gutem Recht unter dem Eindruck meines Referates auch mündlich mit Nachdruck vertreten. Ich glaube, daB ich im Grundsätzlichen gegenüber diesen Einwendungen kaum etwas anderes sagen kann, als ich bereits eingangs gegenüber meinem Herrn Korreferenten gesagt habe. Auch Sie, Herr Spanner, kommen aus einer wesentlich anderen Tradition des öffentlichen Rechts und der Verwaltung, so daB sich auch eine Diskussion zwischen uns alsbald auf eine andere Ebene verlagern müßte, wenn wir den beiderseitigen Standpunkten gerecht werden wollen. Da dieses hier und heute nicht möglich ist, möchte ich mich auf eine bescheidene positivrechtliche Anmerkung beschränken. Ihre These, daß die Verwaltung in jedem Fall des gesetzlichen Mediums gegenüber der Verfassung bedürfe, gründet sich offenbar auf den Art. 18 der österreichischen Verfassung, die ich hier nicht zur Hand habe. Diese These läßt sich $\mathrm{m}$. E. auf deutsche Verhältnisse keinesfalls übertragen, da das deutsche Verfassungsrecht eine solche Bestimmung nicht kennt. Im übrigen habe ich stets nur von einer verfassungsunmittelbaren, jedoch niemals von einer parakonstitutionellen Organisationsgewalt gesprochen. $\mathrm{DaB}$ letztere seit dem Wechsel der Staatsform nicht mehr besteht und daß man sich daher zugunsten der Organisationsgewalt auch nicht auf das ältere Schrifttum berufen darf, dachte ich mit genügendem Nachdruck unterstrichen zu haben.

Wenn schließlich Herr Ipsen in Verbindung mit unserem Thema von einer Mission der Verwaltung gesprochen hat, so muß ich auch hier bekennen, daß ich an Kühnheit der Formulierungen durch die Kollegen nicht unwesentlich übertroffen wurde. Herr Ipsen hat seine Position, offenbar im Gedanken an 
das gute Recht disziplinierter Reiztherapie, mit bemerkenswerten Akzenten versehen. Danach gehört es zum Wesen der Organisationsgewalt, daß sie keine Rechtsgrundlage - gemeint war offenbar keine Gesetzesgrundlage - besitzt. Das ist insofern in voller Ubereinstimmung mit meiner Thematik, als auch ich unser Thema bewußt in diesem Sinne verengert habe. So wie ich das staatsrechtliche Phänomen der Organisationsgewalt verstehe, erstreckt es sich nicht auf diejenigen Fälle, in denen durch Gesetz oder auf Grund eines Gesetzes organisiert wird. Nur eine solche Thematik scheint mir dem rechtsstaatlichen Ärgernis der Organisationsgewalt adäquat zu sein. Deshalb weiß ich mich auch mit Herrn Ipsen voll darin einig, da $\beta$ es ein nicht $\mathrm{zu}$ unserem Thema gehörendes aliud ist, wenn das Parlament in Gesetzesform organisiert. Ob ähnliches allerdings auch für den Personalrat gilt, dessen Einschaltung in organisatorische Fragen Herr Ipsen offenbar ebenfalls aus dem Kreis unserer Uberlegungen ausschalten wollte, erscheint mir demgegenüber vorerst zweifelhaft.

$\mathrm{Zu}$ den Ausführungen von Herrn Pfeiffer darf ich nur sagen, daß sie bei mir den Eindruck verstärkt haben, welch entscheidende Rolle bei der Behandlung unseres Themas der jeweils maßgeblichen Tradition in Verfassung und Verwaltung zukommt. Die in der Perspektive zumindest eng verwandten Ausführungen unserer österreichischen Kollegen haben insofern für uns alle einen über das spezielle Thema hinaus bedeutsamen Erkenntniswert.

Ein letztes Wort zu denjenigen Kollegen, die mich auf die Verlustliste meines Referates - und zwar stets mit vollem Recht - hingewiesen haben. Das gilt sowohl für die von mir nicht behandelte Kontrolle der Organisationsgewalt, an die Herr Scupin erinnert hat, als an das schwierige Verhältnis der Verfassungsgerichtsbarkeit zu der Organisationsgewalt, auf das mich Herr Drath heute morgen in einem mündlichen Gespräch angesprochen hat. Im Unterschied zu Herrn Ermacora, der sich hier auf eine Zeitplanung berufen könnte, die ihn dem Gesetz des Minutenzeigers unterwarf, vermag ich für diese und manch andere Unterlassung nicht ohne weiteres eine Indemnität $\mathrm{zu}$ verlangen. Allerdings möchte ich meinen, daß die spezifisch sozialrechtlichen Uberlegungen, auf die unsere Diskussion gewiß nicht zufällig wiederholt zurückgekommen ist, den Rahmen unseres Themas sprengen. Dies gilt dabei nicht nur für die eigentümliche Utberlagerung des hergebrachten studentischen Status durch den bislang noch reichlich amorphen Status eines Stipendiaten, mit der Herr Scupin sich beschäftigt hat. Niemand wird die Tragweite dieser Entwicklung 
verkennen und mancher unter uns sieht im Geiste bereits den ersten Stipendiaten in diesem Hause vor dem höchsten deutschen Verwaltungsgericht um seine Rechte streiten. Die Organisationsgewalt berührt diese Entwicklung allerdings nur am Rande, was ähnlich auch für die von Herrn Weber erwähnte Anpassung des rechtsstaatlichen Postulates gesetzmäßiger Verwaltung an eine veränderte Verfassungslage zu gelten hat. Daß wir diese eminent aktuellen Fragen keinesfalls aus den Augen verlieren dürfen, unterliegt auch für mich keinem Zweifel, nur daß sie zumindest nicht zu der Kernproblematik unseres beutigen Themas gehören dürften. 